\title{
ॠUSGS
}

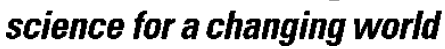

Prepared in cooperation with The University of Arizona, School of Natural Resources and the Environment, Naval Facilities Engineering Command, Nauman Geospatial, National Park Service, and the U.S. Marine Corps

\section{An Inventory and Monitoring Plan for a Sonoran Desert Ecosystem: Barry M. Goldwater Range-West}

Open-File Report 2011-1232

U.S. Department of the Interior U.S. Geological Survey 
Cover: Photograph of the Tinajas Altas Mountains partially obscured by dust during a high-wind event, October 27, 2009. Photograph by Miguel L. Villarreal. 


\section{An Inventory and Monitoring Plan for a Sonoran Desert Ecosystem: Barry M. Goldwater Range-West}

By Miguel L. Villarreal, Charles van Riper III, Robert E. Lovich, Robert L. Palmer, Travis Nauman, Sarah E. Studd, Sam Drake, Abigail S. Rosenberg, Jim Malusa, and Ronald L. Pearce

Prepared in cooperation with The University of Arizona, School of Natural Resources and the Environment, Naval Facilities Engineering Command, Nauman Geospatial, National Park Service, and the U.S. Marine Corps

Open-File Report 2011-1232

U.S. Department of the Interior

U.S. Geological Survey 


\section{U.S. Department of the Interior \\ KEN SALAZAR, Secretary}

\section{U.S. Geological Survey \\ Marcia K. McNutt, Director}

U.S. Geological Survey, Reston, Virginia: 2011

For product and ordering information:

World Wide Web: http://www.usgs.gov/pubprod

Telephone: 1-888-ASK-USGS

For more information on the USGS-the Federal source for science about the Earth,

its natural and living resources, natural hazards, and the environment:

World Wide Web: http://www.usgs.gov

Telephone: 1-888-ASK-USGS

Suggested citation:

Villarreal, M.L., van Riper, Charles, III, Lovich, R.E., Palmer, R.L., Nauman, Travis, Studd, S.E., Drake, Sam, Rosenberg, A.S., Malusa, Jim, and Pearce, R.L., 2011, An inventory and monitoring plan for a Sonoran Desert ecosystem; Barry M. Goldwater Range-West: U.S. Geological Survey Open-File Report 2011-1232, 103 p., available at http://pubs.usgs.gov/of/2011/1232/.

Any use of trade, product, or firm names is for descriptive purposes only and does not imply endorsement by the U.S. Government.

Although this report is in the public domain, permission must be secured from the individual copyright owners to reproduce any copyrighted material contained within this report. 


\section{Contents}

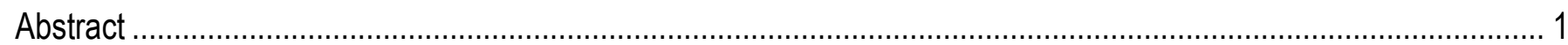

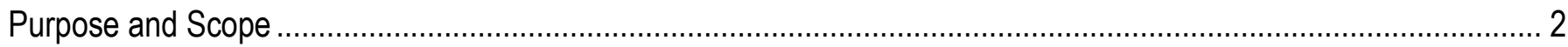

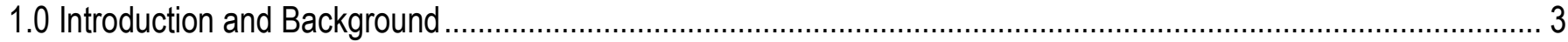

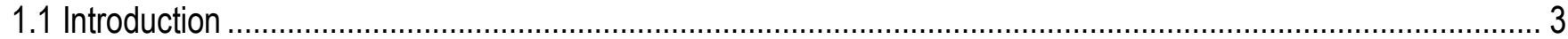

1.1.1 Barry M. Goldwater Range: Environmental Setting ……………................................................. 3

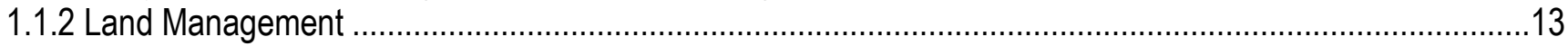

1.1.3 Review of Range Status, Stressors and Drivers.........................................................................14

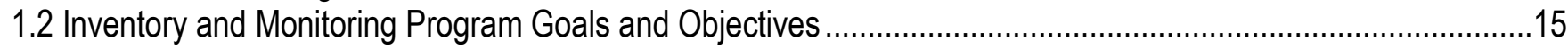

1.2.1 Inventory, Monitoring, and Adaptive Management ...........................................................................15

1.2.2 Inventory and Monitoring Program Goals and Objectives .................................................................16

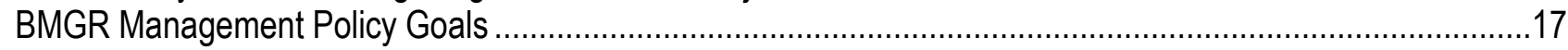

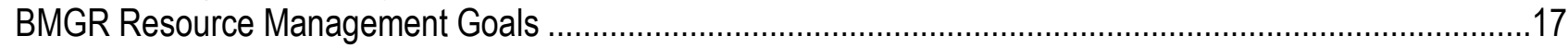

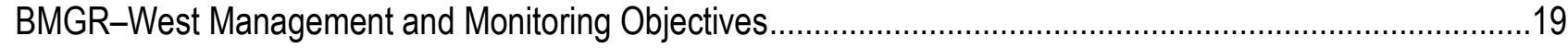

1.2.3 Sonoran Desert Regional Monitoring Partnerships...........................................................................20

Barry M. Goldwater Range Executive Committee and Interagency Executive Committee ...............................20

Barry M. Goldwater Range-East ...................................................................................................

National Park Service Sonoran Desert Network Inventory and Monitoring Program .....................................21

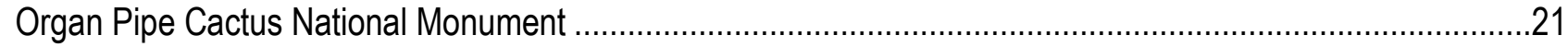

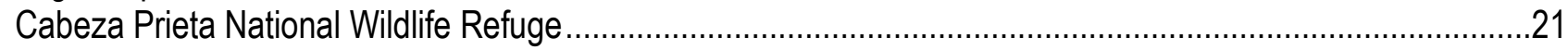

Sonoran Desert National Monument.....................................................................................................22

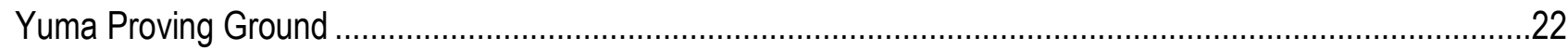

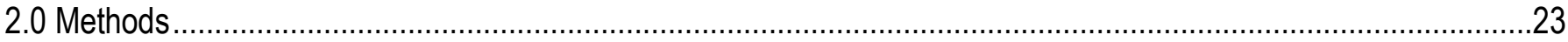

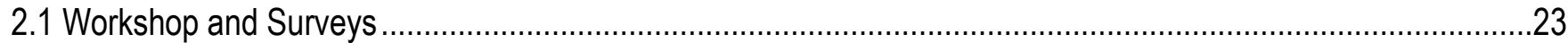

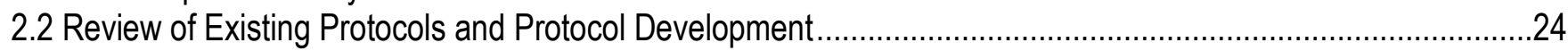

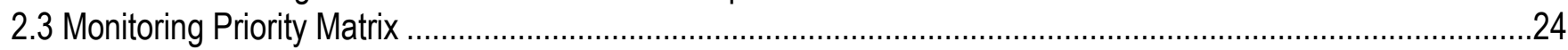

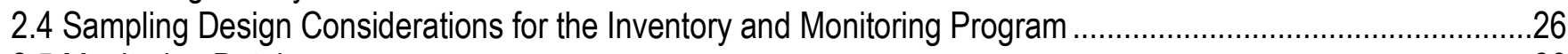

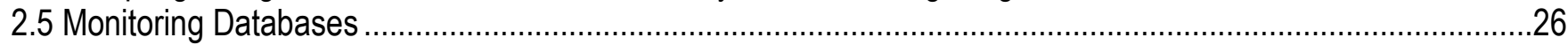

3.0 Background Information on Monitoring Protocols for the Inventory and Monitoring Plan....................................28

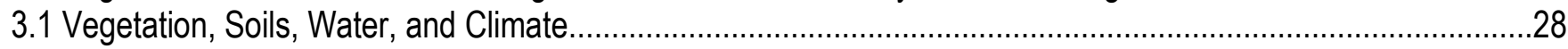

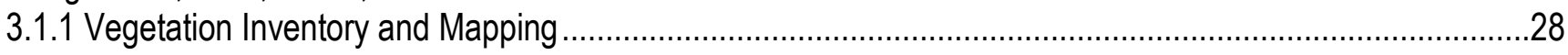

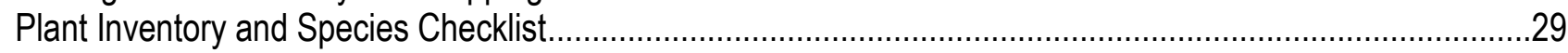

Regional Monitoring Status..........................................................................................................

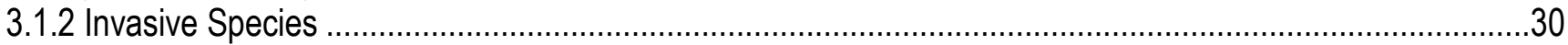

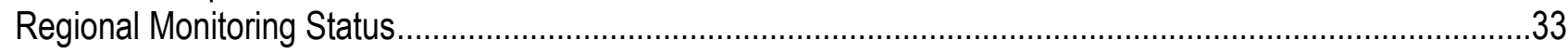

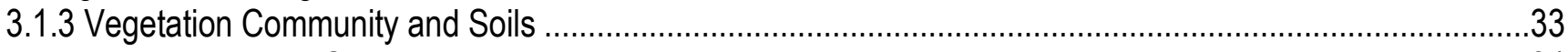

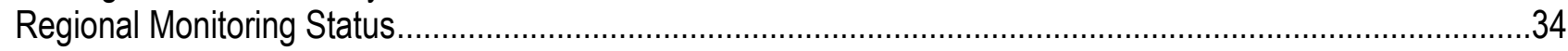

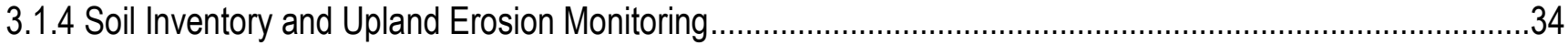

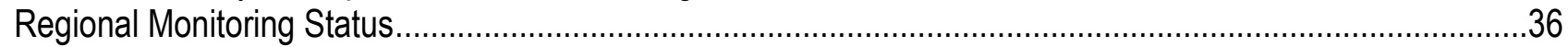

3.1.5 Stream-Channel Erosion Monitoring ........................................................................................36

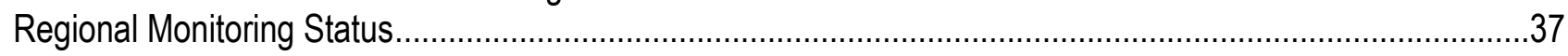

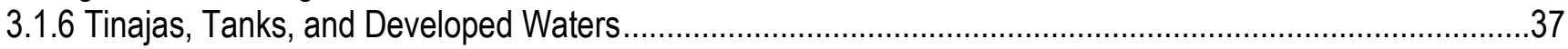

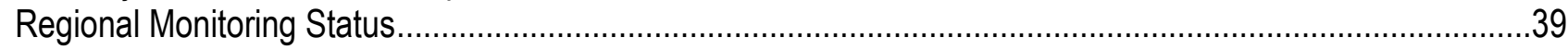

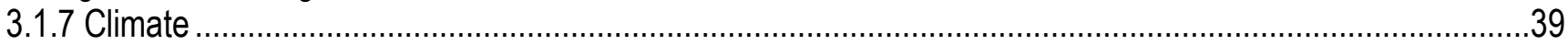

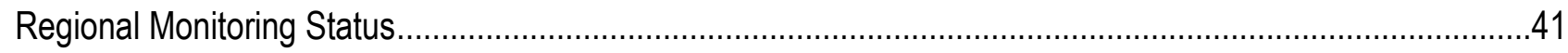

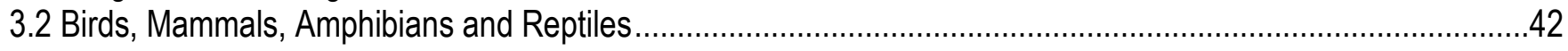

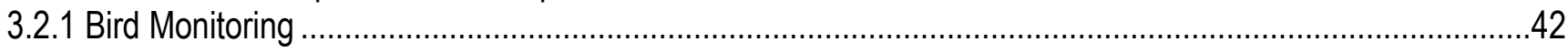




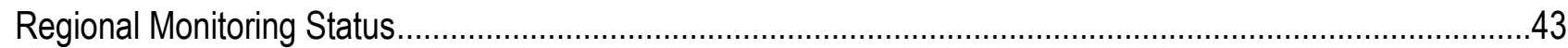

3.2.2 Small Mammals and Nocturnal Rodents ................................................................................

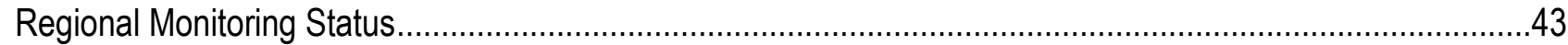

3.2.3 Sonoran Pronghorn and Desert Bighorn Sheep ………….......................................................4

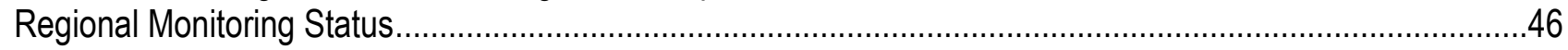

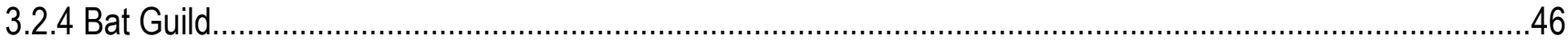

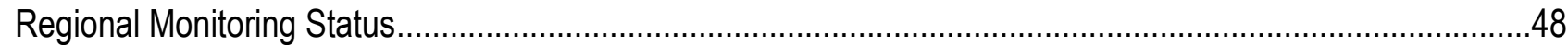

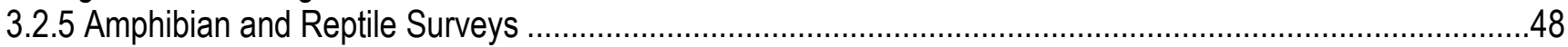

Flat-Tailed Horned Lizard .........................................................................................................4

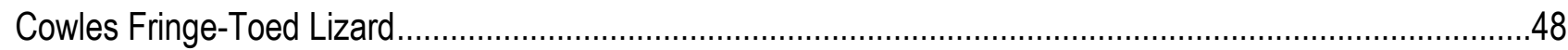

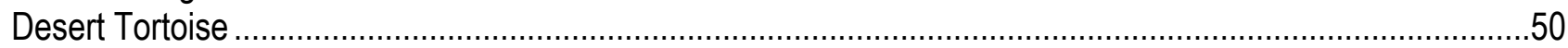

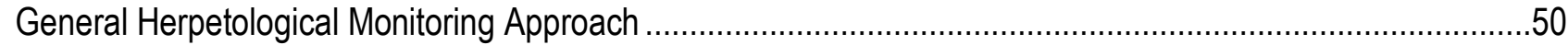

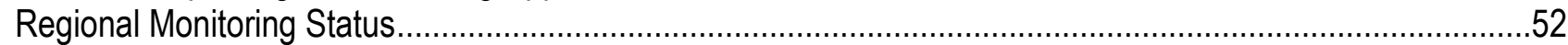

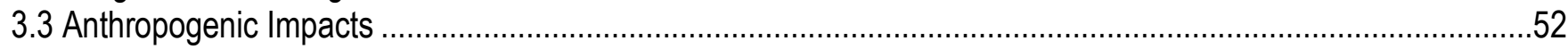

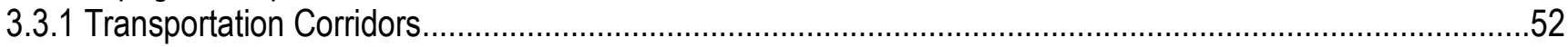

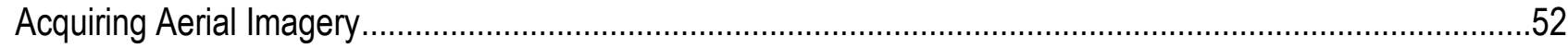

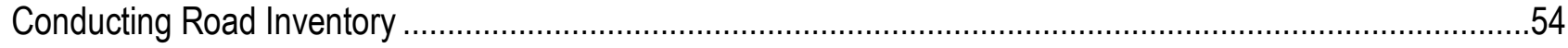

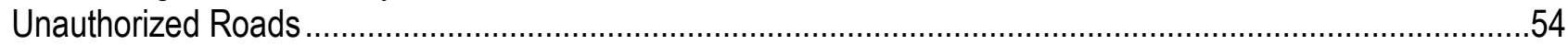

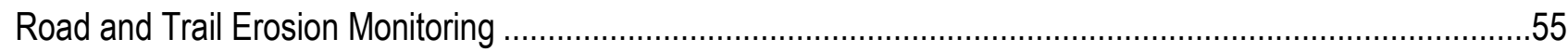

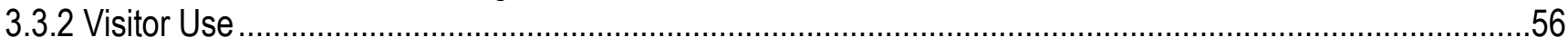

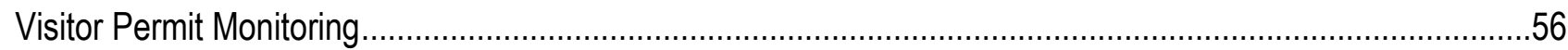

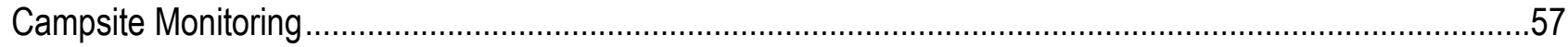

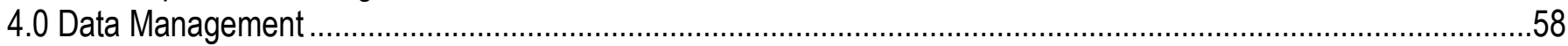

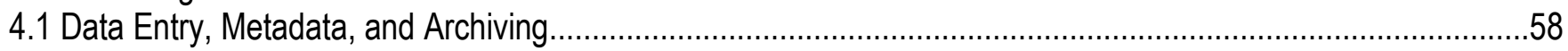

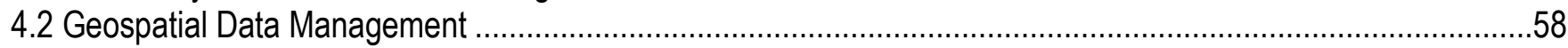

4.3 Monitoring Data Repository: Location and Oversight .............................................................................

5.0 Management Actions as a Result of Inventory and Monitoring .....................................................................60

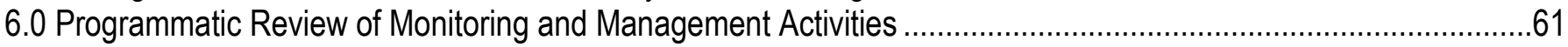

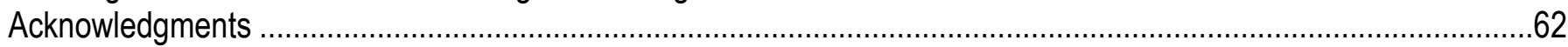

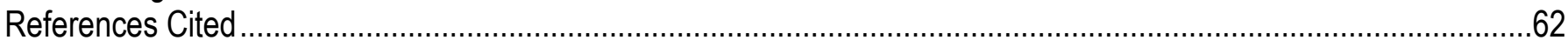

Appendix A. Vegetation Inventory and Mapping Protocol.................................................................................

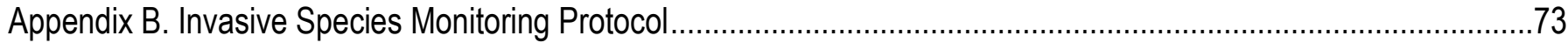

Appendix C. Soil Inventory and Erosion Monitoring Protocol..............................................................................

Appendix D. Small Mammals and Nocturnal Rodents Monitoring Protocol ...........................................................82

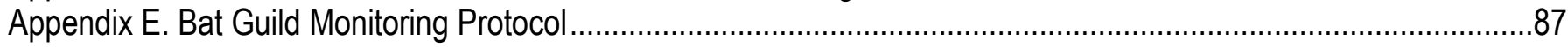

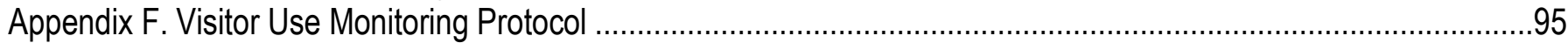

Appendix G. BMGR-West Workshop Participants, Followup Survey, and Survey Results .........................................97

\section{Figures}

1.1. Map depicting the location of the Barry M. Goldwater Range within the Sonoran Desert Ecoregion, adjacent land

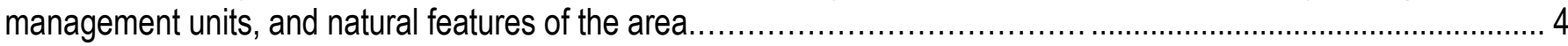

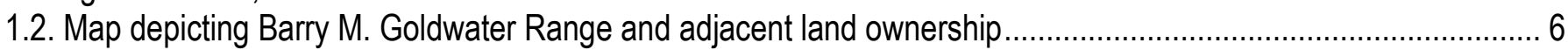

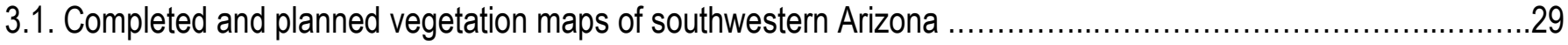

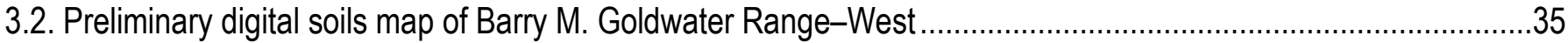

3.3. Developed waters of Barry M. Goldwater Range-West ...........................................................................38

3.4. Distribution of Remote Automated Weather Stations and other weather stations in areas surrounding Barry M.

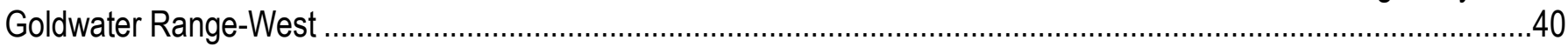

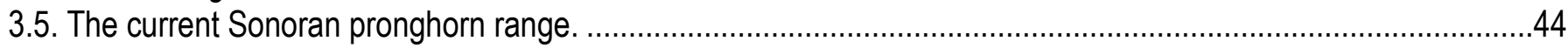


3.6. Location of Arizona Game and Fish Department Bat Monitoring Sites on Barry M. Goldwater Range-West.......47

3.7. Flat-tailed horned lizard Management Area, including plot locations, survey points and observation locations.....49

5.1. The relationship between an ecological monitoring program and management activities.

\section{Tables}

1.1. Natural vegetation community types of the Barry M. Goldwater Range........................................................ 9

1.2. Resource-specific management goals for Barry M. Goldwater Range …........................................................ 18

1.3. Natural resource management objectives for the Barry M. Goldwater Range …….........................................20

2.1. Monitoring matrix showing monitoring elements by priority that was designed to help prioritize monitoring efforts

3.1. Existing and potential invasive plant species located on Barry M. Goldwater Range lands .................................32

A.1. Percent cover system for vegetation mapping........................................................................................

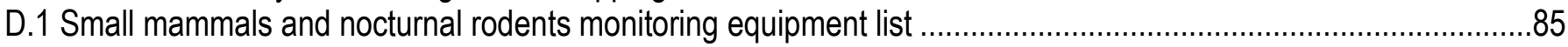

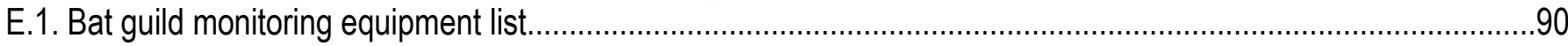

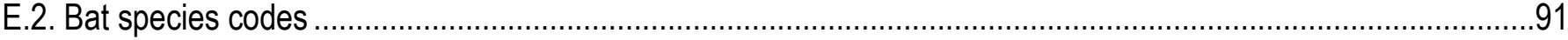




\section{List of Acronyms}

$\begin{array}{ll}\text { ABCl } & \text { Arizona Bird Conservation Initiative } \\ \text { ACEC } & \text { Areas of Critical Environmental Concern } \\ \text { AKN } & \text { Avian Knowledge Network } \\ \text { AMT } & \text { Above Mean Terrain } \\ \text { ARIA } & \text { Arizona Regional Image Archive } \\ \text { ARMI } & \text { Amphibian Research and Monitoring Initiative } \\ \text { ARSC } & \text { Arizona Remote Sensing Center } \\ \text { ASPRS } & \text { American Society of Photogrammetry and Remote Sensing } \\ \text { AZGFD } & \text { Arizona Game and Fish Department } \\ \text { BBS } & \text { Breeding Bird Survey } \\ \text { BEC } & \text { Barry M. Goldwater Range Executive Committee } \\ \text { BLM } & \text { Bureau of Land Management } \\ \text { BMGR } & \text { Barry M. Goldwater Range } \\ \text { CBP } & \text { Customs and Border Protection } \\ \text { CDC } & \text { Center for Disease Control } \\ \text { CEDES } & \text { Commission of Ecology and Sustainable Development for the State of Sonora (Mexico) } \\ \text { CEMML } & \text { Center for Ecological Management of Military Lands } \\ \text { CONANP } & \text { National Commission for Protected Natural Areas (Mexico) } \\ \text { CPNWR } & \text { Cabeza Prieta National Wildlife Refuge } \\ \text { DEM } & \text { Digital Elevation Model } \\ \text { DHS } & \text { Department of Homeland Security } \\ \text { DOD } & \text { Department of Defense } \\ \text { DOI } & \text { Department of the Interior } \\ \text { DOQ } & \text { Digital Orthophoto Quadrangle } \\ \text { DPS } & \text { Distinct Population Segment } \\ \text { ECE } & \text { Environmental Compliance Evaluations } \\ \text { EIS } & \text { Environmental Impact Statement } \\ \text { EMP } & \text { Ecological Monitoring Program } \\ \text { EMS } & \text { Environmental Management System } \\ \text { EROS } & \text { Earth Resources Observation Systems } \\ \text { ESA } & \text { Endangered Species Act } \\ \text { FGDC } & \text { Federal Geographic Data Committee } \\ \text { FSA } & \text { Farm Service Agency } \\ \text { FTHL } & \text { Flat-Tailed Horned Lizard (Phrynosoma mcallii) } \\ \text { GBAFAF } & \text { Gila Bend Air Force Auxiliary Field } \\ \text { GIS } & \text { Geographic Information Systems } \\ \text { GPS } & \text { Global Positioning System } \\ \text { GRS } & \text { Geodetic Reference System } \\ \text { GRTS } & \text { Generalized Random Tessellation Stratified } \\ \text { GSD } & \text { Ground Sample Distance } \\ \text { HDMS } & \text { Heritage Data Management System } \\ \text { HQMC } & \text { Inveadquarters Marine Corps } \\ \text { I\&M } & \\ & \end{array}$




\begin{tabular}{|c|c|}
\hline IEC & Interagency Executive Committee \\
\hline INRMP & Integrated Natural Resources Management Plan \\
\hline LAFB & Luke Air Force Base \\
\hline LIDAR & Light Detection and Ranging \\
\hline MA & Management Area \\
\hline MCAS-Yuma & Marine Corps Air Station Yuma \\
\hline MLWA & Military Lands Withdrawal Act \\
\hline MMDM & Mean Maximum Distance Moved \\
\hline MODIS & Moderate Resolution Imaging Spectroradiometer \\
\hline MP & Management Policy \\
\hline MSCP & Multiple Species Conservation Plan \\
\hline NAD83 & North American Datum 1983 \\
\hline NAIP & National Agriculture Imagery Program \\
\hline NAWMA & North American Weed Management Association \\
\hline NDVI & Normalized Difference Vegetation Index \\
\hline NOAA & National Oceanic and Atmospheric Administration \\
\hline NPS & National Park Service \\
\hline NRCS & Natural Resources Conservation Service \\
\hline NVCS & National Vegetation Classification System \\
\hline NWR & National Wildlife Refuge \\
\hline OALS & Office of Arid Lands Studies \\
\hline ОСРО & Outside Count-Period Observation \\
\hline OPCNM & Organ Pipe Cactus National Monument \\
\hline PMO & Provost Marshal's Office \\
\hline QA/QC & Quality Assurance and Quality Control \\
\hline RAWS & Remote Automated Weather Stations \\
\hline RGB & Red, Green, Blue \\
\hline RMBO & Rocky Mountain Bird Observatory \\
\hline RMO & Range Management Office \\
\hline RMSE & Root Mean Square Error \\
\hline RUSLE & Revised Universal Soil Loss Equation \\
\hline RWEQ & Revised Wind Equation \\
\hline SDNHM & San Diego Natural History Museum \\
\hline SDNM & Sonoran Desert National Monument \\
\hline SDRS & Sonoran Desert Research Station \\
\hline SEINet & Southwest Environmental Information Network \\
\hline SNM & Saguaro National Monument \\
\hline SODN & Sonoran Desert Network \\
\hline SOP & Standard Operating Procedure \\
\hline SPH & Sonoran Pronghorn (Antilocapra americana sonoriensis) \\
\hline SRMA & Special Recreation Management Area \\
\hline SSURGO & Soil Survey Geographic Database \\
\hline TON & Tohono O'odham Nation \\
\hline UA & University of Arizona \\
\hline UA-SNRE & University of Arizona-School of Natural Resources and $\mathrm{E}$ \\
\hline
\end{tabular}




$\begin{array}{ll}\text { UDA } & \text { Undocumented Aliens } \\ \text { USAF } & \text { U.S. Air Force } \\ \text { USBP } & \text { U.S. Border Patrol } \\ \text { USDA } & \text { U.S. Department of Agriculture } \\ \text { USFS } & \text { U.S. Forest Service } \\ \text { USFWS } & \text { U.S. Fish and Wildlife Service } \\ \text { USGS } & \text { U.S. Geological Survey } \\ \text { USMC } & \text { U.S. Marine Corps } \\ \text { USNG } & \text { U.S. National Grid } \\ \text { USPED } & \text { Unit Stream Power based Erosion and Deposition } \\ \text { UTM } & \text { Universal Transverse Mercator } \\ \text { WEQ } & \text { Wind Erosion Equation } \\ \text { WGS } & \text { World Geodetic System } \\ \text { WGS84 } & \text { World Geodetic System 1984 } \\ \text { WRCC } & \text { Western Regional Climate Center } \\ \text { YPG } & \text { Yuma Proving Ground }\end{array}$




\title{
An Inventory and Monitoring Plan for a Sonoran Desert Ecosystem: Barry M. Goldwater Range-West
}

By Miguel L. Villarreal, ${ }^{1}$ Charles van Riper III, ${ }^{2}$ Robert E. Lovich, ${ }^{3}$ Robert L. Palmer, ${ }^{3}$ Travis Nauman, ${ }^{4}$ Sarah E. Studd, ${ }^{5}$ Sam Drake, ${ }^{6}$ Abigail S. Rosenberg, ${ }^{7}$ Jim Malusa, ${ }^{1}$ and Ronald L. Pearce ${ }^{7}$

\begin{abstract}
Marine Corps Air Station Yuma manages the Barry M. Goldwater Range-West, which encompasses approximately 2,800 square kilometers of Sonoran Desert habitat in southwestern Arizona. The Barry M. Goldwater Range is a major U.S. military installation designed as an air combat training location for the U.S. Marine Corps and U.S. Air Force, but it also includes some of the most pristine desert habitat in the United States. In an effort to ensure the long-term viability of this unique natural resource, the U.S. Geological Survey (USGS) has developed an Integrated Natural Resources Management Plan and Inventory and Monitoring Plan to guide natural resource management of the Barry M. Goldwater Range-West. This Inventory and Monitoring Plan provides a framework for longterm ecosystem monitoring on Barry M. Goldwater Range-West lands by identifying existing and potential threats to ecosystem function, prioritizing resources for monitoring, and providing information and protocols necessary to initiate a long-term ecosystem monitoring program. The Inventory and Monitoring Plan and related protocols were developed through extensive review of existing Sonoran Desert monitoring programs and monitoring literature and through a 2-day workshop with resource managers, monitoring experts, and other stakeholders. The Barry M. Goldwater Range-West Inventory and Monitoring Plan stresses the importance of regional monitoring partnerships and protocol standardization for understanding landscape-scale ecosystem changes in the Sonoran Desert; information and protocols contained within the plan may also be of interest to land managers engaged in large-scale ecosystem monitoring and adaptive management of other arid regions.
\end{abstract}

Key Words: Inventory and Monitoring, Ecosystem Monitoring, Sonoran Desert, Marine Corps, Barry M. Goldwater Range, Adaptive Management

\footnotetext{
${ }^{1}$ University of Arizona, School of Natural Resources and the Environment, Tucson, AZ, 85721

${ }^{2}$ U.S. Geological Survey, Sonoran Desert Research Station, Tucson, AZ, 85721

${ }^{3}$ Naval Facilities Engineering Command (NAVFAC) Southwest, San Diego, CA, 92132

${ }^{4}$ Nauman Geospatial, Flagstaff, AZ, 86001

${ }^{5}$ National Park Service, Sonoran Desert Network, Tucson, AZ, 85710

${ }^{6}$ University of Arizona, Office of Arid Lands Studies, Tucson, AZ, 85719

${ }^{7}$ Marine Corps Air Station, Yuma, AZ, 85369
} 


\section{Purpose and Scope}

The purpose of this report is to provide background information to facilitate long-term ecosystem monitoring of Sonoran Desert ecosystems, specifically the natural resources of the Barry M. Goldwater Range-West. The report includes information on existing monitoring efforts in the Sonoran Desert, cooperative monitoring activities, and background information on key natural resources, and it reviews monitoring techniques and monitoring protocols. 


\subsection{Introduction and Background}

\subsection{Introduction}

The Barry M. Goldwater Range (BMGR) in southwestern Arizona is a major U.S. military installation, encompassing 7,050 square kilometers $\left(\mathrm{km}^{2}\right)$ of land designated as an air combat training location for the U.S. Marine Corps (USMC) and the U.S. Air Force (USAF). The Range is separated into two components: BMGR-West $\left(\sim 2,800 \mathrm{~km}^{2}\right)$ managed by Marine Corps Air Station Yuma (MCAS-Yuma) and BMGR-East $\left(\sim 4,250 \mathrm{~km}^{2}\right)$ managed by Luke Air Force Base (LAFB). While the primary mission of MCAS-Yuma and LAFB is to train military aircrews to fly combat missions, the range occupies a significant area of Federal lands recognized for their diverse natural resources, cultural resources, and outdoor recreation opportunities. A requirement of both the Sikes Act of 1960 and the Military Lands Withdrawal Act (MLWA) of 1999 was the development and implementation of an Integrated Natural Resources Management Plan (INRMP) (Integrated Natural Resources Management Plan, 2007) to facilitate a program that provides for the conservation and rehabilitation of natural resources and the sustainable multipurpose use of the resources. In compliance with the INRMP, MCAS-Yuma entered into a cooperative agreement with the U.S. Geological Survey (USGS) Sonoran Desert Research Station (SDRS) to develop an Inventory and Monitoring (I\&M) Plan for the BMGRWest. To facilitate the management of natural resources on the BMGR-West, a long-term natural resources inventory and monitoring plan was developed based on the management objectives of the BMGR-West and through the input of natural resource experts, cooperators, and stakeholders. This plan addresses the major environmental and conservation concerns of the BMGR-West and presents a set of monitoring protocols to inventory natural resources and to identify and track changes in these resources over time. Furthermore, the I\&M Plan provides a compendium of existing monitoring efforts within the Sonoran Desert region and a discussion of their relevance to monitoring and management of natural resources across the BMGR-West.

\subsubsection{Barry M. Goldwater Range: Environmental Setting}

The BMGR is located in southwestern Arizona, within the Lower Colorado River Valley Subdivision of the Sonoran Desert Ecoregion (fig. 1.1). The area is part of the basin and range province characterized by long, thin mountain ranges separated by wide alluvial valleys. Elevation within the BMGR ranges from $<61 \mathrm{~m}$ in the alluvial valleys to $1,220 \mathrm{~m}$ at the Sand Tank Mountains.

The BMGR and surrounding areas are characterized by extreme aridity and high temperatures, particularly during the summer months. Temperature of the area ranges from an average high of $106.1^{\circ} \mathrm{F}$ in July to an average low of $39.1^{\circ} \mathrm{F}$ in January (http://www.wrcc.dri.edu/; Yuma Citrus Station, 19202005). The area received an average annual precipitation of $87 \mathrm{~mm}$ during 1920-2005 (http://www.wrcc.dri.edu/; Yuma Citrus Station). 


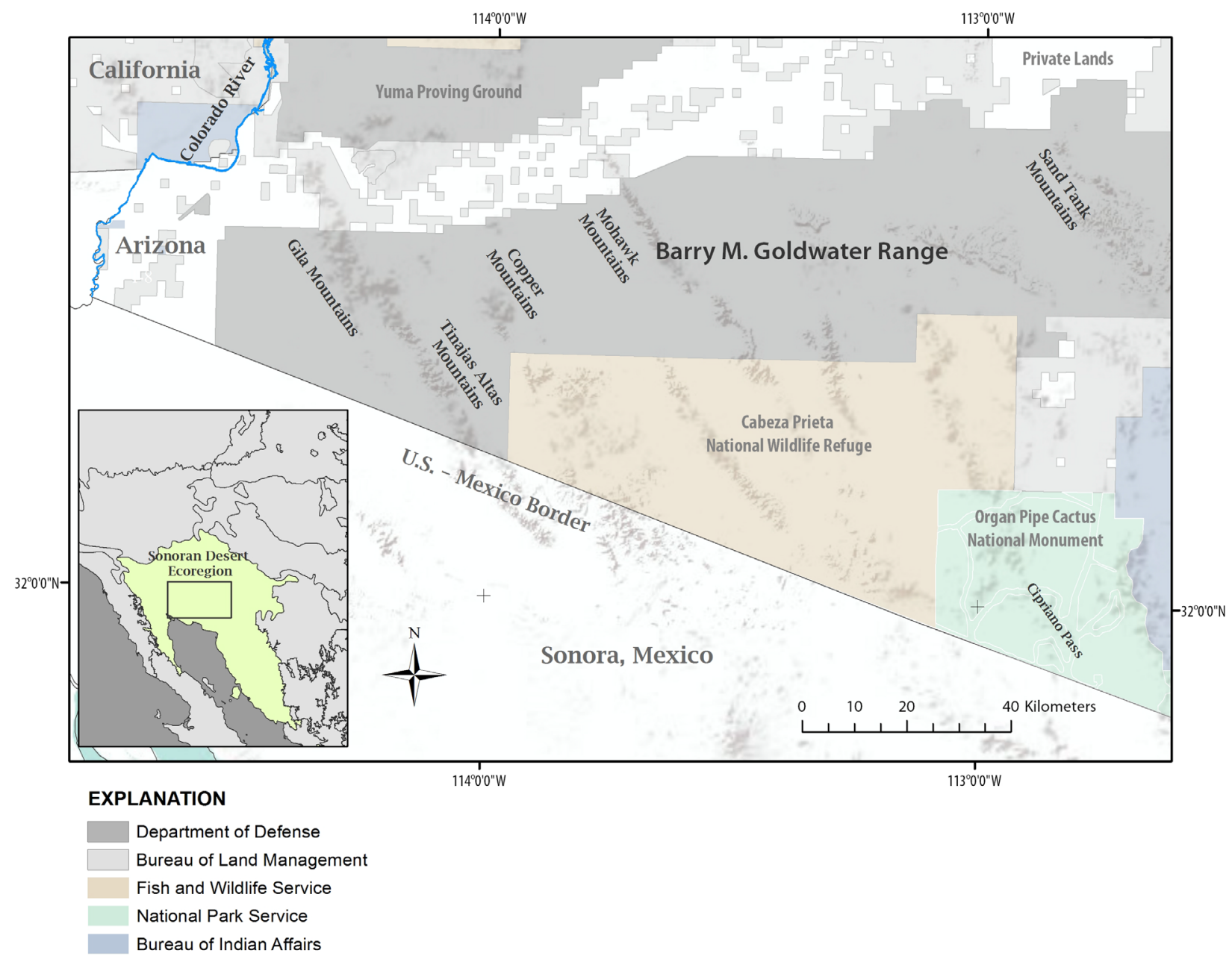

Figure 1.1. Map depicting the location of the Barry M. Goldwater Range within the Sonoran Desert Ecoregion, adjacent land management units, and natural features of the area. 
Because of the lack of precipitation, surface water is extremely limited on the BMGR. There are no perennial streams; however, ephemeral streams flow in response to large precipitation events during the summer monsoon (July-August). The main surfacewater resources on the BMGR are natural tanks, or "tinajas," rock catchments that store small amounts of runoff following precipitation events. The U.S. Fish and Wildlife Service (USFWS) and Arizona Game and Fish Department (AZGFD) maintain several water sources to support wildlife populations, particularly the endangered Sonoran pronghorn (Antilocapra americana sonoriensis) and the desert bighorn sheep (Ovis canadensis mexicana).

The BMGR is nationally significant as a major component of the largest remaining tract of relatively unfragmented Sonoran Desert in the United States that, with the exception of State Route 85 (fig. 1.2), is free of major developments that may disrupt ecological connectivity. The tract currently totals about $12,950 \mathrm{~km}^{2}$ and, in addition to the BMGR, includes the adjacent, ecologically linked areas of Organ Pipe Cactus National Monument (OPCNM), Cabeza Prieta National Wildlife Refuge (CPNWR), Sonoran Desert National Monument (SDNM), Tohono O'odham Nation (TON), and other lands administered by the Bureau of Land Management (BLM; fig. 1.2). Additional protected areas surrounding BMGR that are separated by constructed barriers include El Pinacate y El Gran Desierto Biosphere Reserve in Mexico (which shares approximately $60 \mathrm{~km}$ of the U.S.-Mexican border with BMGR-West ), Kofa National Wildlife Refuge, and the U.S. Army Yuma Proving Ground (YPG) north of Interstate 8 (fig.1.2). 


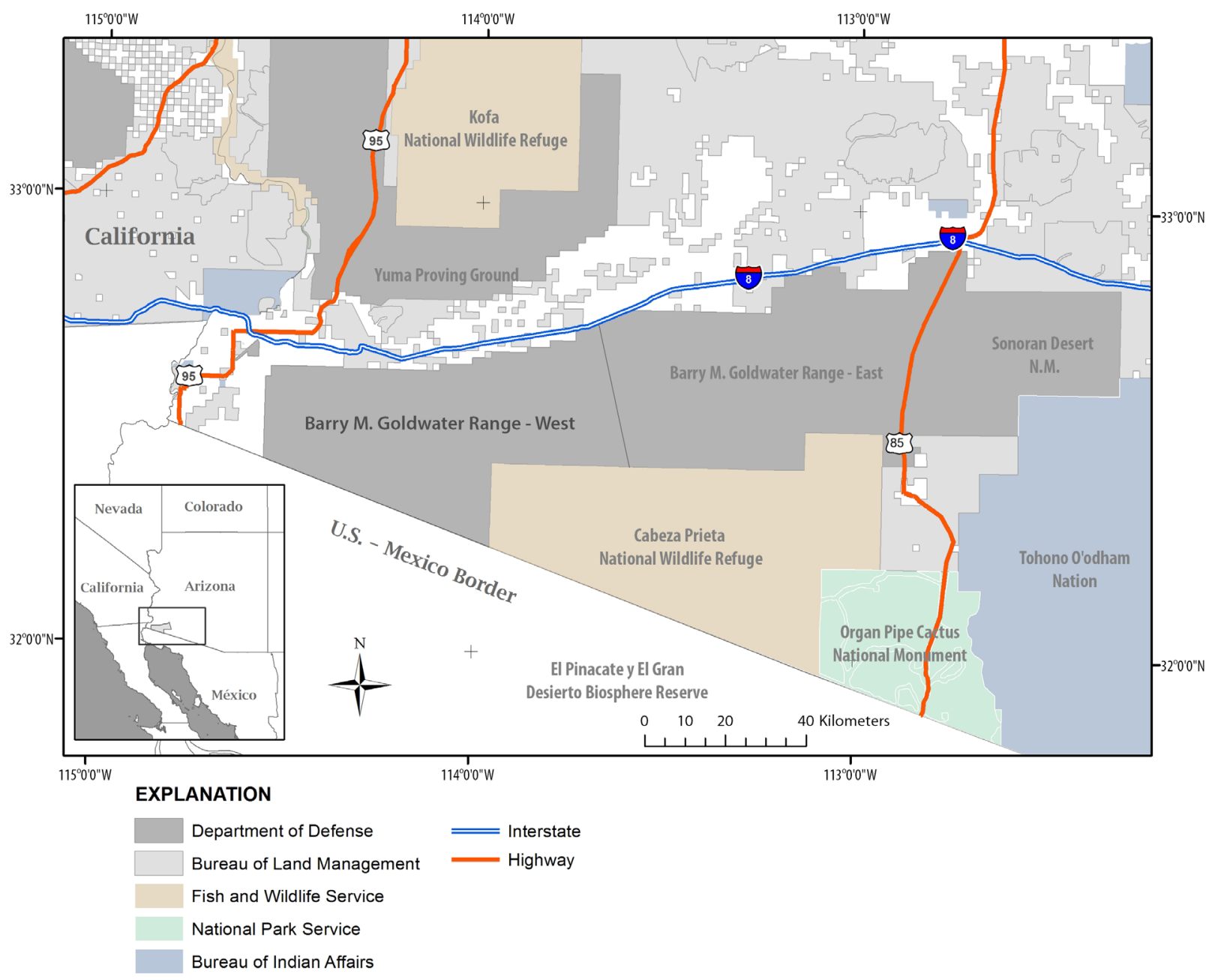

Figure 1.2. Map depicting Barry M. Goldwater Range and adjacent land ownership. 
The BMGR's extensive east-west land base includes a wide range of soils, geology, landforms, and vegetation types that are typical of the Sonoran Desert Ecoregion. Fifteen mountain ranges exist on the BMGR and are composed of igneous, metamorphic, and sedimentary rock types. The western section of BMGR falls within the Gran Desierto dune system, which extends to the west and south into Mexico. The Mohawk dune system of BMGR-West, located in the center of the range, is smaller and independent of the Gran Desierto dune system. Hall and others (2001) described and coarsely mapped the native vegetation communities, which include the Valley Bottom Floodplain Complex, Valley Xeroriparian Scrub, Mountain Xeroriparian Scrub, Dune Complex and Dune Endemics, Creosotebush-Bursage Desert Scrub, Creosotebush-Big Galleta Scrub, Paloverde-Mixed Cacti-Mixed Scrub, Sand Tank Mountains Uplands, Elephant Tree-Limberbush on Xeric Rocky Slopes, Desert Playa, and Salt Desert Scrub (table 1.1). These vegetation communities provide habitat for a number of rare, threatened, or endangered species, including the Sonoran pronghorn, desert bighorn sheep, Le Conte's thrasher (Toxostoma lecontei), Cowles fringe-toed lizard (Uma rufopunctata), flat-tailed horned lizard (Phrynosoma mcallii), desert tortoise (Gopherus agassizii), crucifixion thorn (Castela emoryi), and harwood milk-vetch (Astragalus insularis var. harwoodii) (Hall and others, 2001). 
This page intentionally left blank 
Table 1.1. Natural vegetation community types of the Barry M. Goldwater Range (Hall and others, 2001).

\begin{tabular}{|c|c|c|c|}
\hline Natural community & Composition & Spatial pattern and distribution & Comments \\
\hline $\begin{array}{l}\text { Valley Bottom } \\
\text { Floodplain Complex }\end{array}$ & $\begin{array}{l}\text { Characteristic vegetation includes } \\
\text { creosotebush, triangle-leaf bursage, white } \\
\text { bursage, acacias, paloverdes, mesquites, and } \\
\text { annual and perennial grasses. }\end{array}$ & $\begin{array}{l}\text { Linear/large patch system that } \\
\text { is likely endemic to the } \\
\text { Sonoran Desert Ecoregion }\end{array}$ & $\begin{array}{l}\text { Linear xeroriparian areas may be embedded within the } \\
\text { complex. As a community type that is characterized by } \\
\text { a shifting mosaic of vegetation patches spread across a } \\
\text { floodplain, it also can be considered a large patch } \\
\text { system. }\end{array}$ \\
\hline $\begin{array}{l}\text { Valley Xeroriparian } \\
\text { Scrub }\end{array}$ & $\begin{array}{l}\text { Characteristic vegetation is highly } \\
\text { variable and includes blue paloverde, } \\
\text { ironwood, mesquite, foothill paloverde, } \\
\text { herbaceous and woody perennial vines, and } \\
\text { sparse annual grasses and forbs. }\end{array}$ & $\begin{array}{l}\text { Linear system that is likely to } \\
\text { be distributed throughout the } \\
\text { Sonoran Desert and Mojave } \\
\text { Desert Ecoregions. }\end{array}$ & $\begin{array}{l}\text { Mesquite bosques (Prosopis spp.) can be associated } \\
\text { with this community. Significant examples of bosques } \\
\text { on the BMGR need to be documented. See comment } \\
\text { below in regard to Mountain Xeroriparian Scrub. }\end{array}$ \\
\hline $\begin{array}{l}\text { Mountain } \\
\text { Xeroriparian Scrub }\end{array}$ & $\begin{array}{l}\text { Characteristic vegetation is highly } \\
\text { variable but typically consists of } \\
\text { paloverdes, ironwood, mesquites, and } \\
\text { succulents. }\end{array}$ & $\begin{array}{l}\text { Linear system that is likely to } \\
\text { be distributed throughout the } \\
\text { Sonoran Desert and Mojave } \\
\text { Desert Ecoregions. }\end{array}$ & $\begin{array}{l}\text { Although its spatial pattern is characterized as linear, it } \\
\text { may create a mosaic pattern with associated matrix and } \\
\text { large-patch communities that is repeated frequently } \\
\text { across the landscape. }\end{array}$ \\
\hline $\begin{array}{l}\text { Dune Complex and } \\
\text { Dune Endemics }\end{array}$ & $\begin{array}{l}\text { Complex is generally sparsely vegetated by } \\
\text { scattered forbs and grasses. May include } \\
\text { shrubs and } \\
\text { dwarf-shrubs such as white } \\
\text { bursage. Stabilized dunes may } \\
\text { support creosotebush and } \\
\text { mesquites while active dune fields } \\
\text { may lack vegetation. }\end{array}$ & $\begin{array}{l}\text { Large patch system that } \\
\text { occurs throughout the } \\
\text { Sonoran and Mojave Desert } \\
\text { Ecoregions. }\end{array}$ & $\begin{array}{l}\text { Sonoran Desert endemic }(\mathrm{E}) / \text { limited }(\mathrm{L}) \text { plants that } \\
\text { demonstrate a strong association with the dune } \\
\text { complex are included within this element's description. } \\
\text { These plants include: } \\
\text { Astragalus insularis var. harwoodii }(\mathrm{E}) \\
\text { Astragalus magdalenae var. peirsonii }(\mathrm{E}) \\
\text { Croton wigginsii }(\mathrm{L}) \\
\text { Cryptantha ganderi }(\mathrm{E}) \\
\text { Eriogonum deserticola }(\mathrm{E}) \\
\text { Euphorbia }(=\text { Chamaesyce) platysperma }(\mathrm{E}) \\
\text { Helianthus niveus }(\mathrm{L}) \\
\text { Pholisma sonorae }(\mathrm{E}) \\
\text { Stephanomeria schottii }(\mathrm{E}) \\
\text { Triteleiopsis palmeri }(\mathrm{E}) .{ }^{.}\end{array}$ \\
\hline
\end{tabular}


Table 1.1. Natural Vegetation Community Types of the Barry M. Goldwater Range (Hall and others, 2001)._Continued

\begin{tabular}{|c|c|c|c|}
\hline Natural community & Composition & Spatial pattern and distribution & Comments \\
\hline $\begin{array}{l}\text { Creosotebush- } \\
\text { Bursage Desert } \\
\text { Scrub }\end{array}$ & $\begin{array}{l}\text { Vegetation is primarily dominated by } \\
\text { creosotebush. Woody and nonwoody cacti } \\
\text { and rosette succulents commonly occur on } \\
\text { rocky slopes. } \\
\text { Seasonally present perennial } \\
\text { grasses with some perennial forbs dominate } \\
\text { the sparse herbaceous layer. }\end{array}$ & $\begin{array}{l}\text { Matrix-forming system that } \\
\text { occurs throughout the Sonoran } \\
\text { and Mojave Desert Ecoregions. }\end{array}$ & None \\
\hline $\begin{array}{l}\text { Creosotebush-Big } \\
\text { Galleta Scrub }\end{array}$ & $\begin{array}{l}\text { Dominant shrub is creosotebush. } \\
\text { Big galleta is the sole or dominant grass in the } \\
\text { herbaceous layer. } \\
\text { White or triangle-leaf bursage can be a co- } \\
\text { dominant. }\end{array}$ & $\begin{array}{l}\text { Large patch system that occurs in } \\
\text { the Sonoran Desert and also may } \\
\text { occur in the Mojave Desert. }\end{array}$ & None \\
\hline $\begin{array}{l}\text { Paloverde-Mixed } \\
\text { Cacti-Mixed Scrub } \\
\text { on Bajadas }\end{array}$ & $\begin{array}{l}\text { Vegetation has a conspicuous but relatively } \\
\text { sparse layer of saguaro cactus. A sparse to } \\
\text { moderately } \\
\text { dense short tree/tall shrub canopy } \\
\text { is also present consisting of } \\
\text { paloverde and creosotebush, along with } \\
\text { ironwood and ocotillo in lesser prominence. A } \\
\text { sparse herbaceous layer dominated by } \\
\text { perennial grasses and forbs with seasonal } \\
\text { annuals is present. }\end{array}$ & $\begin{array}{l}\text { Matrix-forming system that } \\
\text { occurs only within the Sonoran } \\
\text { Desert. }\end{array}$ & None \\
\hline $\begin{array}{l}\text { Paloverde-Mixed } \\
\text { Cacti-Mixed Scrub } \\
\text { on Rocky Slopes }\end{array}$ & $\begin{array}{l}\text { This community is of similar } \\
\text { composition to that of the } \\
\text { Paloverde-Mixed Cacti-Mixed } \\
\text { Scrub on Bajadas, but contains } \\
\text { additional associates such as } \\
\text { Opuntia bigelovia. }\end{array}$ & $\begin{array}{l}\text { Large patch system that occurs } \\
\text { throughout the Sonoran Desert. }\end{array}$ & None \\
\hline
\end{tabular}


Table 1.1. Natural Vegetation Community Types of the Barry M. Goldwater Range (Hall and others, 2001).-Continued

\begin{tabular}{|c|c|c|c|}
\hline Natural community & Composition & Spatial pattern and distribution & Comments \\
\hline $\begin{array}{l}\text { Sand Tank } \\
\text { Mountains Uplands }\end{array}$ & $\begin{array}{l}\text { Vegetation in this complex } \\
\text { includes saguaro cactus and a } \\
\text { sparse to moderately dense short } \\
\text { tree/tall shrub canopy consisting of } \\
\text { paloverde and creosotebush. } \\
\text { Typical associates include } \\
\text { crucifixion thorn and Vaquelinea } \\
\text { californica sonorensis. Also } \\
\text { present is a sparse herbaceous layer } \\
\text { dominated by perennial grasses and forbs. }\end{array}$ & $\begin{array}{l}\text { Large patch system that occurs in } \\
\text { the Sonoran Desert; in addition } \\
\text { to the Sand Tank } \\
\text { Mountains, limited in } \\
\text { distribution to a few high- } \\
\text { elevation mountain ranges } \\
\text { throughout the Sonoran Desert; } \\
\text { includes an unusual combination } \\
\text { of plant species. }\end{array}$ & $\begin{array}{l}\text { Unusual combination of plants that occur only at high } \\
\text { elevations are included within this element's } \\
\text { description. These plants include: } \\
\text { Canotia holocantha } \\
\text { Juniperus coahuilensis } \\
\text { Vaquelinia californica sonorensis. }\end{array}$ \\
\hline $\begin{array}{l}\text { Elephant Tree- } \\
\text { Limberbush on } \\
\text { Xeric Rocky Slopes }\end{array}$ & $\begin{array}{l}\text { The composition of this community is similar } \\
\text { to that of the Paloverde-Mixed Cacti-Mixed } \\
\text { Scrub system, but is characterized by } \\
\text { additional associates. Elephant tree, } \\
\text { limberbush, Nolina bigelovii, and Rhus } \\
\text { kearnyi are dominant in a mixed canopy. } \\
\text { Vegetation of this system may differ with } \\
\text { substrate. }\end{array}$ & $\begin{array}{l}\text { Large patch system that occurs in } \\
\text { arid mountain ranges within the } \\
\text { Lower Colorado Valley, Central } \\
\text { Gulf Coast, and Arizona Uplands } \\
\text { subdivisions of the Sonoran } \\
\text { Desert. On the BMGR it occurs } \\
\text { on the western mountain ranges } \\
\text { (Cabeza Prieta, Copper, Gila, } \\
\text { and Tinajas Altas Mountains). }\end{array}$ & None \\
\hline Desert Playa & $\begin{array}{l}\text { Generally desert playas in the central Sonoran } \\
\text { Desert are sparsely vegetated, with periodic } \\
\text { emergence of ephemeral species. Large } \\
\text { playas in the Sonoran Desert may have } \\
\text { surrounding rings of vegetation. } \\
\text { Characteristic vegetation differs between } \\
\text { playas and unpredictable annuals may } \\
\text { emerge. }\end{array}$ & $\begin{array}{l}\text { Large patch system that occurs } \\
\text { throughout the Sonoran Desert } \\
\text { and may occur in the Mojave } \\
\text { Desert. }\end{array}$ & None \\
\hline
\end{tabular}


Table 1.1. Natural Vegetation Community Types of the Barry M. Goldwater Range (Hall and others, 2001).-Continued

\begin{tabular}{clll}
\hline Natural community & \multicolumn{1}{c}{ Composition } & Spatial pattern and distribution \\
\hline Desert Tinaja/Spring & $\begin{array}{l}\text { Tinajas are typically small aquatic ecosystems } \\
\text { formed through water accumulation in } \\
\text { bedrock depressions. Vegetation is typically } \\
\text { absent or present as a few individual plants. }\end{array}$ & $\begin{array}{l}\text { Small patch system that occurs } \\
\text { throughout the desert southwest. }\end{array}$ & None \\
Salt Desert Scrub & $\begin{array}{l}\text { Two main types of saltbush communities } \\
\text { occur. Saltbush communities found along }\end{array}$ & $\begin{array}{l}\text { Large patch system that occurs } \\
\text { throughout the desert southwest. Specific occurrences still need to be mapped on the }\end{array}$ & BMR.
\end{tabular}
major riverine systems typically have been converted to agriculture. The drier upland type is associated with creosotebush and numerous cactus species. The community is dominated by the xeromorphic shrub Atriplex polycarpa. The sparse to moderately dense graminoid layer may be dominated by warm season medium-tall and short grasses. Forb cover is generally sparse.

\footnotetext{
${ }^{1}$ The occurrence of each of these species on the BMGR is documented as follows: Astragalus insularis var. harwoodii, Mohawk Dunes (Felger and others, 1997) and Yuma Dunes (Center for Ecological Management of Military Lands [CEMML] unpublished data); Astragalus madgalenae var. peirsonii, Yuma Desert northwest of Yuma Dunes (unpublished data; collected by D. Turner and identified by R. Felger); Croton wigginsii, Yuma Dunes (Felger and others, 1997; Warren and Laurenzi, 1987); Cryptantha ganderi, Mohawk Dunes (Felger, 2000, Felger and others, 1998); Eriogonum deserticola, Yuma Dunes (CEMML, Felger and others, 1997, Warren and Laurenzi, 1987); Euphorbia (= Chamaesyce) platysperma, Yuma Dunes (CEMML, Warren and Laurenzi, 1987); Helianthus niveus, Yuma Dunes (CEMML, Warren and Laurenzi, 1987); Pholisma sonorae, Yuma Dunes (CEMML, Felger and others, 1997, Warren and Laurenzi, 1987); Stephanomeria schottii, Mohawk Dunes (Felger and others, 1997, Warren and Laurenzi, 1987) and Yuma Dunes (CEMML, Warren and Laurenzi, 1987); Triteleiopsis palmeri, Yuma Dunes (CEMML, Felger and others, 1997, Warren and Laurenzi, 1987).

${ }^{2}$ The occurrence of each of these species on the BMGR is documented in Felger and others (1997).
} 


\subsubsection{Land Management}

The BMGR INRMP identifies the protection of natural resources and sustainable public use as fundamental goals of the range management, provided that management and use are consistent with military purposes of the range. Three Federal agencies and one State agency (USAF, USMC, USFWS, and AZGFD) share responsibilities for natural resource management within the BMGR. A fifth agency, BLM, has reserve oversight roles but no direct resource management responsibilities. The USAF and USMC have primary surface management responsibility for BMGR lands and related natural and cultural resources. The Secretaries of the Navy, Air Force, and Interior jointly prepared the INRMP, and the Secretary of the Interior remains involved in the management of natural and, to a lesser extent, cultural resources within the BMGR. The Secretary of the Interior acts through the Director of the USFWS when participating in the preparation and implementation of INRMPs. Furthermore, USFWS maintains responsibilities for administering compliance with the Endangered Species Act of 1973 and Migratory Bird Treaty Act of 1918 within the BMGR.

The MLWA of 1999 designates BMGR land as (1) an armament and high-hazard testing area, (2) an area for training for aerial gunnery, rocketry, electronic warfare, and tactical maneuvering and air support, and (3) an area for other defense-related purposes. The impacts on natural resources from military training and weapons testing are estimated to be minimal and generally contained within relatively small and discrete areas. Only a small percentage $(\sim 3$ percent) of soil and vegetation resources has been highly disturbed by military training activities (Integrated Natural Resources Management Plan, 2007. A majority of BMGR-West lands have received no disturbance or low disturbance from military training activities over the past six decades and have been preserved and protected in a relatively natural state (Integrated Natural Resources Management Plan, 2007).

The commitment of the USMC to resource conservation has helped to limit degradation of much of the BMGR environment. The ecological integrity of the BMGR has been maintained over the past 60 years because (1) most land uses that are known to have negative ecological effects (for example, urban development and infrastructure, cattle grazing, unmanaged and poorly enforced recreation) have been excluded from the range in order to effectively carry out military training operations, and (2) only a small percentage of the restricted land area is physically disturbed by military training activities. Operational or other safety requirements restrict both habitation and economic development of the range and specify that recreational uses be controlled by MCAS-Yuma. Land-use activities such as livestock grazing, mining, agriculture, and residential/commercial development have been legally excluded from the range since the 1940s (Integrated Natural Resources Management Plan, 2007).

The State of Arizona has primary jurisdiction over resident wildlife management within the BMGR, and the AZGFD implements this jurisdiction on behalf of the State. The AZGFD's mission is to "conserve, enhance, and restore Arizona's diverse wildlife resources and habitats through aggressive protection and management programs, and to provide wildlife resources and safe watercraft and off-highway vehicle recreation for the enjoyment, appreciation, and use by present and future generations."

Approximately 80 percent of all range areas open to general public access is located within BMGR-West. The area of BMGR-West usually open to public access encompasses about 
75 percent of the BMGR-West land area (about 2,100 $\mathrm{km}^{2}$ ). Portions of this area are at times closed to public access to support regularly scheduled activities that present safety hazards or have security requirements. Beginning in 2001, a portion east of the Copper Mountains (fig. 1.1) has been closed to public access each year for the fawning season of the Sonoran pronghorn, a Federally-listed endangered species. The fawning season is from March 15 to July 15 and represents the period of greatest sensitivity to animal disturbance. The road network approved for public use within affected areas includes $790 \mathrm{~km}$ of roads.

Within the BMGR-West, the AZGFD is responsible for three major monitoring and management activities:

- Hunting: issuing hunting permits and enforcing hunting regulations. Establishing game limits for hunting, trapping, and non-game species collection;

- Wildlife management: developing and maintaining habitat assessment/evaluation, protection, management, and enhancement projects (for example, artificial water developments and Sonoran pronghorn food plots). Conducting wildlife population surveys and managing wildlife predators and endangered species/special status species (management of Federally listed endangered species is a responsibility shared with the USFWS); and

- Recreation: managing off-highway vehicles in terms of habitat protection and user opportunities.

Specific AZGFD management activities on the BMGR include conducting annual bighorn sheep and golden eagle (Aquila chrysaetos) surveys and maintaining wildlife watering holes.

\subsubsection{Review of Range Status, Stressors and Drivers}

There are a number of anthropogenic stressors and natural environmental drivers affecting Sonoran Desert ecosystems that may result in various degrees and types of habitat degradation. Such phenomena can lead to species extirpation or extinction. Biota of the Sonoran Desert Ecoregion evolved to survive and reproduce under extreme environmental conditions and with limited resources. However, these biotas can become stressed when scarce resources are further limited or degraded by competition with hardier nonnative species or through anthropogenically induced physical degradation. Disturbed vegetation and soils in arid environments tend to have long recovery times, and many restoration and revegetation efforts have low success rates (Lovich and Bainbridge, 1999; Webb and others, 2009). Anthropogenic stressors and natural ecosystem drivers with potential to impact ecosystem function at the BMGR-West include invasive plants and animals, human population growth, adjacent agricultural land use, off-highway vehicle and recreation impacts, military and U.S. Border Patrol (USBP) activities, prolonged drought, disease, wildfire, and others. The following is a short list and description of the chief stressors and drivers with potential to compromise ecosystem integrity of BMGR-West:

Invasive Plants and Animals. - Invasive plants and animals are of great concern to land managers throughout the Sonoran and Mojave Deserts (Tellman, 2002; Brooks and others, 2004). If left undetected, unmonitored, and unmanaged, nonnative herbaceous species - for example, Sahara mustard (Brassica tournefortii), buffelgrass (Pennisetum ciliare), and red brome (Bromus rubens) - could fundamentally alter BMGR's ecosystem structure through competition with native species, reduction of species diversity and enhancing the spread of 
wildfires. Nonnative animals also threaten ecosystem function- the European starling (Sturnus vulgaris), which has been identified on the BMGR, is associated with urban development/encroachment and is known to compete for resources with native cavity-nesting birds. Invasive animal species pose an even more insidious threat, in that they have been documented to harbor parasites and diseases from their native species ranges, sometimes even from other continents (Warburton and others, 2002; Kuperman and others, 2004).

Roads, Trails and Off-highway Vehicles.-The creation of new roads and the continued use of existing roads can affect ecosystem function in numerous ways: roads function as corridors for the spread of invasive species (Rutman and Dickson, 2002), are directly associated with native species mortality, can restrict species range through habitat fragmentation and direct disturbance (Forman and Alexander, 1998; Duncan and others, 2010), and can alter the hydrological functions of a given area. In general, roads affect soil cover by displacing, adding to, or changing its physical and compositional structure. Alterations of soil conditions and hydrological function in turn influence water availability to native vegetation.

Regional Population Growth and Recreation.-Urban growth and rural development in areas surrounding the BMGR have direct and indirect effects on ecosystem function. Air pollution, water pollution, water use, and habitat fragmentation outside of the range boundary can profoundly impact ecosystem function and dynamics inside the management area. Local and regional population growth may lead to increased visitor and recreation uses, thus intensifying pressures on BMGR natural resources through the creation of trails and roads, vegetation trampling, and soil compaction, and from possible resource extraction activities such as hunting, collecting (for example, rocks, reptiles, and others), or even poaching.

Military Training Operations.-Military training activities, including live ordnance jettison, air combat training flights, and large vehicle maneuvers, are known to affect ecosystem function directly (that is, soil compaction) or indirectly (that is, aircraft noise levels) (Prose and Wilshire, 2000; Webb, 2002). Training activities are part of the BMGR's primary military mission and are restricted to designated areas of the range (see section 1.1.2).

Drought and Climate Change.-Drought and climate change are regional and global drivers of ecosystem change that land managers rarely have control over at their management scale. However, land managers can implement management strategies that help to minimize climate impacts on resident biota. Knowledge about drought, and climate patterns and forecasts, can help managers prepare for alternate future scenarios. The American Southwest has experienced drought for the past decade, and some climate models predict a continued drought under climatic warming (Seager and others, 2007). Increased temperatures and variable precipitation events related to drought and climate change will likely affect BMGR-West by decreasing soil moisture, increasing drought stress, and decreasing the availability of surfacewater resources.

\subsection{Inventory and Monitoring Program Goals and Objectives}

\subsubsection{Inventory, Monitoring, and Adaptive Management}

A typical Inventory and Monitoring program commences with an extensive inventory of resources followed by systematic, long-term monitoring. An Inventory is a point-in-time collection of information describing the occurrence, spatial distribution, and condition of a given 
resource. Inventories are typically designed to locate populations of species, locate all species within a specific area, describe the habitat of a species or assess ages, sizes, and conditions of individuals within a population. As a point-in-time collection, an inventory often becomes the starting point for a monitoring program. The two may be decoupled in time, however, if prior work only included disjunct inventories, or rapid assessments, without the follow-up of a monitoring component as the next step. Monitoring is a means to detect trends in a resource over time and is typically accomplished by measuring resources at the same locations over time. Elzinga and others (2001) define monitoring as "the collection and analysis of repeated observations or measurements to evaluate changes in condition and progress toward meeting a management objective."

A statistically sound and robust monitoring program is a prerequisite for management activities aimed at restoring or maintaining ecosystem function. Adaptive management is a systematic and iterative learning process whereby management objectives are informed by management outcomes. Adaptive management is designed to reduce management uncertainties, to better understand how ecological systems function, and to provide information required to achieve desired management outcomes. The following is a working definition of adaptive management proposed by the National Resource Council and adopted as a standard definition by the Department of the Interior ( Williams and others, 2009):

Adaptive management is a decision process that promotes flexible decision making that can be adjusted in the face of uncertainties as outcomes from management actions and other events become better understood. Careful monitoring of these outcomes both advances scientific understanding and helps adjust policies or operations as part of an iterative learning process. Adaptive management also recognizes the importance of natural variability in contributing to ecological resilience and productivity. It is not a "trial and error" process, but rather emphasizes learning while doing. Adaptive management does not represent an end in itself, but rather a means to more effective decisions and enhanced benefits. Its true measure is in how well it helps meet environmental, social, and economic goals, increases scientific knowledge, and reduces tensions among stakeholders.

It is suggested that adaptive management be considered once a monitoring program is initiated and change in a monitoring parameter is detected (established by means of a threshold value determined beforehand). Adaptive management decisions may not be initiated based on monitoring data alone but may require additional, well designed, and targeted scientific research. In such a case, monitoring data serve as guidance for identifying potential hypotheses for changing conditions and to inform the design of additional research. It is the aim of the investigators to employ a strategy of adaptive management based on the outcome of the inventory and monitoring efforts and resulting data and analyses.

\subsubsection{Inventory and Monitoring Program Goals and Objectives}

Successful monitoring programs are structured around clear management objectives. Objective-based monitoring programs support adaptive management by establishing desired conditions for specific resources (Elzinga and others, 2001). In addition to supporting management activities, the success of a monitoring plan can only be evaluated relative to goals and objectives stated beforehand. BMGR goals and objectives for natural resource monitoring and management were established during the INRMP planning process (Integrated Natural 
Resources Management Plan, 2007). Goals and objectives specific to BMGR-West were explicated further by monitoring experts and stakeholders during the monitoring protocol development workshop facilitated by the USGS and University of Arizona (UA).

BMGR Management Policy Goals

Resource management goals were developed to guide the INRMP in accordance with BMGR legal requirements (that is, MLWA and Sikes Act) to address military mission requirements of the range and interests of other stakeholders (that is, USFWS, AZGFD, USBP and selected Native American tribes). Five non-resource-specific management policy (MP) goals established during the INRMP planning process were:

1. MP1-Maintain and enhance the natural resources to ensure that these resources are sustained in a healthy condition for compatible uses (for example, low-impact recreation) by future generations, while supporting the existing and future military purposes of the BMGR.

2. MP2 - Manage cultural resources in accordance with the BMGR Integrated Cultural Resources Management Plan.

3. MP3 - Allow for public access to BMGR resources for sustainable multipurpose uses that are consistent with the military purposes (that is, security and safety requirements) and ecosystem sustainability.

4. MP4-Apply ecosystem management principles through a goal- and objective-driven approach that recognizes social and economic values; is adaptable to complex, changing requirements; and is realized through effective partnerships among private, local, State, Tribal, and Federal interests.

5. MP5-Meet or exceed the statutory requirements of the MLWA of 1999, Sikes Act, and other applicable resource management regulatory requirements.

\section{BMGR Resource Management Goals}

Eleven resource-specific goals were specified further to guide the INRMP process that address soil, water, vegetation, wildlife, visual resources, transportation, recreation, Native American access, nonmilitary and perimeter land use, and special natural/interest areas (table $1.2)$. 
Table 1.2. Resource-specific management goals for Barry M. Goldwater Range (adapted from Integrated Natural Resources Management Plan, 2007).

\footnotetext{
Resource

Soil resources

Water resources

Vegetation resources

Wildlife resources

Visual resources

Transportation

Recreation

\section{Management Goal(s)}

- Implement best management practices to control and prevent excessive soil erosion, implement soil conservation measures, and restore or rehabilitate degraded landscapes wherever practicable, subject to budgetary constraints.

- Manage water resources to protect, maintain, and improve water quality; water conservation to prevent aquifer depletion; and ensure regulatory compliance while maintaining unrestricted access for military purposes.

- Protect and conserve plant communities and species diversity.

- Identify, protect, conserve, manage, and ensure regulatory compliance for threatened and endangered plant species or otherwise important or sensitive plant species.

- Inventory exotic plant species occurrence and distribution and implement management measures for their removal or control.

- Restore or rehabilitate altered or degraded plant communities wherever practicable, subject to budgetary constraints.

- Incorporate the principles of ecosystem management and promote biodiversity.

- Protect and conserve wildlife habitat, species diversity, and viable populations.

- Identify, protect, conserve, manage, and comply with regulatory requirements for federally threatened and endangered wildlife species or otherwise significant or sensitive species.

- Restore or rehabilitate human-altered or degraded wildlife habitats wherever practicable, subject to budgetary constraints.

- Incorporate the principles of ecosystem management and promote biodiversity.

- Control trespass livestock, or other nonnative species.

- Protect or enhance the integrity and diversity of visual resources (that is, scenic landscape qualities) on the BMGR.

- Develop a BMGR transportation plan that addresses continued land-based access for military training and testing; provide access for wildlife research and wildlife habitat management, land management, and law enforcement by Federal and State agencies; and provide public access for wildlife-oriented recreation and sustainable multipurpose use.

- Establish policies and provide procedures that ensure vehicle use on the BMGR is controlled and directed to protect resources, promote safety, and minimize multi-use conflicts.

- Provide public access and use of natural resources for sustainable multi-purposes when such activities are compatible with mission activities and other considerations such as security, safety, and resource sensitivity.

- Assess the continuing applicability of Special Recreation Management Area (SRMA) designations in consideration of their incompatibility with military operations.

- Manage all activities in accordance with the INRMP for the BMGR.
} 
Table 1.2. Resource-specific management goals for Barry M. Goldwater Range (adapted from Integrated Natural Resources Management Plan, 2007).-Continued

\begin{tabular}{|c|c|}
\hline Resource & Management Goal(s) \\
\hline $\begin{array}{l}\text { Native American } \\
\text { access }\end{array}$ & $\begin{array}{l}\text { - Provide for Native American access to Traditional Cultural Places and sacred sites, } \\
\text { consistent with the military mission and natural resource management goals. }\end{array}$ \\
\hline $\begin{array}{l}\text { Non-military } \\
\text { land use }\end{array}$ & $\begin{array}{l}\text { - Develop a program for addressing rights-of-way on the BMGR. } \\
\text { - Participate in local initiatives to advance ecoregional planning and biodiversity } \\
\text { goals. }\end{array}$ \\
\hline $\begin{array}{l}\text { Perimeter land } \\
\text { use }\end{array}$ & $\begin{array}{l}\text { - Cooperate with land managers of adjoining property for conservation, public } \\
\text { relations, and compliance benefits. } \\
\text { - Develop strategies, in coordination with ranchers when feasible, to reduce trespass } \\
\text { livestock occurrences. }\end{array}$ \\
\hline $\begin{array}{l}\text { Special } \\
\text { natural/interest } \\
\text { areas }\end{array}$ & $\begin{array}{l}\text { - Recognize and review existing special resource management areas, such as Areas of } \\
\text { Critical Environmental Concern (ACEC) and the backcountry byway, and assess the } \\
\text { continuing applicability of special management provisions for the protection of these } \\
\text { areas. }\end{array}$ \\
\hline \multicolumn{2}{|c|}{ BMGR-West Management and Monitoring Objectives } \\
\hline \multicolumn{2}{|c|}{$\begin{array}{l}\text { During the August 26, 2009, workshop held at the University of Arizona, participants } \\
\text { assisted in refining the BMGR-West natural resource management objectives and developing } \\
\text { basic monitoring strategies to guide I\&M Plan development. Table } 1.3 \text { contains the original } \\
\text { management objectives and modified objectives created to specifically guide the monitoring } \\
\text { process. }\end{array}$} \\
\hline
\end{tabular}


Table 1.3. Natural resource management objectives for the Barry M. Goldwater Range.

\begin{tabular}{ll}
\hline \multicolumn{1}{c}{ Original management objectives } & \multicolumn{1}{c}{ Modified management objectives } \\
\hline Manage to control invasive species & $\begin{array}{l}\text { Identify (location, source and transmission), assess, eradicate, } \\
\text { reduce, mitigate, and/or minimize problematic invasive species }\end{array}$ \\
$\begin{array}{l}\text { Minimize erosion (wind, water, and others) } \\
\text { Identify (natural events), avoid, and control problematic erosive and } \\
\text { deleterious landscape impacts }\end{array}$ \\
$\begin{array}{l}\text { Maximize partnerships, including international } \\
\text { partnerships, and engage public/demonstrate } \\
\text { stewardship }\end{array}$ & $\begin{array}{l}\text { Expand and integrate with local, regional, and international } \\
\text { partnerships to enhance resource management. Enhance public } \\
\text { outreach and recognition of military operations and stewardship }\end{array}$ \\
$\begin{array}{l}\text { Ensure that the base functions as a wildlife } \\
\text { preserve without compromising military }\end{array}$ & $\begin{array}{l}\text { Ensure that the base functions to conserve plant and animal } \\
\text { communities without compromising military activities. }\end{array}$ \\
$\begin{array}{l}\text { Improve base resource management through } \\
\text { sound science }\end{array}$ & $\begin{array}{l}\text { Apply natural resource management and protections using sound } \\
\text { scientific principles and data acquisition }\end{array}$ \\
$\begin{array}{l}\text { Regional comparability of information/data } \\
\text { Integrate and/or enhance regional inventory and monitoring data } \\
\text { throughout the Sonoran Desert ecosystem }\end{array}$ \\
$\begin{array}{l}\text { Exceed and/or meet natural resource inventory and monitoring } \\
\text { regulatory requirements }\end{array}$ \\
$\begin{array}{l}\text { Regulatory requirements under the law } \\
\text { Track basic ecosystem functions } \\
\begin{array}{l}\text { Responsive/compatible with adaptive } \\
\text { management }\end{array}\end{array}$ \\
\hline
\end{tabular}

\subsubsection{Sonoran Desert Regional Monitoring Partnerships}

There are several active monitoring programs in the Sonoran Desert Ecoregion, and one objective of the BMGR-West I\&M Plan is to facilitate integration of regional monitoring programs through protocol standardization and establishment of a central data repository. This section describes the organizations responsible for existing monitoring programs in the region and the resources monitored, as well as committees and partnerships fostering collaborative management.

\section{Barry M. Goldwater Range Executive Committee and Interagency Executive Committee}

The Barry M. Goldwater Range Executive Committee (BEC) was formed in August 1997 to provide a forum for collaborative management of BMGR lands, resources, and their uses. As a result of the MLWA of 1999, land management of the BMGR was transferred from the BLM to the LAFB and MCAS-Yuma commanders. LAFB and MCAS-Yuma manage BMGR resources through collaborative processes with several agencies that have a vested legal interest in the lands, including BLM, USFWS, AZGFD, USBP, and directors for the adjacent SDNM, OPCNM, and CPNWR. Together, these entities form the BEC and provide oversight of management activities on the range. The BEC is chaired by the Director of the 56th Fighter Wing Range Management Office, LAFB, Ariz. The BEC addresses resource management issues and conflicts arising from land uses on the BMGR or affected by the BMGR with the intention 
of resolving those issues and conflicts. Past subcommittees include: Pronghorn, Public Relations, Law Enforcement, Transportation, Natural Resources, and Cultural Resources. Membership was limited to agencies with direct responsibility for lands or resources on the BMGR or directly affected by military or other activities on the BMGR.

The Interagency Executive Committee (IEC), as mandated by the MLWA of 1999, is a public outreach forum with the purpose of exchanging views, information, and advice related to the management of the natural and cultural resources of the BMGR lands.

\section{Barry M. Goldwater Range-East}

The 1.05-million-acre BMGR-East, managed by LAFB, borders BMGR-West, CPNWR, TON, and SDNM. In August 2007, the BMGR-East, 56th Range Management Office published an Inventory and Monitoring Plan: Barry M. Goldwater Range-East, and it has since implemented several components of the plan, including vegetation, bird, and climate monitoring. The BMGR-East plan adopted several protocols from existing regional monitoring programs, allowing for integration of BMGR-West and BMGR-East monitoring efforts, collaboration, and data sharing.

\section{National Park Service Sonoran Desert Network Inventory and Monitoring Program}

The Sonoran Desert Network (SODN) is 1 of 32 National Park Service (NPS) inventory and monitoring networks implementing "vital signs" monitoring to assess the condition of park resources. Specifically, NPS-SODN is implementing an integrated natural resource monitoring program for 11 national park units (10 in Arizona and 1 in New Mexico). Of the 11 park units monitored by SODN, 2 are of particular interest for BMGR monitoring partnerships: OPCNM and Saguaro National Monument (SNM). Both parks are biologically representative of the Sonoran Desert Ecoregion, sharing similar climate, landform, biological, and vegetation elements with BMGR. The network began monitoring landbirds and streams in 2005, air quality in 2006, and vegetation and soils in 2007.

\section{Organ Pipe Cactus National Monument}

Organ Pipe Cactus National Monument (OPCNM) was established in 1937 under the Antiquities Act to preserve a representative portion of the Sonoran Desert ecosystem as well as its namesake, the organ pipe cactus (Stenocereus thurberi). The $1,335-\mathrm{km}^{2}$ park developed an extensive in-house ecosystem monitoring program before the establishment of the NPS-SODN I\&M program. Monitoring activities at OPCNM date back to the 1970s, and many monitoring projects were formalized and integrated in 1994 with the development of an Ecological Monitoring Program (EMP) (Organ Pipe Cactus National Monument, 2006). OPCNM's EMP was integrated with other SODN parks beginning in 2001 with the establishment of the SODN I\&M program. Current monitoring protocols at OPCNM relevant to BMGR monitoring include those related to vegetation and soils, amphibians, reptiles, climate, small mammals, bats, and anthropogenic impacts.

\section{Cabeza Prieta National Wildlife Refuge}

Cabeza Prieta National Wildlife Refuge (CPNWR) was established as a Wildlife Refuge in 1939 "for the conservation and development of natural wildlife resources." Since the 
Endangered Species Act of 1973, CPNWR has become central in the recovery and protection of the endangered Sonoran pronghorn. CPNWR staff have conducted general inventories of birds, plants, mammals, and herpetofauna and developed a vegetation map of Sonoran pronghorn habitat for an NPS cooperative project supported by OPCNM and the BLM, Yuma Office. The vegetation map includes the distribution of 20 plant associations and subassociations (Malusa, 2003). CPNWR staff have been actively monitoring border-related anthropogenic impacts, mapping roads, and monitoring change in road networks across the refuge. CPNWR staff are currently (2011) in the process of developing a more comprehensive I\&M plan.

\section{Sonoran Desert National Monument}

The Sonoran Desert National Monument (SDNM) has been managed by the BLM Phoenix Field Office since its designation by President Clinton in 2001. Before 2001, the area was part of BMGR-East and managed by LAFB. This relatively new National Monument has no monitoring program is yet in place; however, a draft biological resource inventory compiled from literature searches and direct observation is available online at http://aznps.com/Floras/sdnm.pdf (Turner and others, 2000).

\section{Yuma Proving Ground}

The U.S. Army Yuma Proving Grounds (YPG) encompasses approximately 3,390 $\mathrm{km}^{2}$ of the Sonoran Desert in southwestern Arizona. The YPG is the Army's center for desert natural environment testing and artillery; target acquisition equipment and armament, vehicles, a variety of munitions, personnel and supply parachute systems, and other specialized equipment are tested at YPG. The YPG supports more than 320 species of plants, 33 species of reptiles and amphibians, and 47 species of mammals native to the Sonoran Desert (Yuma Proving Ground, 2010). One hundred thirty-seven native bird species have been documented on the installation, of which 49 species breed on YPG (YPG, 2010).

No plants or resident animal species with protection under the Endangered Species Act are known to occur on YPG, with the possible exception of the endangered Nichol's Turk's head cactus (Echinocactus horizonthalonius var. nicholii) and the threatened Sonoran Desert Distinct Population Segment (DPS) of the bald eagle (Haliaeetus leucocephalus). 


\subsection{Methods}

Development of this long-term natural resources I\&M plan was based on the needs and objectives of the MCAS-Yuma and goals specified in the INRMP. The I\&M Plan addresses the major environmental and conservation concerns of the BMGR-West and is organized to include an inventory and monitoring priority matrix and associated monitoring protocols. The four main objectives specified in the I\&M Plan are to:

1. Identify the natural resources on the BMGR-West that are sensitive to changing land use, climate, and biological conditions.

2. Identify and resolve gaps in the current BMGR-West inventorying and monitoring efforts.

3. Prioritize inventory and monitoring efforts on BMGR-West.

4. Identify regionwide monitoring efforts and standardize inventory and monitoring protocols for regional stakeholders.

In addition to input from stakeholders and local experts, development of the I\&M Plan for BMGR-West was guided by a comprehensive review of relevant research, monitoring, and natural history literature. Methods include four main components: (1) surveys of monitoring experts and facilitation of a monitoring workshop to identify sensitive resources and monitoring approaches, (2) development of a comprehensive plan based on relevant literature and existing monitoring protocols, (3) development of a monitoring priority matrix, and (4) development of monitoring databases based on proposed data parameters described in the protocols.

\subsection{Workshop and Surveys}

The U.S. Geological Survey facilitated a monitoring workshop (August 26-27, 2009) designed to gather input from cooperators and local stakeholders. Workshop participants included representatives from AZGFD, CPNWR, NPS SODN, LAFB, OPCNM, Pima County, San Diego Natural History Museum (SDNHM), San Diego Zoo, UA, USFWS, USMC, U.S. Navy, USGS, and YPG. Before the workshop, a monitoring questionnaire was emailed to 15 scientists and resource managers. The questionnaire was designed to identify key protocols, methods, and parameters used for monitoring natural resources in Sonoran Desert ecosystems and gather recommendations for BMGR-West monitoring efforts (appendix G).

Workshop coordinators compiled and presented a list of target resources and monitoring approaches identified by both questionnaire respondents and the BMGR INRMP. The first workshop component was a series of presentations describing monitoring efforts and resource issues facing Sonoran Desert land managers, which included land managers and researchers from BMGR-West, Pima County Sonoran Desert Conservation Plan, NPS SODN I\&M Program, USGS, and UA. The remainder of the workshop consisted of a series of group and subgroup exercises meant to refine resource lists, provide information on available data sources, review monitoring methods, and provide general direction for the monitoring program.

A workshop follow-up survey (hosted online, September 21-28, 2009) was designed to help prioritize monitoring efforts and develop a monitoring priority matrix. The survey consisted of 10 questions, 1 related to general resources and 9 related to specific resources monitoring. 
Respondents were asked to rank the elements in each question in terms of monitoring priority for the BMGR-West. Each survey question had a blank field for additional comments. A link to an online survey was emailed to all 26 workshop participants, and 22 participants completed the survey. Survey questions and results are provided in appendix G.

\subsection{Review of Existing Protocols and Protocol Development}

The plan and associated protocol documents were developed by examining and reviewing existing monitoring programs and protocols in the Sonoran Desert and other arid regions. Existing protocols were identified during the monitoring workshop or identified by reviewing pertinent monitoring and scientific literature. Included, with little revision, are several welldeveloped and tested protocols implemented on other public lands in the region (for example, protocols for Vegetation Community and Soils, and Birds). In some cases protocols were compiled from multiple sources and tailored to BMGR-West resources (for example, protocols for Small Mammals and Nocturnal Rodents, and Bat Guild). In cases where existing monitoring programs are currently (2011) in progress on BMGR-West lands, relevant protocols and information were excerpted, or references to the protocol and monitoring agencies were included (for example, protocols for flat-tailed horned lizard, and Sonoran pronghorn and desert bighorn sheep). In cases where no protocol existed or where existing protocols seemed inappropriate, a basic monitoring strategy was proposed that addresses management needs but requires additional on-site research and development before implementation. These special-case protocols deal primarily with monitoring disturbances and stressors specific to BMGR-West environs (for example, invasive plants, transportation corridors, and soil erosion), as opposed to monitoring natural communities or individual species.

\subsection{Monitoring Priority Matrix}

A monitoring matrix (table 2.1) was designed to prioritize and facilitate annual monitoring efforts by ranking the relative importance of each natural resource element based on survey responses from cooperators and stakeholders (appendix $\mathrm{G}$ ). The matrix consists of a series of natural resources with assigned monitoring priorities of high, medium, or low based on the conservation status of the resource, the current monitoring effort, and the potential impact to resources from military training and public use. The protocols included in this document are for all high-priority resources. Protocols for some medium- and low-priority resources are included if they were covered under the protocols for high-priority resources (for example, Water Quality monitoring within Seeps, Springs and Tinajas), if the resources are subject to compliance monitoring under the ESA (for example, Sonoran pronghorn), or if the resources have been monitored historically at BMGR-West as rare or threatened species of concern (for example, flat-tailed horned lizard). Each priority element of the matrix is assigned a monitoring protocol based on the best available information. These protocols are meant to provide natural resource managers of MCAS-Yuma with sufficient information and appropriate citations to implement monitoring of the resources on the BMGR-West. 
Table 2.1. Monitoring matrix showing monitoring elements by priority that was designed to help prioritize monitoring efforts.

\begin{tabular}{|c|c|c|c|}
\hline Sub-element & Priority & Protocol(s) in document & Referemces \\
\hline \multicolumn{4}{|c|}{ Vegetation (high priority) } \\
\hline Invasive species & High & Invasive Species (3.1.2) & $\begin{array}{l}\text { North American Weed Management } \\
\text { Association, } 2002\end{array}$ \\
\hline Vegetation communities & High & $\begin{array}{l}\text { Vegetation Community and } \\
\text { Soils (3.1.3) }\end{array}$ & $\begin{array}{l}\text { Harrick and others, 2005a,b; Hubbard and } \\
\text { others, 2009; Malusa } 2009\end{array}$ \\
\hline \multicolumn{4}{|c|}{ Climate (high priority) } \\
\hline Precipitation & High & Climate (3.1.7) & $\begin{array}{l}\text { World Meteorological Organization, } \\
1983\end{array}$ \\
\hline Temperature & Medium & Climate (3.1.7) & $\begin{array}{l}\text { World Meteorological Organization, } \\
1983\end{array}$ \\
\hline \multicolumn{4}{|c|}{ Anthropogenic impacts (high priority) } \\
\hline Transportation corridors & High & Transportation Corridors (3.3.1) & Drake and others, 2004 \\
\hline Visitor use & High & $\begin{array}{l}\text { Visitor Permit and Campsite } \\
(3.3 .2)\end{array}$ & Cole, 1986 \\
\hline Military & Medium & Transportation Corridors (3.3.1) & Drake and others, 2004 \\
\hline \multicolumn{4}{|c|}{ Water resources (high priority) } \\
\hline Seeps, springs, and tinajas & High & $\begin{array}{l}\text { Tinajas, Tanks and Developed } \\
\text { Waters (3.1.6) }\end{array}$ & Broyles 1997 \\
\hline \multicolumn{4}{|c|}{ Birds (medium priority) } \\
\hline General Bird surveys & High & Bird Monitoring (3.3.1) & Powell and others, 2007 \\
\hline \multicolumn{4}{|c|}{ Mammals (medium priority) } \\
\hline Bat guild & High & Bat Guild (3.2.4) & $\begin{array}{l}\text { Petrysyzn, 1994; Arizona Game and Fish } \\
\text { Department, } 1997\end{array}$ \\
\hline Sonoran pronghorn & High & $\begin{array}{l}\text { Sonoran Pronghorn Survey } \\
(3.2 .3)\end{array}$ & Arizona Game and Fish Department, 2006 \\
\hline $\begin{array}{l}\text { Nocturnal and small } \\
\text { mammals }\end{array}$ & High & $\begin{array}{l}\text { Small Mammals and Nocturnal } \\
\text { Rodents (3.2.2) }\end{array}$ & $\begin{array}{l}\text { Organ Pipe Cactus National Monument, } \\
\text { 2006; Powell and others, } 2007\end{array}$ \\
\hline Desert bighorn sheep & Medium & $\begin{array}{l}\text { Desert Bighorn Sheep Survey } \\
(3.2 .3)\end{array}$ & Arizona Game and Fish Department, 2006 \\
\hline General smphibians & High & $\begin{array}{l}\text { Amphibians (medium proiority) } \\
\text { Amphibian and Reptile Surveys } \\
\text { (3.2.5) }\end{array}$ & Heyer and others, 1994 \\
\hline \multicolumn{4}{|c|}{ Reptiles (medium priority) } \\
\hline Flat-tailed horned lizard & High & Flat-tailed Horned lizard (3.2.5) & $\begin{array}{l}\text { Flat-tailed Horned Lizard Interagency } \\
\text { Coordinating Committee, } 2003\end{array}$ \\
\hline Reptile inventory & High & $\begin{array}{l}\text { Amphibian and Reptile Surveys } \\
(3.2 .5)\end{array}$ & Heyer, 1994 \\
\hline Desert tortoise & Low & Desert Tortoise (3.2.5) & $\begin{array}{l}\text { Averill-Murray, 2000; Arizona Game and } \\
\text { Fish Department, } 2007\end{array}$ \\
\hline \multicolumn{4}{|c|}{ Soil (medium priority) } \\
\hline Channel change/washes & High & Stream-Channel Erosion (3.1.5) & Wiberg and Smith, 1989 \\
\hline $\begin{array}{l}\text { Soil erosion (roads and } \\
\text { other infrastructure) }\end{array}$ & High & $\begin{array}{l}\text { Soil Inventory and Upland } \\
\text { Erosion Monitoring (3.1.4) }\end{array}$ & Mitasova and Mitas,1999 \\
\hline
\end{tabular}




\subsection{Sampling Design Considerations for the Inventory and Monitoring Program}

The purpose of sampling is to make statistical inferences about a population without conducting a complete census of the population, which often is prohibitively expensive and time consuming. The number of sample units (sample size), spatial distribution of sampling units, and sample frequency vary according to monitoring objective and particular protocol. The aim of a sound sampling design is to provide scientifically defensible monitoring data which can be used to make general inferences beyond the sites sampled. The sample size and sampling frequency required to detect changes in a monitoring parameter are affected by many factors. Below are several important considerations:

1. What are the monitoring objectives?

2. What precision is required in change or trend?

3. What is the likely variability of monitoring data (based on collected data or literature review)?

4. How will the data be analyzed?

5. How many years of data are required to detect a trend?

6. How many times a year will sampling occur?

7. What is the availability of resources and manpower?

The spatial distribution of sampling locations typically follows a randomized approach, with the exception of resources with discrete locations and small areal coverage, such as tinajas. "Judgment-based" or "representative" sampling sites chosen by experts can introduce bias into the data, may come under criticism, and would be best avoided, if possible. However, additional, targeted sampling of special interest areas (for example, Mohawk dunes) or increased sampling at certain locations of interest (for example, soil erosion monitoring near highly disturbed areas) is appropriate once a randomized sample design is in place. Simple random sampling is, in most cases, not ideal for landscapes like BMGR-West with rugged terrain and few major roads. Therefore, to minimize travel time to a sample location, and to maximize field safety and data collection, it may be necessary to restrict sampling to areas within a pre-set distance from roads and/or by not sampling areas of dangerous or extreme topography. Discussions on randomized, spatially balanced sample designs can be found in Stevens and Olsen (2004). Co-location of monitoring sites (for example, vegetation, soils, and climate stations) may also reduce costs and has the added benefit of providing additional ecological information to guide management decisions. For more information about sampling designs and statistical techniques for analyzing monitoring data see Schreuder and others (2004) and Elzinga and others (2001). Elzinga and others (2001) provide a good general discussion on the importance of power analysis of data collected in monitoring programs, and Cohen (1988) details power analysis techniques for the most common statistical tests and includes power tables.

\subsection{Monitoring Databases}

Monitoring databases were developed to manage and store data collected for each monitoring/survey protocol on the BMGR-West. When possible, databases were constructed to be compatible with existing I\&M databases utilized by land managers of the Sonoran Desert. Databases developed for the I\&M Plan described in this report use Microsoft Excel, Microsoft 
Access or ESRI Geodatabases, depending on the spatial requirements and relational complexity of the monitoring variables collected (see section 4.1).

Spatial data collected for USMC are stored in GEOfidelis Geodatabase format.

GEOfidelis is a common database infrastructure that supports inter-operability across the USMC, allowing for integration of monitoring data with existing spatial data sets (see section 4.2). 


\subsection{Background Information on Monitoring Protocols for the Inventory and Monitoring Plan}

The background sections below provide the following general summaries of (1) the protocol for each variable to be monitored, including general techniques and key information to be collected, (2) the authors and organizations that developed the protocol, (3) organizations in the region currently (2011) implementing the protocol, and (4) caveats and suggestions for tailoring the protocols to the BMGR-West environment. Where applicable, protocols, standard operating procedures (SOPs), and data sheets are shown in appendixes.

\subsection{Vegetation, Soils, Water, and Climate}

\subsubsection{Vegetation Inventory and Mapping}

An inventory map describing the vegetation of the BMGR-West is under development and expected to be completed by 2014 (fig. 3.1; Malusa, 2009). The purpose of the mapping effort is to develop a comprehensive vegetation map and GIS database for the BMGR-West to enable management of the vegetation communities and also provide a baseline for ecosystem management. In addition to mapping, it is suggested that all plant species previously undocumented at the BMGR-West be described or collected and delivered to the Installation Representative for an herbarium collection. 


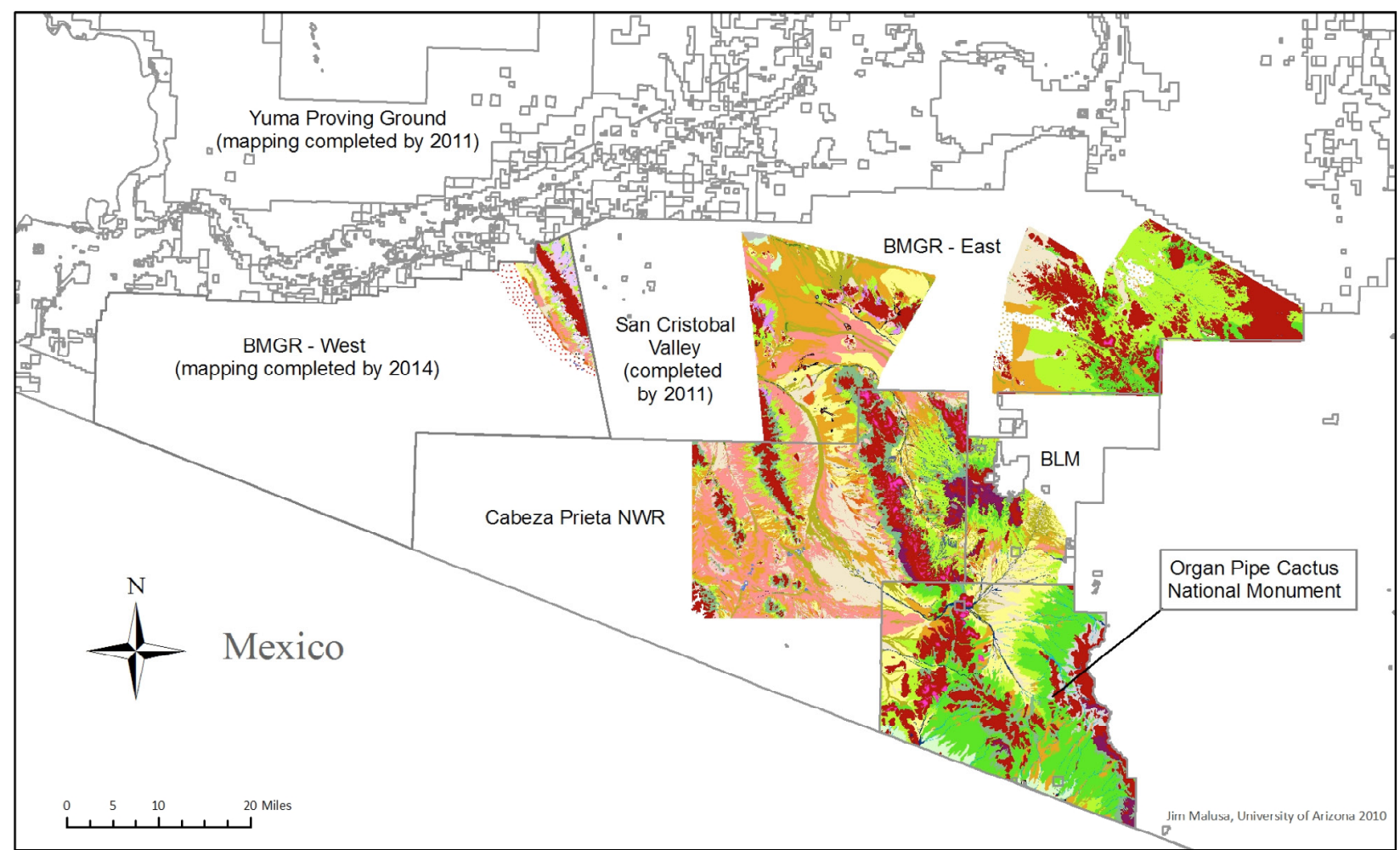

EXPLANATION

Larrea tridentate with annuals

Larrea tridentate - Ambrosia dumos

Larrea tridentata - Ambrosia deltoidea

Larrea tridentate - Ambrosia recently burned

Larrea tridentata - Ambrosia delioidea - Ambrosia dumos

Larrea tridentata - Ambrosia deltoidea - Opuntia bigelovi

Larrea tridentata - Prosopis glandulosa floodplain
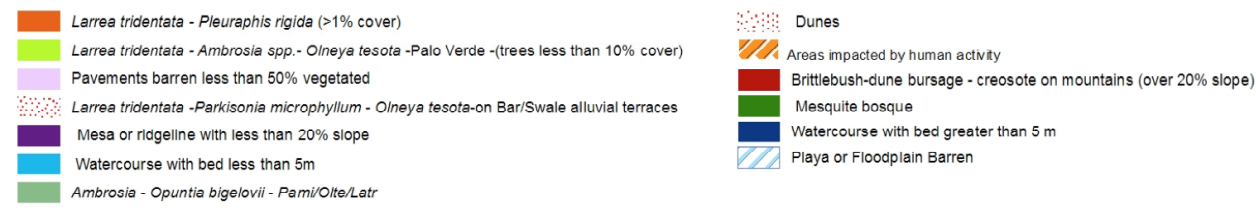

Figure 3.1. Completed and planned vegetation maps of southwestern Arizona (Malusa, 2009).

Plant Inventory and Species Checklist

The vegetation mapping field team collects and presses plant specimens of any previously unrecorded species on the BMGR-West (Malusa, 2009). Herbarium species collections consist of three sets of specimens, two mounted sets and one laminated set, with one of the mounted sets stored in an archival container. All new plant species are documented with photographs and location coordinates and added to the GIS vegetation database (Malusa, 2009).

A floristic inventory of the BMGR-East was published in 1996 and may provide a draft checklist and plant inventory for the BMGR-West (Arnett and Douglas, 1996). Additional plant collections from the BMGR-West are available at the Southwest Environmental Information Network (SEINet) database at http://swbiodiversity.org/seinet/. SEINet hosts data for a large number of specimens collected on the BMGR-West that were submitted and verified by UA Herbarium, Arizona State Vascular Plant Herbarium, Northern Arizona University Deaver Herbarium, Herbario de la Universidad de Sonora, Desert Botanical Garden Herbarium Collection, University of California Riverside Plant Herbarium, and New York Botanical 
Garden. Some of the species vouchers date back to the 1930s, but a large number were collected in recent decades by Felger and VanDevender. SEINet records contain information on species collected and verified, collector's name, collection date and location (written description and approximate coordinates), and general species information.

\section{Regional Monitoring Status}

The eastern half of CPNWR and portions of BMGR-East were mapped using the protocols and classification system described in appendix A (Malusa, 2003, 2009). The classification system was designed to be cross-walked with the USGS/NPS National Vegetation Classification System (NVCS) currently (2011) used for vegetation mapping at SODN park units (see Drake and others, 2009) as well as the Brown, Lowe, and Pase system used for earlier NPS maps (see Warren and others, 1981). The existing, 30-year-old vegetation map of OPCNM (Warren and others, 1981) will be updated in 2012 by SODN as part of the NPS I\&M Vegetation Mapping Program. CPNWR (Cabeza Prieta National Wildlife Refuge, 1995), BMGR-East (Arnett and Douglas, 1996), OPCNM (Schmidt and others, 2006) and SDNM (Turner and others, 2000) all have some level of plant inventory.

\subsubsection{Invasive Species}

Human-induced and natural biological invasions into new regions, whether accidental or deliberate, have increased at unprecedented rates in the past few hundred years (D'Antonio and Vitousek, 1992). Once established, nonnative plant species introductions often lead to changes in ecosystem processes (such as fire frequency, size, and intensity, or altered nutrient levels) that are self-maintaining and evolving, leading to functional as well as compositional ecosystem change (Brooks and others, 2004). Invasive nonnative species are estimated to cause more than $\$ 100$ billion in economic damage annually in the United States alone (Pimentel and others, 1999). In addition to competing with and displacing native species, these introduced species can hybridize with native species and alter conditions to promote the establishment and spread of other nonnative species. They also bring their respective pathogens and parasites (Warburton and others, 2002; Kuperman and others, 2004). Several studies have pointed to various environmental and climatic variables as potential drivers for sustaining or increasing nonnative plant dominance in semiarid ecosystems (Shinneman and Baker, 2009). Especially in the arid southwest, historical and current land-management practices, such as livestock grazing and fire suppression, are thought to have contributed to the susceptibility of arid lands to nonnative plant invasion and subsequent loss of native species and decreased biodiversity (Brown and Archer, 1999; Brooks and Berry, 2006). Reduced species richness and biological soil cover are indicative of communities degraded by grazing, and these factors have been linked to invasion by nonnative grasses in place of native species not adapted to such pressures (Shinneman and Baker, 2009). Nonnative species often garner a foothold over native species due to their ability to thrive under harsher conditions with fewer resources and their ability to be prolific reproducers.

The BMGR-West and monitoring workshop specialists identified invasive nonnative plants as a high priority for monitoring. Furthermore, Executive Order 13112 requires Federal agencies to (1) identify actions that may affect invasive species, (2) use relevant programs to prevent introduction of invasive species, (3) detect, respond, and control such species, (4) monitor invasive species populations, (5) provide for restoration of native species, (6) conduct 
research on invasive species, and (7) promote public education (Executive Order 13112, 1999). Acquiring reliable baseline data on the presence and abundance of invasive nonnative species is a priority in the development of a comprehensive invasive plant monitoring program. This is necessary to accomplish two goals: (1) identify which exotic species are not yet present at BMGR-West but may require early detection monitoring and (2) map the location, abundance, and distribution of established nonnative species (trend assessment). This baseline information allows managers to track the spread of known populations and identify new infestations with the ultimate result of allowing the evaluation of effectiveness of the management actions or treatments. Early detection of new species or infestations enables managers to employ a rapid management response while the populations are still small and manageable. Because most invasive plants of concern at BMGR-West are annual species, monitoring should be conducted during the active growing season, which is slightly variable but typically March-April for winter annuals and July-September for summer annuals.

The BMGR INRMP identified 11 invasive plant species of concern for range management (table 3.1). Of the 11 species of concern, several are currently (2011) found on BMGR-West, including Sahara mustard, red brome, Lehmann lovegrass (Eragrostis lehmanniana), Arabian grass (Schismus spp.), Russian thistle (Salsola tragus), and buffelgrass. Observations by Malusa (2009) indicate that Sahara mustard is actively invading large swaths of the BMGR-West. As part of the ongoing vegetation mapping (Malusa, 2009), field crews identify and map the location of Sahara mustard using handheld GPS receivers.

Potential invasive animal species include European starlings, Rio Grande leopard frogs (Lithobates berlandieri), and others.

Mapping efforts may be focused on areas known to be at high risk of invasion (see Brooks and Berry, 2006), including

- roads, trails, campsites and wash corridors;

- areas in proximity to other nonnative plant populations;

- recently or continually disturbed areas; and

- areas of high management priority and protection (sensitive or endangered species communities).

A well-designed spatial database will make data entry and analysis efficient and easy to manage. Surveys can be expensive and time consuming and so it is imperative to document where they have occurred, even if no species were found (North American Weed Management Association, 2002). The construction of a spatially explicit database with invasive vegetation information allows managers to visualize the extents and distribution patterns of areas where invasive species are still absent. 
Table 3.1. Existing and potential invasive plant species located on Barry M. Goldwater Range lands.

\begin{tabular}{|c|c|c|c|}
\hline Species & Common name & $\begin{array}{l}\text { Monitoring } \\
\text { priority }\end{array}$ & Comments \\
\hline $\begin{array}{l}\text { Brassica } \\
\text { tournefortii }\end{array}$ & Sahara mustard & High & $\begin{array}{l}\text { Already widespread on the BMGR, Sahara mustard } \\
\text { may pose a risk to sensitive areas by competing with } \\
\text { and excluding native plants. Management in limited } \\
\text { areas may be desirable. }\end{array}$ \\
\hline Bromus rubens & Red brome & High & $\begin{array}{l}\text { Red brome has ecosystem modifying abilities and } \\
\text { increases fire frequency. } \\
\text { It is widespread on the BMGR and its control is } \\
\text { difficult. } \\
\text { Management may be necessary in sensitive areas. }\end{array}$ \\
\hline $\begin{array}{l}\text { Eragrostis } \\
\text { lehmanniana }\end{array}$ & $\begin{array}{l}\text { Lehmann } \\
\text { lovegrass }\end{array}$ & High & $\begin{array}{l}\text { Lehmann lovegrass has ecosystem-modifying abilities } \\
\text { and increases fire frequency. On the BMGR, } \\
\text { populations are still relatively small and localized. }\end{array}$ \\
\hline $\begin{array}{l}\text { Pennisetum } \\
\text { ciliare }\end{array}$ & Buffelgrass & High & $\begin{array}{l}\text { Buffelgrass increases fire frequency and has } \\
\text { ecosystem-modifying ability. }\end{array}$ \\
\hline $\begin{array}{l}\text { Pennisetum } \\
\text { setaceum }\end{array}$ & Fountain grass & High & $\begin{array}{l}\text { Fountain grass may eventually be found on the } \\
\text { BMGR. } \\
\text { This grass increases fire frequency and has ecosystem- } \\
\text { modifying ability. }\end{array}$ \\
\hline $\begin{array}{l}\text { Tamarix } \\
\text { ramosissima }\end{array}$ & Saltcedar & High & $\begin{array}{l}\text { Saltcedar is closely associated with water features, and } \\
\text { its potential to despoil these scarce resources on the } \\
\text { BMGR makes control important. }\end{array}$ \\
\hline $\begin{array}{l}\text { Schismus } \\
\text { arabicus }\end{array}$ & Arabian grass & Moderate & $\begin{array}{l}\text { Arabian grass is abundant and range-wide; further } \\
\text { study is needed to clarify its importance on the } \\
\text { BMGR. Control efforts, if deemed necessary, would } \\
\text { be best limited to local sensitive areas such as the } \\
\text { Mohawk Dunes. }\end{array}$ \\
\hline $\begin{array}{l}\text { Cynodon } \\
\text { dactylon }\end{array}$ & Bermuda grass & $\begin{array}{l}\text { Low to } \\
\text { Moderate }\end{array}$ & $\begin{array}{l}\text { Bermuda grass is generally a problem only in moist } \\
\text { places. Managers may elect to control it in sensitive } \\
\text { areas when these efforts do not affect other species } \\
\text { adversely. }\end{array}$ \\
\hline Salsola tragus & Russian thistle & Low & $\begin{array}{l}\text { Spot control of Russian thistle may be desirable } \\
\text { because of fire concerns; it is limited to highly } \\
\text { disturbed soils. }\end{array}$ \\
\hline $\begin{array}{l}\text { Centaurea } \\
\text { melitensis }\end{array}$ & $\begin{array}{l}\text { Malta } \\
\text { Starthistle }\end{array}$ & Unknown & $\begin{array}{l}\text { Malta Starthistle is currently not found on the BMGR. } \\
\text { Occurrence can be monitored and managed to prevent } \\
\text { its widespread establishment on the BMGR-West. }\end{array}$ \\
\hline $\begin{array}{l}\text { Hordeum } \\
\text { murinum }\end{array}$ & Smooth barley & Unknown & $\begin{array}{l}\text { A species of concern that may be monitored, its future } \\
\text { importance to the BMGR is not well understood. }\end{array}$ \\
\hline
\end{tabular}


Regional Monitoring Status

OPCNM actively monitors and controls buffelgrass. Various research and management activities involving Sahara mustard have been implemented at BMGR, OPCNM, CPNWR, and Kofa NWR.

\subsubsection{Vegetation Community and Soils}

Vegetation communities are commonly monitored in long-term ecological monitoring programs, because vegetation often responds conspicuously to climate patterns, land-use practices, and natural disturbances. Vegetation is often synonymous with habitat, and thus changes in vegetation can be linked to the management of species of concern (for example, Sonoran pronghorn).

Vegetation Community and Soils Monitoring procedures follow the "Terrestrial Vegetation and Soils Monitoring Protocol" developed for NPS Sonoran Desert Network park units (Hubbard and others, 2009). The protocol is based on well-tested monitoring techniques developed for vegetation and soils monitoring by Herrick and others (2005a,b). The NPS protocol recognizes the relationship between vegetation and local edaphic factors (for example, soil texture, mineralogy, depth, and landform type) and co-locates spatial and temporal sampling of both. The protocol uses plot-based sampling to determine status and detect trends in (1) vegetation cover (percent) of common plants, (2) frequency (percent) of uncommon plants, and (3) soil cover and stability.

Plot-based measurement of vegetative cover of common perennial species is an effective and traditional approach for monitoring plant populations (Elzinga and others, 2001). Cover is commonly used as a measure of community composition primarily because it is intuitive and the measure is easily equated with biomass or annual production. Measurement of percent cover facilitates status and trend monitoring for a single species of interest, especially "indicator" species and species of management concern. Determining the cover of all common perennial species allows management to retrospectively analyze status and trends of any species, even if they are not currently a species of concern.

For tracking dynamic soil function, the protocol calls for monitoring status and trends of factors that influence soil movement. The protocol focuses on monitoring the (1) cover of soil by biological soil crusts, vegetation, organic litter, and abiotic materials and (2) the stability of surface soil aggregates. Specifically, soils monitoring involves determining the status and detecting trends in soil surface cover (percentage by substrate type) and biological soil crusts cover and frequency (percentage by lichen species and morphological group for cyanobacteria and bryophytes). Surface cover is the percentage of mineral soil surface covered by substrate class (Herrick and others, 2005b), providing an absolute and relative measure of these objects that influence erosion resistance. Bryophytes and cyanobacteria serve profoundly different ecological functions but are difficult to identify in the field. Therefore, they would be best identified to the morphological group level.

Measurements of surface soil aggregate stability (by stability category, 1-6) allow for detection of status and trends in soil degradation resistance (Herrick and others, 2005b). Soil aggregate stability is both an indicator of disturbance and site resistance to soil erosion. In addition, it provides insights into soil water-holding capacity and infiltration rates. For detailed 
information regarding laboratory methods for soil surveys consult the NRCS Soil survey laboratory methods manual (Burt, 2004).

The exact number of plots and the design of spatial sampling should be determined by vegetation monitoring experts, using a statistical sampling approach and considering the potential benefits of co-locating with other resource monitoring efforts. In general, the locations of vegetation community and soils monitoring plots should be stratified by vegetation type, specifically the NVCS vegetation associations identified and mapped during the vegetation mapping of the BMGR-West (Malusa, 2009).

\section{Regional Monitoring Status}

Staff from OPCNM and other SODN park units monitor vegetation and soils using the protocol described above. BMGR-East staff monitor vegetation with a similar $20 \times 50 \mathrm{~m}$ plot adapted from the OPCNM EMP (Lowe and others, 1995).

\subsubsection{Soil Inventory and Upland Erosion Monitoring}

Soil resources are a key concern on the BMGR. Currently BMGR-West has no completed and verified soil map, thus reducing our knowledge about the basic characteristics of the local soils that can have large implications for the soil ecology, vulnerability to erosion, compaction, and hydrologic degradation under different management decisions. Of particular concern are soil particle size distribution, mineralogy, and horizon development - common static features that are described in soil surveys. Creation of a suitable soil map would involve a onetime field sampling effort to create a map and associated database and report, which would be used for many future management issues (fig. 3.2). Many new digital tools can be used to efficiently create soil maps (McBratney and others, 2003; Scull and others, 2003; See appendix $\mathrm{C}$ for methodology details). 


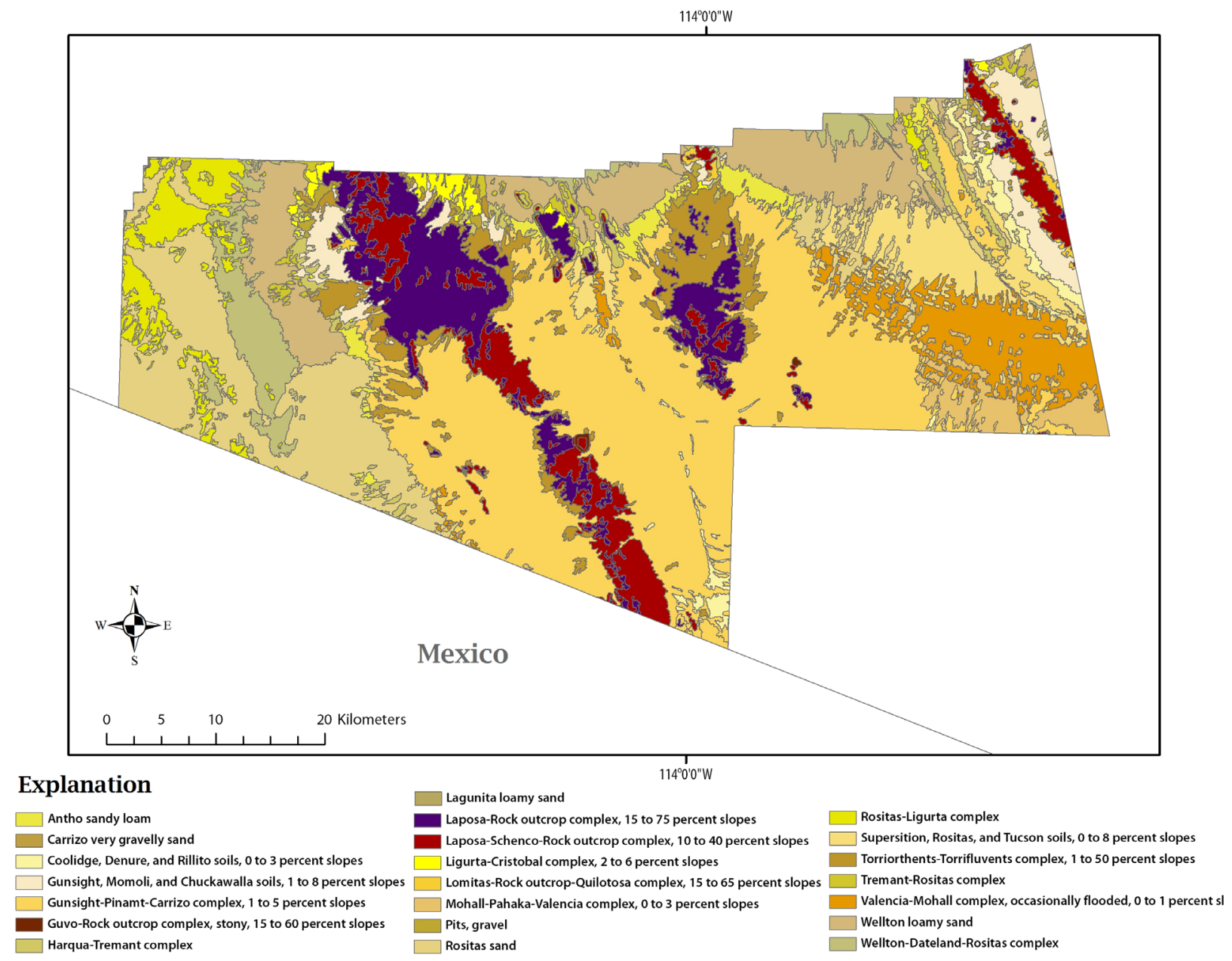

Figure 3.2. Preliminary digital soils map of Barry M. Goldwater Range-West (Created by Nauman Geospatial for Arizona Game and Fish Department, 2009).

Soil loss to wind and water erosion can be monitored by a variety of both quantitative and qualitative means. It is important to include wind and water erosion monitoring in rangewide monitoring efforts, because erosion can cause problems in many areas of the ecology and causes negative feedback loops (for example, more erosion causes more vegetation loss, which leads to more erosion). Soil-erosion monitoring, as described in this section, is different from the soil quality measures described in section 3.1.3 in that once an area is significantly eroding, soil loss tends to reset the ecology of a site, and only stabilizing soil loss will allow vegetation and organisms to return to a site and begin rebuilding the fertility and resilience of a site. Thus, soil erosion has to be tracked by different methods from the soil-quality parameters presented in section 3.1.3 in order to determine if erosion is increasing or decreasing in areas where it occurs.

Because BMGR-West covers a large area, it is helpful to have some method for narrowing down potential sampling locations for monitoring erosion. Because methods for soils and vegetation monitoring presented in section 3.1.3 locate plots based on statistical inference, vegetation and soils plots would be good candidates for potential co-locations of terrestrial 
erosion monitoring. Also, having co-located erosion, vegetation, and soil-quality measures offers valuable insight into surface dynamics once researchers begin to analyze monitoring data.

Another tool to help identify areas prone to erosion that might be overlooked in plot placement is GIS models. Theory derived from the Revised Universal Soil Loss Equation (Renard and others, 1997) and Revised Wind Erosion Equation (Fryrear and others, 2001) can be modeled in GIS to create erosion-potential-index maps to help focus monitoring efforts (see appendix C). A good baseline soil map greatly increases the accuracy of such modeling, but topography and satellite data can also be used independently for rougher approximations.

Once plots are prioritized for monitoring, a variety of erosion monitoring tools can be implemented based on the location status and resources available. Erosion manifests in visible forms identifiable in the field (for example, sheet, rill, or gully erosion). At the very least, field technicians need to record the presence or absence and general abundance of these features at monitoring sites (part of the protocol by Hubbard and others, 2009). At sites where these features are found in abundance, more quantitative methods should be considered. Appropriate field methods would include base-level pin surveys and both wind and water sediment traps. Pin surveys simply quantify the depth and dimensions of soil erosion features to help approximate soil loss, and sediment traps actually capture sediments for direct measurement of soil loss on the plot. These methods are costly and should be allocated only to areas where erosion features are visually observed, unless resources are available to implement more detailed erosion rate monitoring (see appendix $\mathrm{C}$ for method details).

\section{Regional Monitoring Status}

A complete NRCS soils map is available for OPCNM. A draft digital soils map, contracted by AZGFD for Sonoran pronghorn monitoring, exists for the entire BMGR, but has not been ground-truthed (Nauman, 2009). Various soils and erosion monitoring projects are in progress at OPCNM.

\subsubsection{Stream-Channel Erosion Monitoring}

Cross-sectional analysis of washes and gullies should be used along with GIS watershed analysis to estimate greater watershed and stream-channel erosion rates. Cross-section locations should be randomly selected while weighting sampling towards higher Strahler orders (Strahler, $1952,1957)$ and watersheds with higher average estimated erosion potential. Points along washes should be allocated using the spatially balanced Generalized Random Tessellation Stratified (GRTS) approach (Hubbard and others, 2009; Stevens and Olsen, 2004), which gives flexibility in adding or subtracting points if resource availability for monitoring changes.

Cross sections can be implemented to measure elevation profiles and capture diagnostic features (for example, thalweg and terraces) across channels, along with general substrate size and vegetation cover. Cross-section sites should be equipped with pressure transducers or other gauges with data loggers to log flow-event depths. From these data, the elevation profile and flow events recorded can be related to calculate basin erosion or denudation rates. This is done using known relationships among channel profile, slope, flow depths, streambed particle size, streambed gradient, and watershed area using Manning's Equation and sediment transport theory (Wiberg and Smith, 1989; Ritter and others, 2002). Steam-channel downcutting and aggradation rates also can be monitored with these data by simply calculating changes to cross-section area, 
leading to estimates of actual channel sediment loss for washes within the GRTS sampling framework.

By subtracting erosion rates calculated from vegetation and soils plots (section 3.1.3) and Transportation Corridor monitoring (section 3.3.1) from overall basin erosion rates derived from channel cross sections, the effects of specific land-use-driven erosion processes may be determined. Sometimes lags or accelerations of sediment pulses from hillslopes or roads in a watershed might cause discrepancies between cross-section stream channel erosion rates and stream channel erosion rates calculated by subtracting other rates of erosion from the basin erosion rate. These dynamics of erosion can be monitored by integrating the different approaches of erosion measurement.

Regional Monitoring Status

A stream monitoring protocol has been implemented as part of the SODN to monitor stream channel morphology.

\subsubsection{Tinajas, Tanks, and Developed Waters}

Tinajas (rain-fed rock tanks) are an important source of seasonal waters for wildlife within BMGR-West. Many natural tinajas in BMGR-West have been developed further to provide water for wildlife, especially Sonoran pronghorn and desert bighorn sheep (Broyles, 1997). Typical wildlife water-developments in southwestern Arizona include constructed catchments or "guzzlers," natural tinajas developed to increase water retention, windmillpowered wells, and developed springs. There is some concern that developed waters may provide habitat for pathogens and disease vectors, potentially harming wildlife. This is especially true for amphibians, and waters should be regularly tested using developed disease-testing protocols. However, recent water quality assessments of developed waters at YPG and Kofa NWR found no evidence of the water-borne pathogen Trichomonas gallinae and inconclusive evidence of hemorrhagic disease vectors (Rosenstock and others, 2004). Waters of the BMGRWest have yet to be tested for the global pathogen Batrachochytrium dendrobatidis that is causing widespread extinctions and extirpations of amphibians (Wake and Vredenburg, 2008), and has also been shown to occur in extremely arid and hot locations (Lovich and others, 2008).

Before monitoring, it would be helpful to inquire with AZGFD for spatial data on the location of tinajas, tanks, and developed water on BMGR-West lands (fig. 3.3). Broyles (1997) compiled information on locations and some general inventory parameters (depth, volume, duration, and animal usage) of water holes throughout BMGR and CPNWR. 


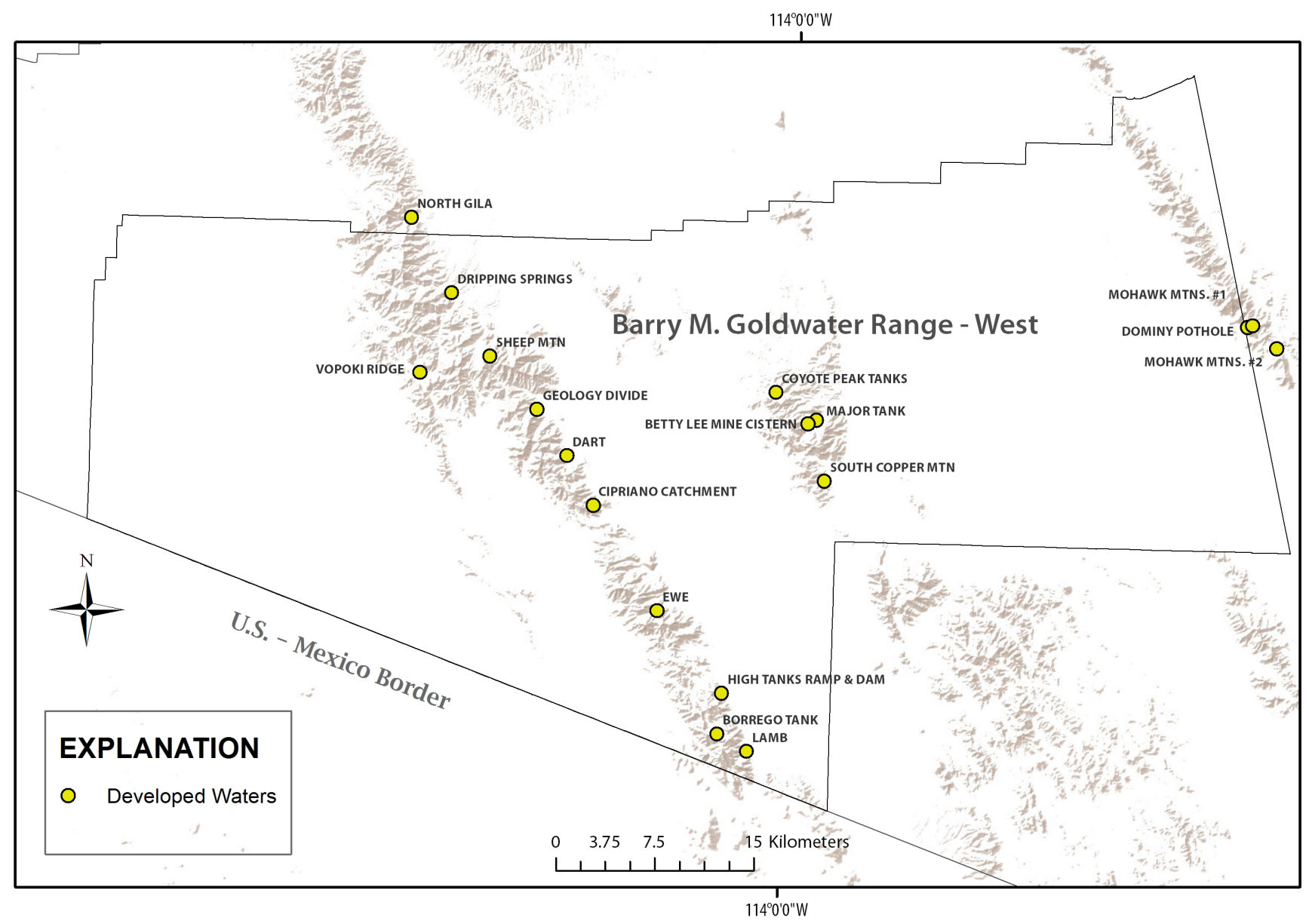

Figure 3.3. Developed waters of Barry M. Goldwater Range-West. 
It is suggested that monitoring efforts focus on tinaja water quantity (water depth) and other basic water quality parameters, and that monitoring be conducted on a yearly basis, preferably multiple times per year in order to assess seasonal variations. In general, three seasons are identified as important for tinaja sampling: (1) after winter rains, (2) in late spring after many tinajas have dried up and water is concentrated at a few important wildlife sites, and (3) after summer monsoon rains.

A multiparameter water quality sonde (http://www.ysi.com/index.php) such as the Yellow Springs Incorporated (YSI) 6820 sonde Multiprobe has been recommended by Sprouse and others (2005) for monitoring water quality in Sonoran Desert parks. Monitoring parameters include:

- water depth

- air and water temperature

- dissolved-oxygen concentrations

- $\quad$ specific conductance

- $\mathrm{pH}$

- reduction-oxidation potential

- alkalinity

To allow for consistent monitoring protocols throughout the study area, it is suggested that all monitoring be conducted according to the methods described in the USGS National Field Manual for the Collection of Water-Quality Data (hereafter referred to as the National Field Manual; U.S. Geological Survey, 2009). This manual provides guidelines and standard procedures for assessing the quality of surface-water and groundwater resources. Chapter A6 of the National Field Manual presents procedures and guidelines for the collection of data on air and water temperature and on dissolved-oxygen concentrations, specific electrical conductance, $\mathrm{pH}$, reduction-oxidation potential, alkalinity, and turbidity in water.

Regional Monitoring Status

OPCNM staff monitors water quality of various springs and tinajas. The AZGFD monitors water resources for BMGR-East, YPG, and CPNWR.

\subsubsection{Climate}

Climate plays a central role in natural systems; the spatial distribution of solar radiation, temperature, precipitation, and wind controls the distribution and physical character of soils and biota over the landscape. This relationship makes climate an integrating factor in ecosystem monitoring programs and provides an important variable for understanding short- and long-term changes in resources.

There are no weather stations currently (2011) operating in the BMGR-West, and limited weather and climate data are available for adjacent areas in the lower Sonoran Desert of Arizona (fig. 3.4). This lack of data is due to the remoteness and ruggedness of the area, and to the fact that much of the southwestern climate network infrastructure was developed as a tool for wildfire monitoring and is distributed in fire-prone areas (for example, interagency Remote Automated Weather Stations (RAWS)). A network of weather stations with locations distributed over BMGR-West and adjacent land management units, covering various vegetation communities, soil types, landforms, and elevation gradients, would provide a high-resolution dataset describing 
regional climate patterns. Using these data, researchers and managers could develop models for high-resolution interpolation of precipitation, temperature, and other variables that would aid ecosystem research, monitoring, and management. These data and associated models would equip managers with a better understanding of local weather and climate patterns within a regional and global context.

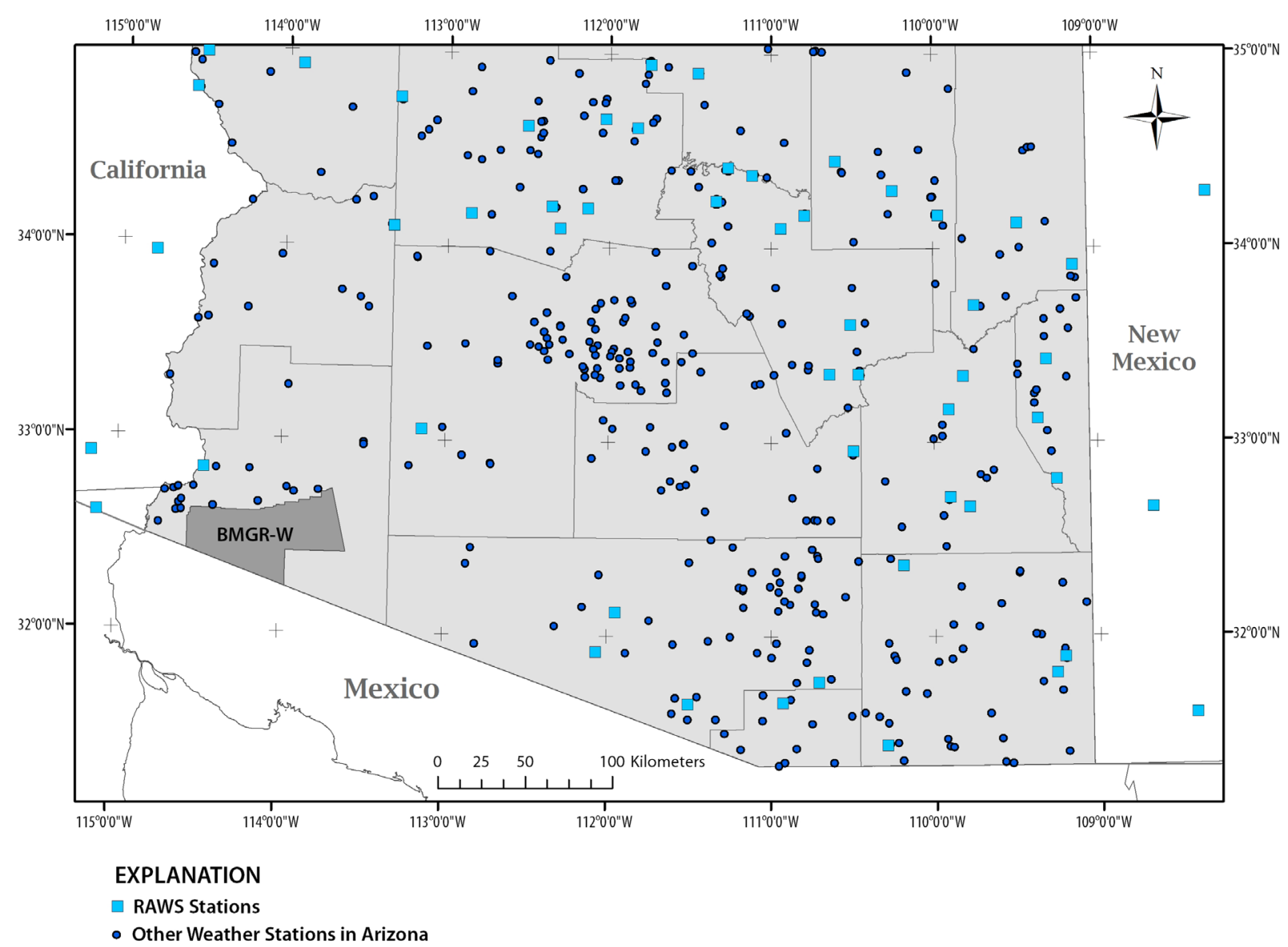

Figure 3.4. Distribution of Remote Automated Weather Stations and other weather stations in areas surrounding Barry M. Goldwater Range-West. Note the scarcity of stations in southwestern Arizona. 
A number of weather stations are commercially available, all of which record similar information. By definition, weather stations are self-contained instrument packages used to automatically record, store, and communicate weather and climate data from remote sites. Stations are independently powered by a solar panel and battery. The weather station model used to record information on the BMGR-West would not be as important as the number and location of these stations and the type and amount of data collected. It is suggested that a weather station be included in at least every major vegetation type and co-located near permanent vegetation monitoring plots.

Climate/weather variables that would be useful for monitoring purposes include:

- air temperature

- relative humidity

- precipitation

- barometric pressure

- $\quad$ solar radiation $(300-1,100 \mathrm{~nm})$

- photosynthetically active radiation $(400-700 \mathrm{~nm})$

- wind speed

- wind direction

- $\quad$ soil moisture (10-cm depth)

- $\quad$ soil temperature (10-cm depth).

To ensure standardized datasets, it is suggested that each variable be monitored in compliance with World Meteorological Organization (WMO) standards (World Meteorological Organization, 1983). Weather stations typically collect data for most variables at 1-hour intervals or less and consequently produce large amounts of raw data. Collected weather data would be downloaded as comma-delimited files with date $/$ time $(\mathrm{yy} / \mathrm{mm} / \mathrm{dd} / \mathrm{hr} / \mathrm{min} / \mathrm{sec})$ and variable values that can be imported into most databases and spreadsheets. Preventative maintenance of the station instrumentation is essential to collecting accurate data, and it is suggested that stations be inspected quarterly. During these quarterly visits, the weather station data could be compared to data measured with a separate set of laboratory-standard sensors. Wind speed and solar sensors would be removed and recalibrated annually. The temperature and humidity sensors would be calibrated every two years. MCAS-Yuma would partner with other institutions to make BMGRWest climate-station data available to researchers and the general public through an appropriate online climate network (for example, Western Regional Climate Center (WRCC), http://www.wrcc.dri.edu/; MesoWest, http://mesowest.utah.edu/; or The Arizona Meteorological Association, http://ag.arizona.edu/azmet/).

\section{Regional Monitoring Status}

A number of weather stations are currently in operation at OPCNM, Kofa NWR, YPG, and BMGR-East. OPCNM staff have been collecting climate data since 1987, and data are housed at the WRCC. Other existing stations with published information include MCAS-Yuma, Yuma Valley, Yuma South, Roll (Tacna), Paloma, and Gila Bend Air Force Auxiliary Field (MesoWest, http://mesowest.utah.edu/; The Arizona Meteorological Association, http://ag.arizona.edu/azmet/). 


\subsection{Birds, Mammals, Amphibians and Reptiles}

\subsubsection{Bird Monitoring}

Bird monitoring follows the "Landbird monitoring protocol for the Sonoran Desert Network" designed by Powell and others (2007) (http://science.nature.nps.gov/im/monitor/protocols/SODN_Landbird.pdf). The protocol uses point-transect survey methods to estimate population size and abundance of species on a yearly basis and is designed to track changes in relative indices of these parameters over time (Buckland and others, 2001). The approach in this protocol focuses on assessing population changes of common species - because of low detection probabilities, uncommon or threatened species (such as Le Conte's thrasher) need to be monitored using targeted surveys.

The protocol focuses on collecting data to monitor and track changes in three population variables: density, relative abundance, and occupancy. All three variables can be estimated using one set of field methods; however, data are analyzed using different statistical tools and approaches. The first variable, density, provides managers with estimates of total population change with error estimates. The approach described in this protocol allows detection of 2percent annual decline in density over a 30-year period, with an 80-percent probability and a 10percent Type I error rate. Over a 30-year monitoring period, a 2-percent annual decline would equal a 45-percent overall population decline. Density is estimated using the point-transect distance-sampling method at fixed points, and the subsequent analysis is conducted using the Distance Program (Thomas and others, 2005; Burnham and Anderson, 2002).

The second variable, relative abundance, is an estimate of the ratio of overall population change among species and years. This ratio is a count of the species of interest divided by the total count of the most abundant species within the survey area (van Riper, 1982; Sogge and others, 1989). Relative abundance is only appropriate for monitoring changes in population size if the ratio of the index count to the actual parameter of interest (for example, population size) does not vary systematically over time and if detectability does not change over time (van Riper and others, 1988). Because of this limitation, relative abundance is a robust measurement for trends, but often it is a secondary measure when density estimates are incalculable (Powell and others, 2007.

The third variable, occupancy, is a measure of presence/absence within sampling units and is a coarse metric that can be used to describe changes in the distribution of a species over time. As with density, techniques for estimating occupancy explicitly account for variation in detectability, thereby adjusting estimates for individuals that are present yet undetected during surveys (Williams and others, 2002; Mackenzie and Royle, 2005). All three measurement techniques are useful, depending on the level of accuracy and detail land managers desire in their monitoring of avian communities.

Although this protocol provides methods to document community dynamics, certain bird species of concern to BMGR-West may require targeted survey efforts (such as Le Conte's thrasher and gray vireo (Vireo vicinior)) or nest-occupancy surveys (such as golden eagle and peregrine falcon (Falco peregrinus)). Other species may be more easily detected during fall or winter, when general community monitoring is not ideal. 
BMGR-West may consider making the bird community monitoring data available for regionwide analysis by providing data to the Avian Knowledge Network (AKN) or Rocky Mountain Bird Observatory (RMBO) Avian Data Center.

Regional Monitoring Status

The Landbird monitoring protocol is currently used by NPS at OPCNM, and a modified version is used by LAFB at BMGR-East. The Arizona Bird Conservation Initiative (ABCI) is developing a strategy to increase coordination of bird monitoring activities across the region through the development of a coordinated monitoring framework that would provide data to help understand regional status and trends of Sonoran Desert species.

\subsubsection{Small Mammals and Nocturnal Rodents}

Small mammals and rodents are an important component of the trophic system; they are primary consumers and are the main prey source for many larger mammals and raptors. As primary consumers, small mammal populations often provide information about resource conditions and can be viewed as indicators of ecosystem productivity.

Live trapping is an effective and usually nonlethal method for monitoring small mammals and rodent populations. Capture provides information on species richness, abundance, diversity, and mean species biomass, the last of which can only be collected using capture or trapping techniques. There are many different mammal capture techniques; the most appropriate depends on the objective of the monitoring program (see Jones and others, 1996; Wilson and others, 1996). The general process for small mammal and nocturnal rodent monitoring, as adapted for this I\&M Plan, requires establishing a $7 \times 7$ (or greater) trap grid of baited live traps. Traps are set just before dusk and checked again at midnight and first thing in the morning. Monitoring would occur annually for two or three consecutive nights during the summer season. A minimum of 500 trap nights (the number of traps multiplied by the number of trapping periods) is suggested for the initial inventory (Jones and others, 1996).

The protocol for small mammal monitoring was adapted from many general monitoring sources (appendix D). The number of traps, grid size, sampling season, and frequency were adapted from OPCNM EMP monitoring documents (Petryszyn and Russ, 1996; Organ Pipe Cactus National Monument, 2006) and meant to provide data consistent with OPCNM long-term monitoring efforts. Long-term (1991-2006) rodent monitoring data from the OPCNM EMP were recently analyzed for trends and statistical power (Flesch, 2008). The power analysis results suggest that the $7 \times 7$ array and annual monitoring provided adequate power for the monitoring program, and reducing the sampling time frame from once per year to every 2 years would greatly reduce the power to detect changes (Flesch, 2008). However, the array size necessary to detect changes in BMGR-West mammal populations over time may be larger (that is, $10 \times 10$ ) than what is currently used at OPCNM (Jones and others, 1996). Therefore, we suggest power analysis and species accumulation curves be conducted on BMGR-West data once sufficient data have been collected.

Regional Monitoring Status

OPCNM staff has monitored small mammals since 1991. 


\subsubsection{Sonoran Pronghorn and Desert Bighorn Sheep}

Sonoran pronghorn is a desert subspecies of the American pronghorn. The Sonoran pronghorn was listed as a Federally endangered in 1967. Currently, there are at least 68 Sonoran pronghorn in the wild and 73 in a captive-breeding pen. Their current distribution is limited to a 7,122- $\mathrm{km}^{2}$ area that includes CPNWR, BMGR and OPCNM (fig 3.5). A draft Environmental Assessment to reestablish a pronghorn population in other protected areas was released in October 2009.

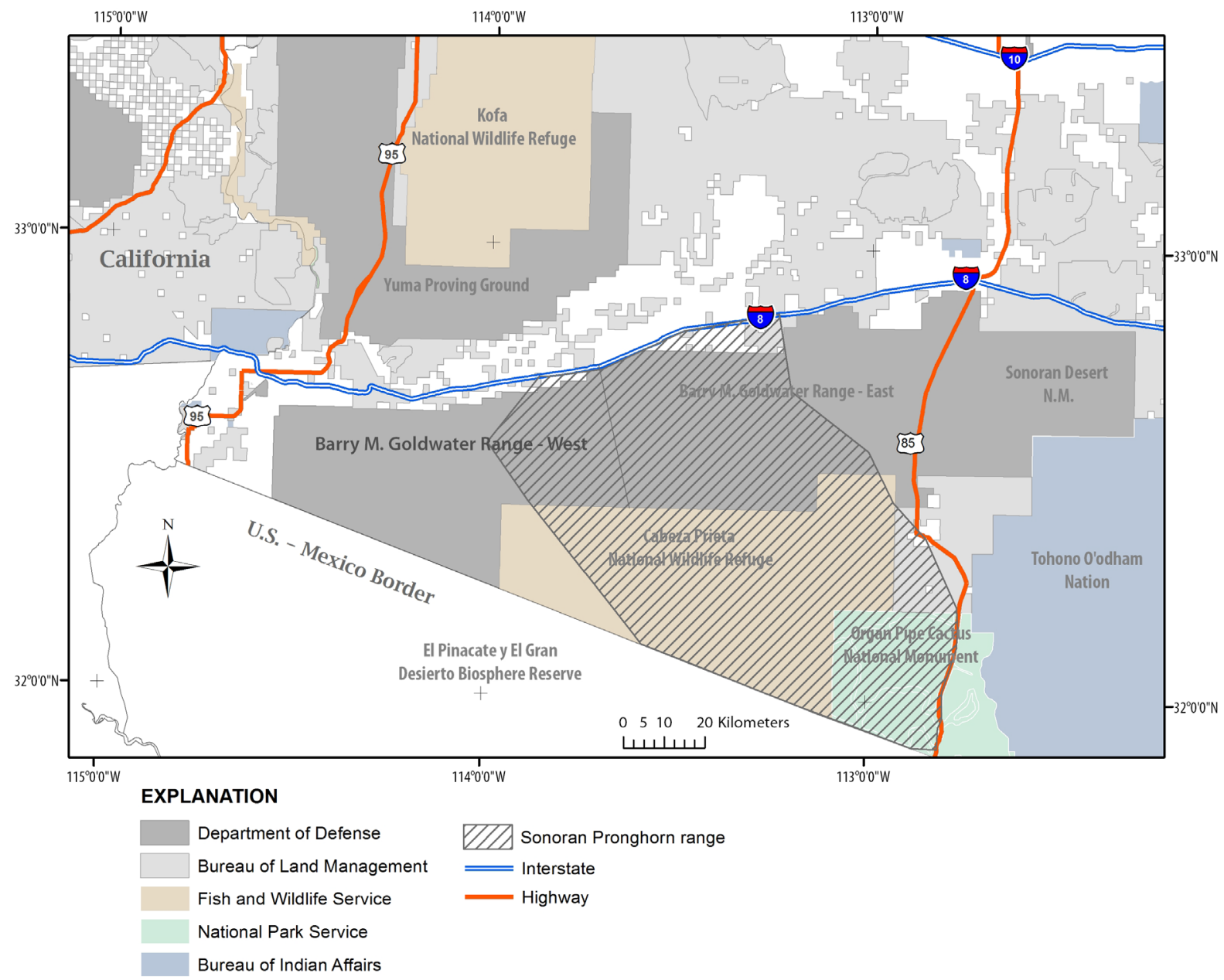

Figure 3.5. The current (2011) Sonoran pronghorn range.

The Sonoran Pronghorn Recovery Plan (Plan) (U.S. Fish and Wildlife Service, 1994) was produced by a recovery team comprising representatives from the AZGFD, CPNWR, BLM, OPCNM, Commission of Ecology and Sustainable Development for the State of Sonora (CEDES), and National Commission for Protected Natural Areas (CONANP) and revised in 1994, 1998, and 2002. Major recovery actions include (1) enhance present populations of 
Sonoran pronghorn by providing supplemental forage and/or water, (2) determine habitat needs and protect present range, (3) investigate and address potential barriers to expansion of presently used range and investigate, evaluate, and prioritize present and potential future reintroduction sites within the historical range, (4) establish and monitor a new, separate herd(s) to guard against catastrophes decimating the core population, (5) continue monitoring populations and maintain a protocol for a repeatable and comparable survey technique, and (6) examine additional specimen evidence to assist in verification of taxonomic status (U.S. Fish and Wildlife Service, 1994).

After the drought-induced die-off of Sonoran pronghorn in 2002, the USFWS, AZGFD, and BMGR worked to rebuild populations using the following tactics: (1) in 2003, a semicaptive breeding facility was constructed in Childs Valley, Cabeza Prieta NWR, and stocked with wild Sonoran pronghorn, (2) forage enhancement plots were created and irrigated to produce forage for pronghorn, and (3) emergency water sources (six on CPNWR, one on OPCNM, and two on BMGR-West) were constructed.

Monitoring is currently conducted by the USFWS and AZGFD using aerial line-transect surveys. For additional information, see USFWS and AZGFD monitoring protocols and reports (U.S. Fish and Wildlife Service, 1994; Bright and others, 1999, 2001 2002).

The desert bighorn sheep is a subspecies of Bighorn sheep that occurs in the southwest desert regions of the United States and northern Mexico. One key adaptation that has set the desert bighorn sheep apart from other sheep species is its ability to go without water for extended periods of time. Although current populations are low, the overall trends since the 1960s show population increases. Currently (2011), managers are working to address several issues that might limit sheep numbers, such as water availability, disease, human disturbance, and predation. AZGFD is the primary managing agency for the desert bighorn sheep. MCAS-Yuma has assisted in the past with water developments and with other projects, as needed. Future projects include development of several new water catchments and upgrades of existing water developments. Every 3 years, the AZGFD conducts aerial helicopter surveys during the months of October and November to monitor sheep populations.

Desert bighorn sheep are currently (2011) surveyed in the Mohawk, Copper, Gila, and Tinajas Altas mountain ranges on BMGR-West. The surveys in the Mohawk Mountains, Copper Mountains, and Tinajas Altas Mountains cover the entire habitat of BMGR-West and represent the population well; the survey in the Gila Mountains is a partial survey, because of funding limitations, so the sheep population there is likely larger than estimates indicate. Bighorn sheep numbers have remained relatively stable within these mountain ranges from 2008 to 2010, with some population fluctuation but no drastic population declines (Arizona Game and Fish Department, 2010; http://www.azgfd.gov/h f/hunting units 40b.shtml). The current (2011) population estimate in this area is about 250 sheep. When the Gila and Tinajas Altas Mountains were surveyed in November 2009, population estimates were as follows: ram to ewe ratio was 94:100, lamb to ewe ratio was 19:100, and yearling to ewe ratio was 11:100. When the Mohawk and Copper Mountains were surveyed in October 2007, population estimates were as follows: ram to ewe ratio was $87: 100$, lamb to ewe ratio was 13:100, and yearling to ewe ratio was 13:100. The AZGFD has a regulated hunt in these mountain ranges for the desert bighorn sheep; the current harvest recommendations are six rams per year. The hunts are allowed in three areas: the Gila Mountains north of Cipriano Pass, the Tinajas Altas Mountains south of Cipriano Pass, and the Mohawk and Copper Mountains. 
Regional Monitoring Status

Sonoran pronghorn monitoring is conducted at CPNWR, BMGR-West, and BMGREast, and desert bighorn sheep monitoring is conducted at BMGR, Kofa NWR, and other locations.

\subsubsection{Bat Guild}

Bat Guild protocol was adapted primarily from a mist-netting protocol developed in 1993-94 by Yar Petrysyzn (University of Arizona) for the OPCNM. There are, however, other bat monitoring protocols that would be helpful in regional monitoring efforts. The Arizona Game and Fish Department (1997) protocol, in particular, was designed to standardize methods across all four of the department's regional jurisdictions. AZGFD bat monitoring protocol is primarily mist-netting, but also includes a protocol for roost monitoring. It would be helpful to include roost monitoring as part of the BMGR-West monitoring efforts. The mist-netting protocol for BMGR-West is based on OPCNM and AZGFD (1997) monitoring protocols, and the roost monitoring is based on AZGFD procedures. It is useful to review both OPCNM and AZGFD protocols and other bat monitoring protocols (for example, Jones and others, 1996) before implementing a bat monitoring program.

A 2006 internal review of the OPCNM EMP suggests that the original bat monitoring protocol could be improved in various ways (Pate, 2006). One suggestion is the use of an Anabat ultrasonic detector/recording system to identify individual species through echolocation reference libraries (O'Farrell and others, 1999; Kuenzi and Morrison, 2003). One advantage of the ultrasonic detector approach is that it is nonobtrusive, and a comparative study in southeast Arizona by Kuenzi and Morrison (2003) suggests that this approach is as effective for bat monitoring as mist-netting, although specimens detected cannot be visually verified and no voucher data can be obtained (for example, blood, tissue, health status, disease detection, and other data). A second recommendation made by Pate (2006) and based on the review of the OPCNM bat monitoring program was to sample during spring/summer as opposed to late summer/fall (postmonsoon). Although there is often more available water and forage after the monsoon, the variability in precipitation is too great and may result in poor monitoring data (Pate, 2006). Finally, environmental conditions (temperature, moonlight, barometric pressure, and wind) can greatly influence the effectiveness and comparability of mist-net data, and minimizing variation in these conditions from one monitoring year to the next increases the accurate identification or long-term trends (Pate, 2006).

Even though there is a scarcity of available surface water at BMGR-West, limiting potential monitoring locations, the mist-netting protocol requires that monitoring be repeated at the exact same locations on an annual basis. It may be efficient to select and co-locate water sampling/survey locations with other sampling/monitoring locations (for example, amphibians, tinajas), but ultimately site selection is based on the biologist and resource manager's knowledge of local bat and water resources (fig. 3.6). The AZGFD bat monitoring protocol suggests that each netting location be surveyed for small terrestrial mammals concurrently with each bat survey.

The goal of roost monitoring is to focus monitoring on selected bat roosts/populations, especially roosts of high-priority species, in order to assess variability in annual and seasonal roost use. Measurements can include (1) relative abundance, (2) seasonal movements, and (3) 
effects of environmental factors (temperature, light intensity, and others). Roosts would be selected by the BMGR biologist and include one roost of a "high priority" species and a second roost of any bat species. Investigators would need to know the species inhabiting a roost and roost type before beginning monitoring. Investigators would also need to know background information on the roosting habits of the target species, likely reproductive condition and physiological state of the roosting individuals, times of nightly emergence and return, effects of temperature and precipitation on roosting behavior, and nightly foraging activities. This knowledge could be used to design a sampling protocol for a specific roost that can reduce disturbance to the bats and minimize sample bias. In a situation where roosts are unknown before monitoring, it is suggested that bats be captured during mist-netting, fitted with radio transmitters and tracked back to their roosts (Ball, 2002; Kuntz, 2003).

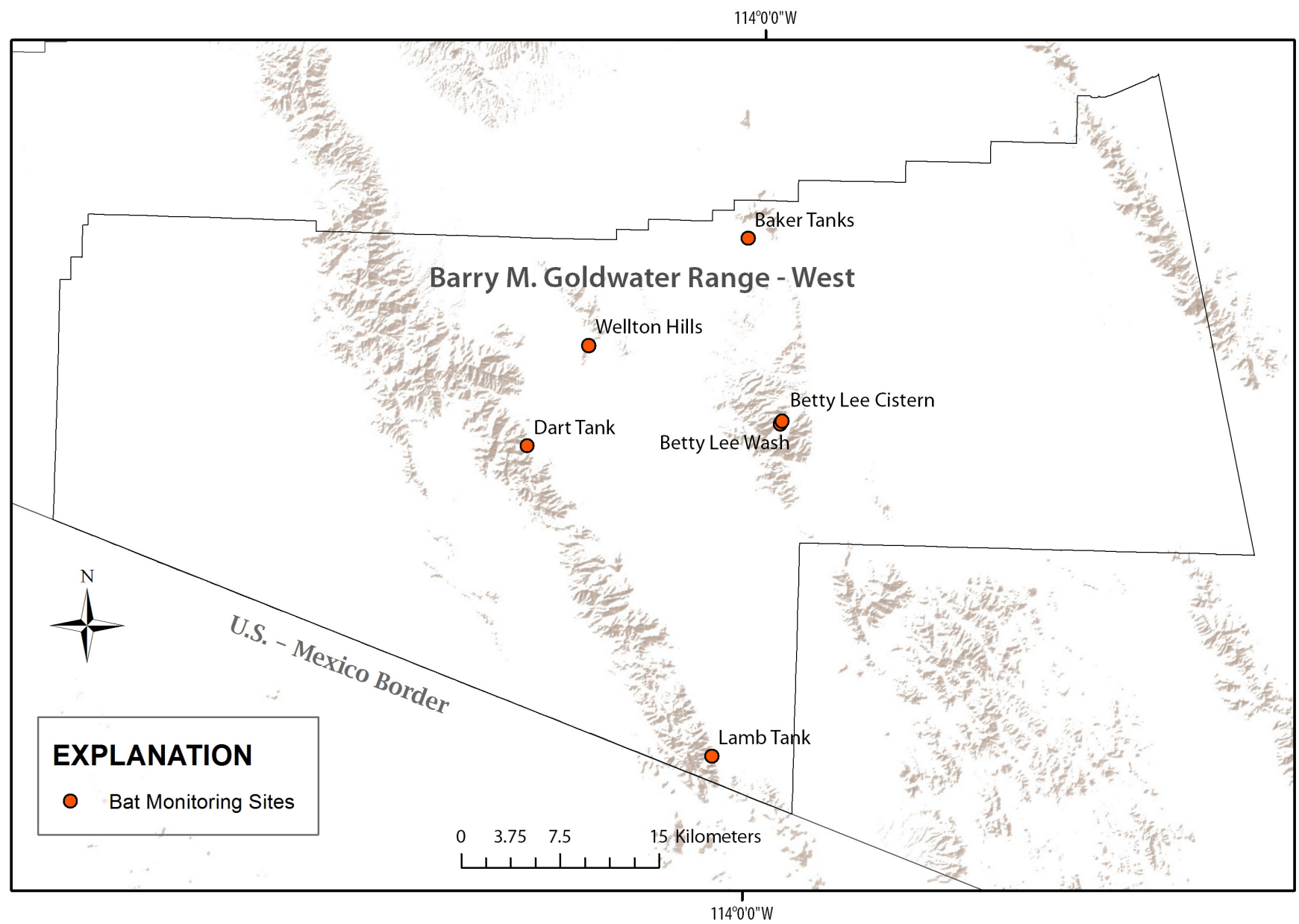

Figure 3.6. Location of Arizona Game and Fish Department Bat Monitoring Sites on Barry M. Goldwater Range-West. 
Regional Monitoring Status

Bat monitoring is currently (2011) conducted at BMGR-West, BMGR-East, OPCNM, and CPNWR.

\subsubsection{Amphibian and Reptile Surveys}

The status and distribution of amphibians and reptiles on the BMGR is not well known. There have been no comprehensive surveys or monitoring conducted to date. Thus, current (2011) management considerations and understanding of these species is based largely on the results of focused sampling of a few at-risk species (see sections below that discuss flat-tailed horned lizard, desert tortoise, and Cowles fringe-toed lizard) and some opportunistic and historical sampling and data collection for other herpetofauna. The following sections include a brief summary of I\&M efforts aimed at these at-risk species, followed by suggestions for more general herpetological monitoring approaches.

\section{Flat-Tailed Horned Lizard}

The flat-tailed horned lizard (FTHL) was first proposed as a threatened species under the Endangered Species Act in 1993. The FTHL proposal has been removed three times since 1993 as a result of legal challenges. The FTHL status is currently being considered by the Department of the Interior and is to be decided in 2011. In response to the proposed listing, the AZGFD developed a flat-tailed horned lizard management strategy that includes monitoring protocols and data analysis techniques (Flat-tailed Horned Lizard Interagency Coordinating Committee, 2003). The Conservation Agreement that resulted from the management strategy remains in effect today, and the rangewide monitoring strategy continues to be implemented by all Conservation Agreement signatory agencies. In an effort to standardize monitoring efforts throughout the species range, FTHL monitoring protocols were updated and refined in 2008 as the "Flat-tailed Horned Lizard Monitoring Plan." Various AZGFD FTHL monitoring efforts are currently (2011) underway at BMGR-West (fig. 3.7).

\section{Cowles Fringe-Toed Lizard}

Cowles fringe-toed lizard is endemic to the Sonoran Desert and only found in the Gran Desierto in Mexico and adjoining portions in the United States (the Yuma Desert and Pinta Sands) and in the Mohawk Dunes on the BMGR. The Gran Desierto of Mexico and the Mohawk Dunes on the BMGR are considered critical areas for the species and the Mohawk Dune habitat is largely free from stressors related to off-highway vehicles. It would be helpful to monitor the lizard population and the habitat quality of Mohawk Dunes regularly, with particular focus on invasive species and visitor use impacts on dune habitat. Turner and others (1997) conducted an initial Cowles fringe-toed lizard inventory at four sites in the Mohawk Dunes. 


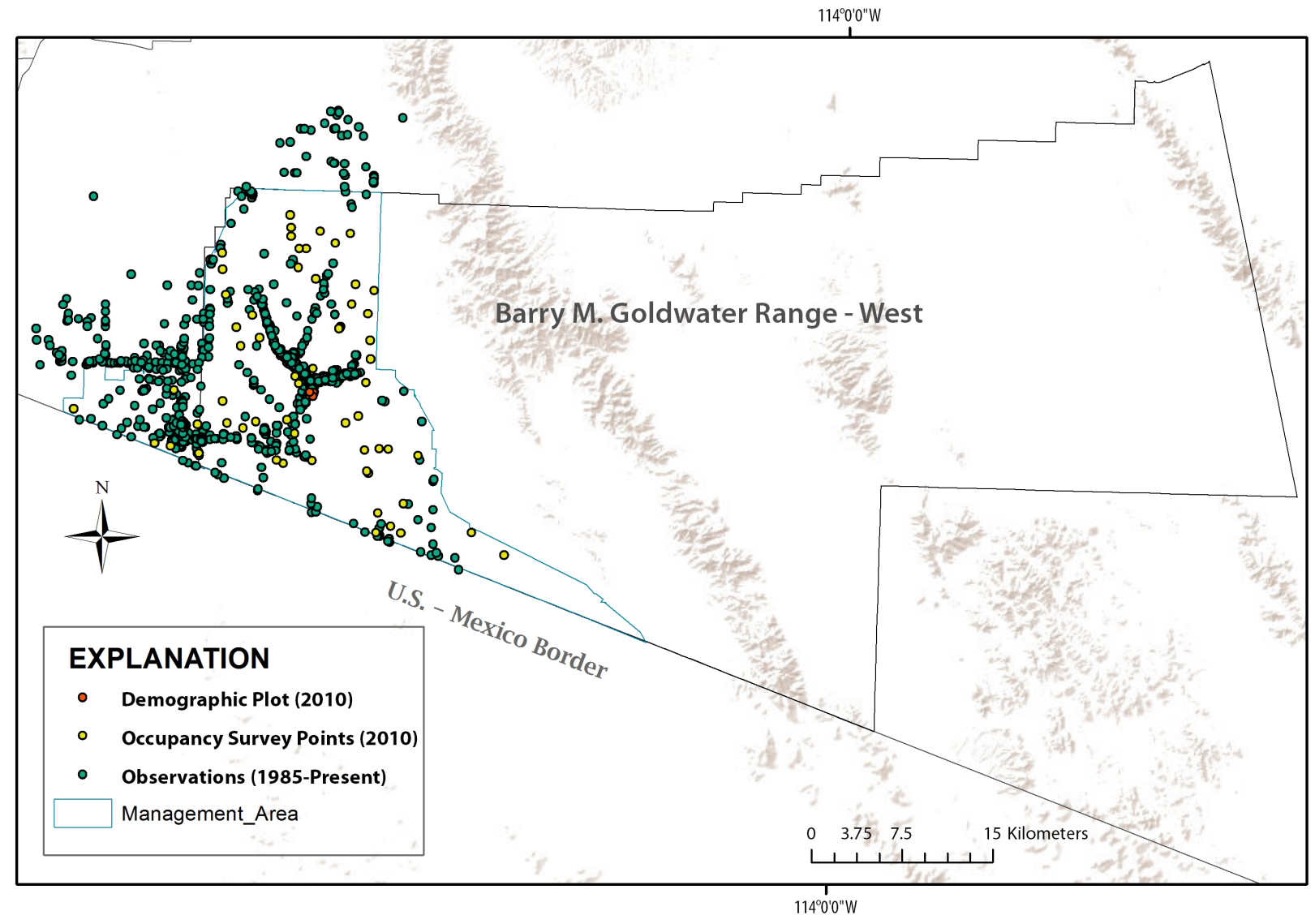

Figure 3.7. Flat-tailed horned lizard Management Area, including plot locations, survey points, and observation locations. 


\section{Desert Tortoise}

The desert tortoise is currently listed as Federally threatened in the northern one-third of its geographic range (U.S. Fish and Wildlife Service, 1990). Declines in the Mojave Desert populations have been attributed to direct and indirect human-caused mortality and inadequate regulatory mechanisms to protect desert tortoises and their habitat. Specific stressors identified in the listing included destruction, degradation, and fragmentation of habitat from urbanization, agricultural development, livestock grazing, mining, and roads.

On December 14, 2010, the USFWS announced a 12-month finding to list desert tortoises in the Sonoran Desert as a distinct population segment under the Endangered Species Act of 1973, adding the Sonoran population of the desert tortoise to the candidate species list. With the new listing of the desert tortoise, commercial and Federal projects that threaten the tortoise are required to obtain incidental take authorization from the USFWS. In addition, listing will require the designation of critical habitat, which would impose additional restrictions on solar energy development.

In fiscal year 2008, the AZGFD was awarded DOD Legacy Funding to identify landscape habitat patterns and subspecies designation of desert tortoises on BMGR and YPG. As a result, the AZGFD is developing a landscape-level habitat model that identifies locations with the highest likelihood of occupancy. Coupled with training area maps, specific locations where there is overlap are identified and appropriate measures taken to reduce potential conflicts between MCAS-Yuma activities and tortoise habitat. During the AZGFD 2008 survey, evidence of one tortoise $(n=1)$ was detected in the Tinajas Altas Mountains on the BMGR-West.

The following information provides basic desert tortoise survey protocols designed by AZGFD for contractors surveying for development projects. If conducting rangewide, long-term desert tortoise monitoring, see "Survey Protocol for Sonoran Desert Tortoise Monitoring Plots: Reviewed and Revised" by Averill-Murray (2000) for protocol information (http://www.AZGFD.gov/pdfs/w_c/tortoise/Monitoring\%20Plot\%20Protocol.pdf). The AZGFD provides "Desert Tortoise Survey Guidelines for Environmental Consultants", which is a set of informal guidelines that are intended to aid private consultants surveying for the presence of tortoises at development projects in the Sonoran Desert (http://www.azgfd.gov/hgis/pdfs/SurveyGuidelinesForConsultants.pdf).

\section{General Herpetological Monitoring Approach}

Data on herpetofauna occurrence can be inferred to some extent from data from land areas surrounding the BMGR-West. In the absence of systematic and BMGR-wide sampling and inventory, the following monitoring suggestions are made:

Herpetological monitoring on the Barry M. Goldwater Range may first require a baseline inventory. For reptiles and some amphibians, snake traps and arrays of pitfall traps utilizing cover boards can be implemented over several years until the accumulated data can be analyzed. Based on the results, the sampling methods, duration, and (or) intensity can be refined. See Heyer and others (1994) and Fisher and others (2008) for comprehensive pitfall trapping survey methods. Besides the recommended pitfall sampling, it would also be important to implement Visual Encounter Surveys (Crump and Scott, 1994) at all waters on the BMGR-West (fig. 3.3).

Although other methods for trap design and layout may be utilized (for example, Heyer and others, 1994; Fisher and others, 2008), Turner and others (1997) have used their method for 
inventory of Cowles fringe-toed lizard. Likewise, surveys for Cowles fringe-toed lizards may be included in the BMGR-West-wide herpetofaunal inventory and monitoring. In the past, Turner and others (1997) utilized six trap arrays, each consisting of four pitfall traps and some with an additional six funnel traps (Campbell and Christman, 1982; Gibbons and Semlitsch, 1982). Pitfalls were 19-liter (5-gallon) buckets sunk into the ground to their rims. These were placed in arrays, each consisting of a central pitfall circled by three others, which were distributed at roughly $120^{\circ}$ angles with radii of $7.7 \mathrm{~m}$. Four arrays had low metal drift fences connecting the central pitfalls with their outliers. Drift fences were occasionally augmented with funnel traps made from metal screening. Two arrays with drift fences were placed in dune swales, while the remainder were on crests. Reptiles were also captured by noose and by hand, on the dunes and in areas adjacent to the dunes. Reptiles were also detected in the course of walking transects as part of the monitoring component of this project, while conducting mark-recapture studies of fringetoed lizards and shovel-nosed snakes, while collecting specimens for ecological studies of fringetoed lizards, and while walking to and from camps and vehicles (Crump and Scott, 1994). These methods were supplemented by night-time road surveys on dirt roads (Campbell and Christman, 1982).

Data Collection: For each survey it is important to collect information in a standardized manner, and the following template is suggested:

1. Date

2. Start and end time of survey

3. Name/s of observer/s

4. Coordinates

5. Name or number of transect

6. Habitat type

7. Weather conditions (for example, sunny, cloudy, dry, or rainy)

8. Air temperature

9. Elevation

Species Information:

1. Species name

2. Sample location (GPS coordinates, UTM NAD83)

3. Sex and/or age of individual

4. Habitat individual was found in/on

5. Substrate (boulder, gravel, leaf litter) found in/on

The collected data would be summarized and a species list generated that shows the number of species, the number of individuals of each species, and the geographic distribution of the sampled species. The relative abundance and diversity of herpetofauna can be estimated and compared with historical data. 
Regional Monitoring Status

OPCNM staff monitor lizards and snakes using various methods, including transects and trap stations. AZGFD conducts various monitoring efforts in the area surrounding BMGR-West (see above).

\subsection{Anthropogenic Impacts}

Anthropogenic impacts on BMGR-West lands were considered the highest priority for monitoring by surveyed stakeholders and monitoring experts. Human activities, especially vehicle-based activities, can directly impact soils, vegetation, and local hydrology (Brooks and Lair, 2009). Repeated use of established or informal campsites can create impacts such as soil compaction, waste disposal, and firewood depletion in the campsite vicinity. Heavy foot and vehicular traffic can impact forbs and grasses (dune species may be especially vulnerable), and can disturb desert pavements and cryptogamic crusts, producing negative aesthetic and biological effects (Kuss, 1986; Gilewitch, 2004). The effects from foot traffic alone may be locally significant, but they are generally more subtle than similar effects produced by vehicle traffic and are best monitored with ground-based data collection in plots or along transects. Surface disturbances caused by vehicles can be seen in aerial and high-spatial-resolution satellite imagery and can thus be monitored using repeated imagery acquisitions. With georeferenced imagery in a GIS, surface disturbances such as road widening, new spurs, vegetation damage, and damage to desert pavements can be identified, quantified, and compared from one time period to another. A trails and roads inventory is currently (2011) being developed for OPCNM and CPNWR using remotely sensed imagery (2008 border aerials, see section below). For the CPNWR area, image interpreters are digitizing unauthorized vehicle tracks, and for the OPCNM area, historical roads, foot trails, and off-highway vehicle tracks are being digitized (Sue Rutman, OPCNM, oral commun., 2010).

The sections below outline basic protocols for monitoring anthropogenic effects on surface resources that are generally visible in remotely sensed imagery. However, it should be noted that image interpretation and feature extraction rely heavily on field reconnaissance and auxiliary data collection. Moreover, human visual interpretation of imagery is still usually more productive and accurate than an automated approach, if one can even be found that approximates the desired results.

The maximum objectivity of visual interpretation among observers and between time periods increases mapping accuracy. Drake and others (2004) showed that it is feasible to train different observers to produce consistent interpretations of high-spatial-resolution imagery with a minimum of effort. Consistently applied protocols and the opportunity to directly overlay multidate image sets for comparison also increases objectivity.

\subsubsection{Transportation Corridors}

Acquiring Aerial Imagery

The repeat interval for monitoring anthropogenic impacts may depend as much on institutional factors, such as budgets and availability of personnel, as on biological and physical factors. Documentation of ecosystem status and trends through imagery would be an important component of monitoring, and because of the cost of custom acquisition of commercial satellite 
imagery, it may prove most feasible to use public-domain, open-source, or shared imagery obtained opportunistically, such as the datasets described below. Transportation monitoring may be accomplished using a retrospective look at 1996 Digital Orthophoto Quarter Quadrangle (DOQQ) imagery for a semiquantitative comparison with 2008 border area orthoimagery as a "current" baseline and using future aerial photograph/satellite imagery acquisitions at 3- to 5year intervals (or as available) for monitoring change from the baseline.

High-resolution $(30 \mathrm{~cm})$ color aerial imagery was acquired in 2008 for the entire United States-Mexico borderlands area, with a minimum area of 30 miles north and 10 miles south of the boundary line. The dataset was created to provide geospatial data for Federal, State, and local emergency responders, as well as for homeland security efforts. The spectral and spatial resolutions of the dataset provide sufficient information to establish a baseline inventory of unauthorized roads and trails.

High-resolution aerial datasets that are currently (2011) available:

1996 Digital Orthophoto Quarter Quadrangles (USGS).-A digital orthophoto quadrangle (DOQ) is a computer-generated image of an aerial photograph in which image displacement caused by terrain relief and camera tilts has been removed. A DOQ combines the image characteristics of a photograph with the geometric qualities of a map. DOQs produced by the USGS are either gray-scale, natural color, or color-infrared (CIR) images with 1-m ground resolution and 3.75-minute spatial extent. All DOQs are referenced to the North American Datum of 1983 (NAD 83) and projected according to the Universal Transverse Mercator (UTM) projection (U.S. Geological Survey, 1998).

1996 Digital Orthophoto Quarter Quadrangles (DOQQs) may be a sufficient scale to help document (possibly only semiquantitatively) ecosystem change at BMGR-West between 1996 and 2008. DOQQs of BMGR-West can be found at: http://aria.arizona.edu/.

2007 Digital Orthophoto Quarter Quadrangles (National Agriculture Imagery Program, 2009).- The NAIP acquires aerial imagery during the agricultural growing seasons in the continental United States. A primary goal of the NAIP is to make digital orthophotography available to governmental agencies and the public within a year of acquisition. NAIP imagery is acquired at a 1-m ground sample distance (GSD), with a horizontal accuracy that matches within six meters of photo-identifiable ground control points that are used during image inspection. The default spectral resolution is natural color (red, green, and blue, or RGB), but beginning in 2007, imagery for some States has been delivered with four bands of data: RGB and near infrared.

The 2007 DOQQs could be used as a bridge to help interpret the 2008 imagery for comparison with the 1996 DOQQs, because the 1996 and 2008 datasets have different formats and image quality. The 2007 DOQQs are organized by State and are on an ArcGIS server maintained by the USDA Farm Service Agency (FSA).

2008 Border Area Orthoimagery (Arizona State Land Department, Arizona Land Resource Information System).- - The 2008 border-area orthoimagery data were collected as a result of the need for geospatial data immediately available and easily accessible to provide geographic reference for Federal, State, and local emergency responders, as well as for homeland security efforts. Orthoimages also serve a number of additional purposes, from interim maps to field references for earth science investigations and analysis. For the 2008 imagery, natural color orthoimages were produced at $0.3-\mathrm{m}$ (approximately $1-\mathrm{ft}$ ) pixel resolution. Natural color orthoimagery is organized in three color bands or channels, which represent the red, green, and blue portions of the spectrum. The design accuracy is estimated not to exceed 6-m horizontal 
Root Mean Square Error (RMSE) for locations within the United States. Each orthoimage provides imagery for a $1,500-\mathrm{m}$ by $1,500-\mathrm{m}$ block on the ground. The projected coordinate system is UTM with datum NAD83.

The imagery was collected at an average altitude of 9,500 ft above mean terrain (AMT) using an ADS40-II digital sensor. The ADS40-II sensor collects 12-bit image data, which requires radiometric adjustment for output in standard 8-bit image channels. Converting to eight bits results in a reduction of the color range from 4,096 to 256 levels. Thus, loss of radiometric detail is inevitable. In addition to color balancing, these eight-bit images were adjusted to create seamless imagery to the highest extent practically achievable. The imagery was mosaicked using a combination of automated and manual seamline generation. Project-specified tiles were extracted from the mosaic to produce a natural color digital orthophoto image map.

\section{Conducting Road Inventory}

In 1999, the BLM completed a comprehensive map of authorized roads at BMGR-West before transferring natural and cultural resource management responsibility to the Secretary of the Navy and the Secretary of the Air Force. MCAS-Yuma updated this authorized road network in 2008 for completion of the BMGR-West Visitor's Guide and Map. Roads were mapped using a Leica System GPS500 with GPS and positional accuracies of $30 \mathrm{~cm}$. The roads are mapped on a continual basis to meet requirements of ongoing projects. The protocol below describes the process required to develop an inventory map documenting additional (unauthorized) roads on BMGR-West.

\section{Unauthorized Roads}

Aerial imagery can be imported into a GIS environment for road network digitization. A "Roads" shapefile can be created and digitization done using the ArcEditor extension of ArcMap. Accurate delineation of roads, trails, and border-related and visitor-related impacts depends on the local substrate and GIS operator's experience with high-resolution image interpretation and knowledge of histogram manipulation techniques. Identifying trails in the imagery is a subjective process, the results of which depend on the interpreter's experience and familiarity with the area; accurate interpretation depends on a set of intuitive, perhaps not easily articulated, criteria for identifying a lineament as a trail rather than a drainage, a random alignment of shrubs, or another natural landscape feature that might look somewhat like a trail.

The following information would be described or developed using the road inventory data, and can be updated at a regular interval with the acquisition of new imagery:

- Total number of miles of roads

- Number of road segments

- Segment lengths

- Qualitative scoring of erosion-potential of soil based on adjacent disturbances

- Road width and number of spurs

- Baseline inventory using 1996 imagery to compare with 2006 imagery

Field transects are necessary to verify the accuracy of digitized maps and may be necessary in areas where it is difficult to interpret aerial imagery (for example, Mohawk Dunes). The general procedure would be to establish a transect route beforehand in a GIS environment and send a field crew out to that location to collect data (with hardcopy maps of aerial imagery). 
Field crews would record locations with a GPS and note the type (road/trail) and general usage (low, moderate, or heavy).

\section{Road and Trail Erosion Monitoring}

Once a road inventory is complete, it is possible to identify areas with high erosion potential by overlaying the digitized road network with a potential erosion map raster layer (section 3.1.4). Ground-based road and trail erosion monitoring (section 3.1.4) would occur in areas with high erosion potential.

Road and trail erosion monitoring would be done with a similar assortment of survey and sediment trap methods to those of the Vegetation Community and Soils plots and StreamChannel Erosion Monitoring (sections 3.1.3 and 3.1.5). Road and trail cross-sectional surveys used along with more selectively placed wind- and water-based sediment traps would be used to try to estimate road contribution to area erosion. A complete road and trail inventory is the most essential tool for implementing a proper erosion monitoring sampling design. The proximity to the United States-Mexico border and military uses of BMGR-West make this a potentially tough inventory to maintain. Thus, from whatever inventory is available, a statistical sampling routine would be created to produce a set of points along trails and roads that allow statistical inference to the entire inventoried landscape. Stratification by road and trail type would also be necessary, and point placement would be weighted more heavily towards areas with higher wind and erosion potentials as modeled in the erosion potential inventory maps. Points would be allocated using the GRTS method (Hubbard and others, 2009; Stevens and Olsen, 2004) in a manner similar to that of the basin-level Stream-Channel Erosion Monitoring method (section 3.1.5).

At each sampling site, a transect would be run perpendicular to the road or trail covering the full extent of the influenced area. The transect endpoints would be permanently marked and recorded by a GPS for repeat measurements. The elevation profile of this transect would be measured at $0.25-\mathrm{m}$ intervals. Vegetation life-form and surface cover would also be measured at each interval in a line-point intercept following Hubbard and others (2009), with the exception of recording vegetation to the species level (that is, only recording if any vegetation was hit in each height class). Eighteen soil aggregate stability samples (Herrick and others, 2001; Hubbard and others, 2009) would also be collected at evenly spaced intervals along the transect. Each sample would be referenced to a length along the transect so the location along the road/trail transect can be used in analysis. Cross-sectional areas would help provide actual soil loss estimates at these transects, while cover and aggregate stability provide additional ecological data and indicate if potential exists for erosion spreading from actual road or trail cuts.

Depending on the availability of resources, all or a sampled subset of trail and road points can be monitored with sediment traps for both wind and water. If all points cannot be instrumented, a random sampling scheme would be used weighted towards points with higher potential erosion in the erosion inventory. Sites may also be selected in retrospect after doing initial cross sections. In that case, sites with noticeable erosion cutting could be weighted more heavily in selection, but within a statistically randomized selection process so inference to the greater area is still possible.

Sediment trap placement requires more preparation for a road or trail, because water bars and off-track sediment traps are required. Placement of water-sediment traps would follow the arrangement outlined by Luce and Black (2001), where the trap is co-located with a water bar to sample an upslope segment of road. This water-bar trap setup would be located downslope of the 
transect, so that the transect falls in about the middle of the segment of trail/road being sampled. Variations of the Wells and Wohlgemuth (1987) trap would be used for smaller trails, and the larger watershed outlet type trap used for larger trails and roads (Robichaud and others, 2008; Robichaud and Brown, 2003).

Wind traps would be set along the cross-section transect to see if proximity to the road increases sediment yields. Fryrear dust samplers (Fryrear, 1986) would be set, with optimal arrangements including at least two traps near the ends of the transects (away from road) and two as close to the road as possible (preferably on both sides). Similarly to the vegetation plots, any road sites that show high wind erosion requiring more detailed wind-emission data would be equipped with the 10-m tower air samplers (Nickling and Gillies, 1993).

\subsubsection{Visitor Use}

Monitoring visitor use at BMGR-West would follow a two pronged approach: (1) monitoring long-term changes in visitor and vehicle numbers through the range visitor permit system and (2) monitoring the physical impacts of visitors on roads, trails, and campsites (including associated soils and vegetation). It is suggested that roads, trails, and campsites be monitored every 3-5 years and sampling be both random and nonrandom (for example, at known camp destinations).

Visitor-use monitoring protocols, particularly campsite monitoring, often rely on changes in soil and plant parameters as indicators of use. Campsites in desert environments are typically void of biotic soil crusts and vascular plants; repeated, moderate to heavy use of desert campsites is known to cause soil compaction, reducing the ability of desert plants to establish healthy root systems and decreasing germination and establishment rates (Cole, 1986). Ironwood (Olneya tesota), paloverde (Parkinsonia spp.), and mesquite trees in the vicinity of campsites are often targeted for fuel wood collection.

There exist no maintained campsites at BMGR-West, but visitors gravitate towards certain areas where the physical environment is conducive to camping. Monitoring data on the impacts of primitive camping on the soils and vegetation of areas can be used to reduce repeated impacts and site expansion and for restoration of areas that appear significantly degraded.

\section{Visitor Permit Monitoring}

The permit system at BMGR-West provides a virtual census of all visitors entering the range (as opposed to nonmandatory visitor registers or pressure counters), allowing management to assess trends and patterns at fine temporal scales. The permit process at BMGR-West requires visitors to fill out the necessary paperwork by mail or in person at the MCAS-Yuma Range Pass and ID Office located on the north side of the main gate. The permit form includes information on the number of vehicles, number of visitors in the party, date of visit, and length of visit.

Permit data would be entered monthly into a spreadsheet/database and analyzed for trends annually. Several descriptive metrics (sum, mean, and standard deviation) can be derived from the data for collected variables, including the number of visitors, the number of vehicles, and the length of visits. 


\section{Campsite Monitoring}

Campsite locations at the BMGR-West may be inventoried every 3-5 years and locations determined by driving the entire road network and identifying both areas used repeatedly as campsites and areas with new signs of light or low-use camping. The campsite monitoring protocol includes three steps: a qualitative condition assessment, measurement of disturbed areas, and photographic documentation of the site (appendix F). 


\subsection{Data Management}

Data management is critical to the success of BMGR-West monitoring efforts. Vigilant and systematic data entry and management ensure data quality, interpretability, security, longevity, and availability. Data availability is an important component of collaborative monitoring and collaborative adaptive management. The following sections provide a basic framework for establishing a sound data management system and suggestions for establishing and maintaining a monitoring data repository for multiagency monitoring datasets that span the Sonoran Desert Ecoregion.

Standard operating procedures (SOPs) can be developed and maintained for all implemented monitoring protocols. It is suggested that all changes and revisions to protocols and SOPs be kept as a record in a "protocol revision history" form, ensuring that the decisionmaking process is transparent and provides a knowledge base for future monitoring staff.

\subsection{Data Entry, Metadata, and Archiving}

Careful and accurate recording of measurements in the field is a first step to ensuring quality monitoring data, but it is important to establish safeguards to reduce both systematic and random data entry errors. Several quality assurance and quality control (QA/QC) mechanisms help identify and correct data entry and measurement errors. QA/QC methods include (1) defining and enforcing data formats, measurement units, and unit/plot naming conventions, (2) checking for data entry errors, unusual patterns in the data and outliers, and (3) checking for compatibility among datasets. After all data for a field season have been entered, verified, validated, and certified, the seasonal data would be appended to a master monitoring database. All resource-specific and master monitoring databases would be archived on a secure server with regularly scheduled backups (weekly backups suggested). It is suggested that all datasets include some level of metadata, providing documentation of how, why, when, and where data were collected and including spatial information (for example, coordinate system, datum) when appropriate. An example of metadata standards is available at http://www.fgdc.gov/metadata/geospatial-metadata-standards.

Staff operating the SODN provided Microsoft Access databases for Vegetation and Soils and Bird monitoring protocols. To update, modify, or develop additional Microsoft Access monitoring databases for BMGR-West, see the National Park Service Database Template (http://science.nature.nps.gov/im/apps/template/).

\subsection{Geospatial Data Management}

Datasets collected for I\&M processes represent a critical component of the overall natural resources management strategy of BMGR-West. GEOFidelis, as the USMC geospatial program of record, recognizes the importance of collecting accurate, reliable, up-to-date, authoritative data to support efficient and effective conservation of resources, efficient and effective planning to avoid and minimize environmental impacts, and sharing data in regional and national contexts. Data need to meet multiple uses at multiple scales and standards to support key data infrastructure goals. 


\subsection{Monitoring Data Repository: Location and Oversight}

data:

Several options exist for a central data repository to house BMGR-West I\&M program

1. Heritage Data Management System (HDMS), AZGFD (URL:

http://www.AZGFD.gov/w_c/edits/species_concern.shtml). The HDMS is an integrated data management system of maps, computer files, and paper files. Data concerning the location of species of concern and habitats are mapped; data concerning the ecological status of species are cataloged; and data concerning the biology of species are consolidated into a wellorganized system whereby a myriad of information can be easily retrieved. Information is constantly being added and updated, creating a dynamic system. Information included in the HDMS comes from published and unpublished reports, data collected by cooperating agencies, museum and herbarium collections, the scientific and academic communities, and many other sources.

2. Arizona Regional Image Archive (ARIA), University of Arizona (URL:

http://aria.arizona.edu/). The ARIA is an interdisciplinary resource system for digital image and map data for the Sonoran Desert region, including the southwestern United States and northern Mexico. ARIA is an image repository maintained by volunteers at the Arizona Remote Sensing Center (ARSC) and the Office of Arid Lands Studies (OALS) at the University of Arizona. ARIA is primarily a satellite image and map database.

3. Earth Resources Observation and Science (EROS) Center (URL: http://eros.usgs.gov/). EROS is a remotely sensed data management, systems development, and research field center of the USGS. Although EROS primarily houses geospatial data (cartographic and satellite imagery), there exists potential for integrating species and plot data. For example, the USGS is leading a cooperative national effort of amphibian monitoring, research, and conservation through the National Amphibian Research and Monitoring Initiative (ARMI). 


\subsection{Management Actions as a Result of Inventory and Monitoring}

The purpose of this I\&M Plan is to guide the implementation and development of a I\&M program that would provide MCAS-Yuma with useful information for describing the status of BMGR-West ecological resources. Data collected through the I\&M process would ultimately help to identify potential changes in the amount, distribution, or quality of BMGR-West resources. Certain management actions or interventions may be indicated if changes in a monitoring parameter are detected and the condition of a resource deviates from the stated monitoring objectives (see section 1.2) of BMGR-West and MCAS-Yuma (fig. 5.1). It is suggested that resource thresholds be determined beforehand by BMGR-West management and that they be based on well-defined objectives and desired conditions for each resource being monitored.

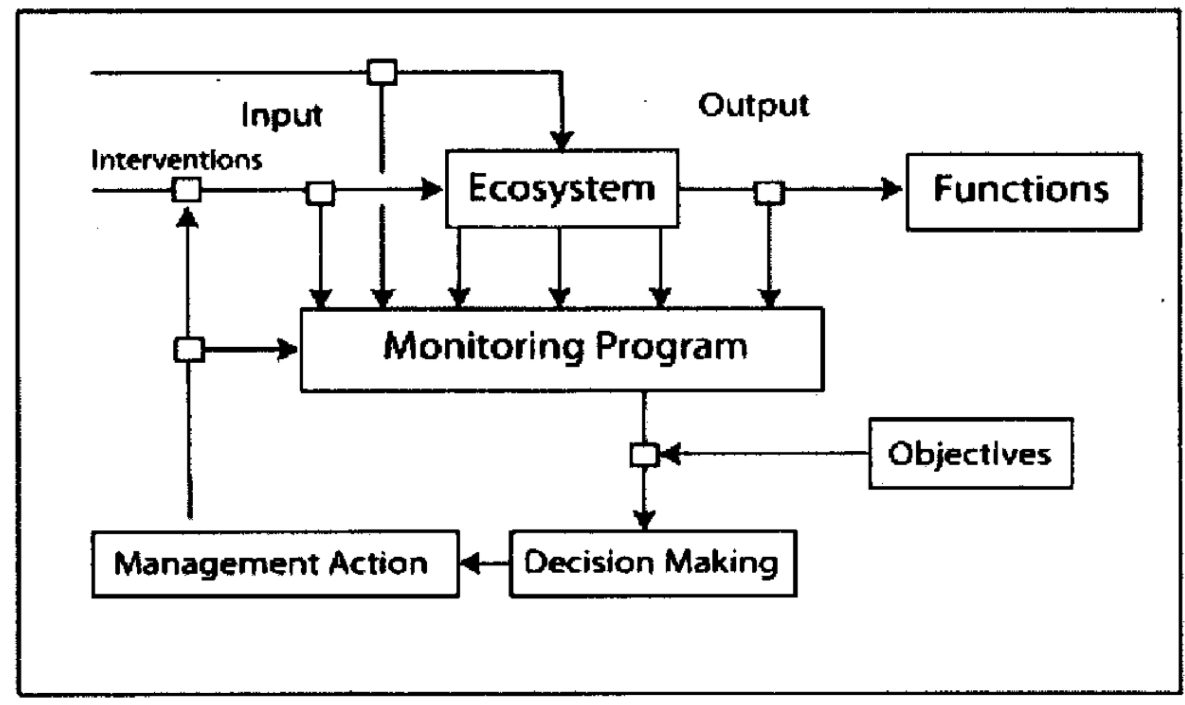

Figure 5.1. The relationship between an ecological monitoring program and management activities (adapted from Vos and others, 2000). 


\subsection{Programmatic Review of Monitoring and Management Activities}

A thorough analysis of monitoring data from all implemented protocols may be undertaken after the first 3 years of monitoring, and a timeframe for future reviews could be established based on the initial program review. An initial 3-year review could involve extensive quantitative analyses to evaluate the efficiency of the program design, results, and ability to meet managers' goals and objectives. At that time, monitoring teams may have identified field techniques and adjustments to the original protocols that warrant inclusion in or revision of the original protocols. A major component of the review would involve suggested revisions to the monitoring program, with explicit justification of each revision.

The program review effort can include trend assessment of monitoring parameters, variance partitioning and power analysis, and an assessment of sampling methods and spatial inferences. BMGR-West staff may want to contract or hire a suitable program reviewer with the appropriate skills and experience to independently review all aspects of the BMGR-West monitoring program. 


\section{Acknowledgments}

The authors wish to thank Brian Powell and Laura Norman for their reviews of this material. The authors would also like to thank the Barry M. Goldwater Range-West I\&M workshop presenters and participants for their input and reviews of the documents. We would like to thank Andy Hubbard, Evan Gwilliam, Kristin Beaupre, and the rest of the National Park Service Sonoran Desert Network staff for their help and the use of protocols and databases for this plan.

\section{References Cited}

Arnett, M., and Douglas, P.P., 1996, Floristic inventory of Barry M. Goldwater Air Force Range. Maricopa, Pima and Yuma Counties, Arizona: Center for Ecological Inventory of Military Lands, Department of Forest Sciences, Colorado State University, Fort Collins CO, 60p.

Arizona Game and Fish Department, 2010, Hunting unit report, Game Management Unit 40B, http://www.azgfd.gov/h_f/hunting_units_40b.shtml

Averill-Murray, R.C., 2000, Survey protocol for Sonoran Desert Tortoise monitoring plots; reviewed and revised: Arizona Interagency Desert Tortoise Team, $46 \mathrm{p}$.

Ball, L.C., 2002, A strategy for describing and monitoring bat habitat: The Journal of Wildlife Management, v. 66, no. 4, p. 1,148-1,153.

Bewket, W., and Sterk, G., 2003, Assessment of soil erosion in cultivated fields using a survey methodology for rills in the Chemoga watershed, Ethiopia: Agriculture, Ecosystems and Environment, v. 97, p. 81-93.

Bright, J.L., and Hervert, J.J., 2002, Sonoran Pronghorn population monitoring progress report; 1999-2001: Arizona Game and Fish Department, Technical Report, 209 p.

Bright, J.L., Hervert, J.J., Piest, L.A., Henry, R.S., and Brown, M.T., 1999, Sonoran Pronghorn 1998 aerial survey summary: Arizona Game and Fish Department, Technical Report, 152 p.

Bright, J.L., Hervert, J.J, and Brown, M.T., 2001, Sonoran Pronghorn 2000 aerial survey summary: Arizona Game and Fish Department, Technical Report, 180 p.

Brooks, M.L., and Berry, K.H., 2006, Dominance and environmental correlates of alien annual plants in the Mojave Desert, USA: Journal of Arid Environments, v. 67, (Supplement 1), p. $100-124$.

Brooks, M.L., and Lair, B.M., 2009, Ecological effects of vehicular routes in a desert ecosystem, in Webb, R.H., Fenstermaker, L., Heaton, J., Hughson, D., McDonald, E., and Miller, D., eds., The Mojave Desert; ecosystem processes and sustainability: Reno, University of Nevada Press, 168-195 p.

Brooks, M.L., D’Antonio, C.M., Richardson, D.M., Grace, J., Keeley, J.J., DiTomaso, J., Hobbs, R., Pellant, M., and Pyke, D., 2004, Effects of invasive alien plants on fire regimes:

Bioscience, v. 54, 677-688 p.

Brown, J.R., and Archer, S., 1999. Shrub invasion of grassland; recruitment is continuous and not regulated by herbaceous biomass or density: Ecology, v. 80, no. 7, p. 2,385-2,396.

Broyles, B. 1997, Wildlife water-developments in southwestern Arizona: Journal of the ArizonaNevada Academy of Science, v. 30, no.1, p. 30-42. 
Buckland, S.T., Anderson, D.R., Burnham, K.P., Laake, J.L., Borchers, D.L., and Thomas, L., 2001, Introduction to distance sampling; estimating abundance of biological populations: Oxford, U.K., Oxford University Press.

Burnham, K.P., and Anderson, D.R., 2002, Model selection and multimodel inference; a practical information-theoretic approach (2d ed.): New York, Springer Verlag.

Burt, R., ed., 2004, Soil survey laboratory methods manual: U.S. Department of Agriculture Natural Resources Conservation Service, Soil Survey Investigations Report No. 42, version 4.0, ftp://ftp-fc.sc.egov.usda.gov/NSSC/Lab_Methods_Manual/SSIR42_2004_print.pdf.

Cabeza Prieta National Wildlife Refuge, 1995, Plants of Cabeza Prieta NWR. (Available online at http://www.fws.gov/southwest/refuges/arizona/cabplant.html).

Campbell, H.W., and Christman, S.P., 1982, The herpetological components of Florida sandhill and sand pine scrub associations, in Scott, N.J., Jr., ed., Herpetological Communities: Washington, DC., US Fish and Wildlife Service, p. 163-171.

Cohen, J., 1988, Statistical Power Analysis for the Behavioral Sciences. 2nd ed. Hillsdale, NJ: Lawrence Erlbaum Associates.

Cole, D.N., 1986, Recreational impacts on backcountry campsites in Grand Canyon National Park, Arizona, USA: Environmental Management, v.10, no. 5, p. 651-659.

Crump, M.L., and Scott, N.J., Jr., 1994, Visual encounter surveys, in Heyer, W.R., Donnelly, M.A., McDiarmid, R.W., Hayek, L.C., and Foster, M.S., eds., Measuring and monitoring biological diversity; standard methods for amphibians: Washington, D.C., Smithsonian Institution Press, 405 p.

D’Antonio, C., and Vitousek. P., 1992, Biological Invasions by exotic grasses, the grass/fire cycle, and global change: Annual Review of Ecology and Systematics, v. 23, p. 63-87.

Daubenmire, R.F., 1959, Canopy coverage method of vegetation analysis: Northwest Science, v. 33, p. 43-64.

David, O.O., 1999, Improvement in field texture accuracy for sustainable agriculture: Journal of Sustainable Agriculture, v. 15, no. 2, p. 61-68.

Drake, S., Sanova, N., and Hubbard, A.J., 2004, Use of remote sensing techniques to quantify border impacts at Coronado National Memorial and Organ Pipe Cactus National Monument: Report for National Park Service Sonoran Desert Network, 30 p.

Drake, S., Buckley, S., Villarreal, M.L., Studd, S., and Hubbard, A.J., 2009, Vegetation classification, distribution and mapping report: Fort Collins, Colorado, National Park Service, Tumacácori National Historical Park, Natural Resource Report NPS/SODN/NRR-2009/148.

Duncan, D.K., Fernandez, E., and McCasland, C., 2010, The U.S.-Mexico border and endangered species. P. 123-130 in Halvorson, W., Schwalbe, C., and van Riper, C., III, eds., Southwestern desert resources: Tucson, The University of Arizona Press.

Elzinga, C.L., Salzer, D.W., Willoughby, J.W., and Gibbs, J.P., 2001, Monitoring plant and animal populations: Malden, Massachusetts, Blackwell Science, Inc., 360 pages.

Executive Order 13112 of February 3, 1999: Federal Registry, v. 64, no. 25.

Felger, R.S., B. Broyles, M. Wilson, and Nabhan, G.P., 1997, The binational Sonoran Desert

Biosphere Network and its plant life. Journal of the Southwest v. 39, p. 411-560.

Fisher, R., Stokes, D., Rochester, C., Brehme, C., Hathaway, S., and Case, T., 2008, Herpetological monitoring using a pitfall trapping design in southern California: U.S. Geological Survey Techniques and Methods, 2-A5, 44 p. 
Flat-tailed Horned Lizard Interagency Coordinating Committee, 2003, Flat-tailed horned lizard rangewide management strategy, 2003, revision: 80 p. plus appendixes. (Available online at http:/www.fws.gov/southwest/es/arizona/Documents/SpeciesDocs/FTHL/Rangewide_Plan_Final_FTHL.pdf).

Flesch, A.D., 2008, Population and community dynamics of lizards and rodents in Organ Pipe Cactus National Monument 1989-2006 and implications for future monitoring: Desert Southwest Cooperative Ecosystems Studies Unit, Cooperative Agreement No H1200050003,

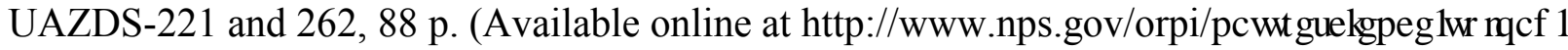

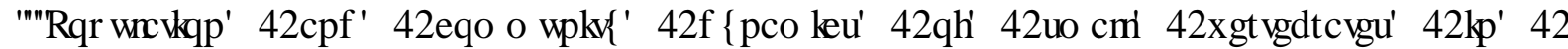

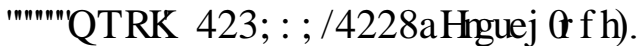

Forman, R.T.T., and Alexander, L.E., 1998, Roads and their major ecological effects: Annual Review Ecological Systems, v. 29, p. 207-231.

Fryrear, D.W., 1986, A field dust sampler: Journal of Soil and Water Conservation, v. 41, p. 17120.

Fryrear, D.W., Sutherland, P.L., Davis, G., Hardee, G., and Dollar, M., 2001, Wind erosion estimates with RWEQ and WEQ, in Stott, D.E., Mohtar, R.H., and Steinhardt, G.C., eds., Sustaining the global farm: Selected papers from the 10th International Soil Conservation Organization, May 24-29, 1999, at Purdue University and the USDA-ARS National Soil Erosion Research Laboratory, 6 p. (Available online from http://www.tucson.ars.ag.gov/isco/isco10/sustainingTheGlobalFarm/P120-Fryrear.pdf).

Gibbons, J.W., and Semlitsch, R.D., 1982, Terrestrial drift fences with pitfall traps; an effective technique for quantitative sampling of animal populations: Brimleyana, v.7, p. 1-6.

Gilewitch, D., 2004, The effect of military operations on desert pavement: case study from Butler Pass, AZ. in D.R. Caldwell, J. Ehlen and R.S. Harmon, eds., Studies in Military Geography and Geology:Kluwer Academic Publishers, Dordrecht, The Netherlands.

Guo-ping, Z., Zeng-xiang, Z., and Ji-yuan, L., 2001, Spatial distribution of wind erosion and its driving factors in China: Journal of Geographic Sciences, v. 11, no. 2, p. 127-139.

Hall, E.R., 1981, The Mammals of North America, Volume 1: John Wiley and Sons, New York, 600 p.

Hall, J.A., Comer, P., Gondor, A., Marshall, R., and Weinstein, S., 2001, Conservation elements of and a Biodiversity Management Framework for the Barry M. Goldwater Range, Arizona: Tucson, The Nature Conservancy of Arizona, $199+$ ix p. + 15 unpaginated figures.

Herrick, J.E., Whitford, W.G., de Soyza, A.G., Van Zee, J.W., Havstad, K.M., Seybold, C.A., and Walton, M., 2001, Field soil aggregate stability kit for soil quality and rangeland health evaluations: Catena, v. 44, no. 1, p. 27-35.

Herrick, J.E., Van Zee, J.W., Havstad, K.M., Burkett, L.M., and Whitford, W.G., 2005a, Monitoring manual for grassland, shrubland and savanna ecosystems. Volume. 1, Quick start: USDA-ARS Jornada Experimental Range, 42 p. (Available online at ftp://ftp-

fc.sc.egov.usda.gov/GLTI/CBC_Range/References/CBC_GL_Refs\%20(D)/Quick_Start.pdf). Herrick, J.E., Van Zee, J.W., Havstad, K.M., Burkett, L.M., and Whitford, W.G., 2005b, Monitoring manual for grassland, shrubland and savanna ecosystems. Volume 2, Design, supplementary methods and interpretation: USDA-ARS Jornada Experimental Range, 206 p $\square$

Heyer, W.R., Donnelly, M., McDiarmid, R.W., Hayek, L.A., and Foster, M.S., 1994, Measuring and monitoring biological diversity; standard methods for amphibians: Washington D.C. and London, Smithsonian Institution Press, 364 p.

Hoffmeister, D.F., 1986, Mammals of Arizona: Tucson, AZ, University of Arizona Press. 
Hubbard, J.A., Mau-Crimmins, T.M., Powell, B.F., Albrecht, E.W., Chambers, N., and Carder, L., 2003, National Park Service Sonoran Desert Network monitoring plan. Phase II: Sonoran Desert Network, Tucson, Ariz., 72 p. (Available online at http://pubs.usgs.gov/of/2006/1076/of2006-1076.pdf).

Hubbard, J.A., McIntyre, C.L., Studd, S.E., Nauman, T.W., Angell, D., Connor, M.K., and Beaupre, K., 2009, Terrestrial vegetation and soils monitoring protocol and standard operating procedures for the Sonoran Desert Network: Natural Resource Report NPS/SODN/NRR2009/0XX. National Park Service, Fort Collins, Colorado. (Available online at http://science.nature.nps.gov/im/monitor/protocols/SODN_Uplands_Protocol_v100.pdf).

Integrated Natural Resources Management Plan, 2007, Integrated Natural Resources Management Plan for Barry M. Goldwater Range, Yuma, Pima, and Maricopa Counties, Arizona: Prepared by Departments of the Air Force and Navy in cooperation with Department of the Interior and Arizona Game and Fish Department, 101 p.

Jabbar, M., Chen, X., and Li, H., 2006, Land degradation due to soil wind erosion in arid and semi-arid regions with the aid of geo-information technology: Geoscience and Remote Sensing Symposium, 2006 (IGARSS 2006), IEEE International Conference, Denver, Colo., 3292 p.

Jones, C., McShea, W.J., Conroy, M.J. and Kunz, T.H., 1996, Capturing mammals, in Cole, F.R., Nichols, J.D., Rudran, R. and Foster, M.S., eds., Measuring and monitoring biological diversity; standard methods for mammals: Washington, D.C., Smithsonian Institution Press, p. $115-155$.

Klik, A., 2000, Wind erosion assessment in Austria using Wind Erosion Equation and GIS: (Available online at http://citeseerx.ist.psu.edu/viewdoc/download?doi=10.1.1.124.9706\&rep=rep1\&type=pdf).

Kouli, M., Soupios, P., and Valliantos, F., 2009, Soil erosion prediction using the Revised Universal Soil Loss Equation (RUSLE) in a GIS framework, Chania, Northwestern Crete, Greece: Environmental Geology, v. 57, p. 483-497.

Kuenzi, A.J., and Morrison, M.L., 2003, Temporal patterns of bat activity in southern Arizona: The Journal of Wildlife Management, v.67, no.1, p. 52-64.

Kuntz, T.H., 2003, Censusing bats; challenges, solutions, and sampling biases, in O'Shea, T.J., and Bogan, M.A., eds., Monitoring trends in bat populations of the United States and territories; problems and prospects: U.S. Geological Survey, Information and Technology Report, USGS/BRD/ITR--2003-0003, 274 p.

Kuperman, B.I., Matey, V.E., Fisher, R.N., Ervin, E.L., Warburton, M.L., Bakhireva, L., and Lehman, C.A., 2004, Parasites of the African clawed frog, Xenopus laevis, in southern California, U.S.A: Comparative Parasitology, v.71, no.2, p. 229-232.

Kuss, F.R., 1986, A review of major factors influencing plant responses to recreation impacts: Environmental Management, v. 10, p. 637-650.

Lagacherie, P., and McBratney, A.B., 2007, Spatial soil information systems and spatial soil inference systems; perspectives for digital soil mapping, in Lagacherie, P., McBratney, A.B., and Voltz, M., eds., Digital soil mapping; an introductory perspective: Amsterdam, Elsevier, p. $3-22$.

Leys, J., McTainsh, G., and Shao, Y., 2001, Wind erosion monitoring and modeling techniques in Australia, in Scott, D.E., Mohtar, R.H., and Steinhardt, G.C., eds., Sustaining the global farm: Selected Papers from the 10th International Soil Conservation Organization Meeting held May 24-29, 1999, at Purdue University and the USDA-ARS National Soil Erosion 
Research Laboratory, $11 \mathrm{p}$.

Lovich, J.E., and Bainbridge, D., 1999, Anthropogenic degradation of the Southern California desert ecosystem and prospects for natural recovery and restoration: Environmental Management, v. 24, no. 3, p. 309-326.

Lovich, R.E., Ryan, M.J., Pessier, A.P., and Claypool, B., 2008, Infection with the fungus Batrachochytrium dendrobatidis in a non-native Lithobates berlandieri below sea level in the Coachella Valley, California, USA: Herpetological Review, v. 39, no. 3, p. 315-317.

Lowe, C.H., Wirt, E.B., and Rosen, P.C., 1995, Vegetation structure and diversity in Natural Communities Monitoring Protocol for the Ecological Monitoring Program in Organ Pipe Cactus National Monument, Arizona: University of Arizona, Department of Ecology and Evolutionary Biology, $61 \mathrm{p}$.

Luce, C. H. and Black, T. A., 2001, Spatial and temporal patterns in erosion from forest roads. Influence of Urban and Forest Land Uses on the Hydrologic-Geomorphic Responses of Watersheds. M.S. Wigmosta and S.J. Burges, Editors. American Geophysical Union, Washington, D.C., p. 165-178.

Mackenzie, D.I., and Royle, J.A., 2005, Designing occupancy studies; general advice and allocating survey effort: Journal of Applied Ecology, v. 42, p. 1,105-1,114.

Malusa, J., 2003, Vegetation of the Cabeza Prieta National Wildlife Refuge, Arizona: Report submitted to Organ Pipe Cactus National Monument, National Park Service, NPS Cooperative Agreement CA1248.00.002, Task Agreement UA2-71, 81 p. (Available online at http://sdrsnet.srnr.arizona.edu/data/sdrs/cabezablmveg/docs/final_cabeza.pdf).

Malusa, J., 2009, Vegetation mapping at the Barry M. Goldwater Range, Marine Corps Air Station, Arizona. Phase I, Mohawk Mountains and Dunes: Cooperative Agreement DACA8705-H-0018, Modification P00012, 2 p.

Malusa, J., Halvorson, W.L., and Angell, D., 2003, Distribution of the exotic mustard, Brassica tournefortii, in the Mohawk Dunes and Mountains, Arizona: Desert Plants, v. 19, p. 31-36.

McBratney, A.B., Santos, M.L.M., and Minasny, B., 2003, On digital soil mapping: Geoderma, v. 117, no. 1-2, p. 3-52.

McBratney, A.B., Minasny, B., and Rossel, R.V., 2006, Spectral soil analysis and inference systems; a powerful combination for solving the soil data crisis: Geoderma, v.136, p. 272-278.

Miles, R., and McTainsh, G.H., 1994, Wind erosion and land management in the mulga lands of Queensland: Journal of Soil and Water Conservation, v. 7, p. 41-45.

Mitasova, H., and Mitas, L, 1999, Erosion/deposition modeling with USPED using GIS: Online at http://skagit.meas.ncsu.edu/ helena/gmslab/erosion/usped.html.

Moore, I.D., Gessler, P.E., Nielsen, G.A., and Petersen, G.A., 1993, Terrain attributes; estimation methods and scale effects, in Jakeman, A.J., Beck, M.B., and McAleer, M., eds., Modelling change in environmental systems: London, Wiley, p. 189-214.

Nauman, T., 2009, Digital Soil Subgroup map of selected areas of the Barry M. Goldwater Range for Arizona Game and Fish:Unpublished Report, AZGF PO \#E0075088, 7 p.

National Agriculture Imagery Program (NAIP), 2009, Information sheet: http://www.fsa.usda.gov/Internet/FSA_File/naip_2009_info_final.pdf.

Nickling, W.G., and Gillies, J.A., 1993, Dust emission and transport in Mali, West Africa: Sedimentology, v. 40, p. 859-868. 
North American Weed Management Association, 2002, North American Invasive Plant mapping standard:. Accessed online January 2010 at http://www.nawma.org/.

Odeh, I.O.A., Crawford, M., and McBratney, A.B., 2007, Digital mapping of soil attributes for regional and catchment modelling, using ancillary covariates, statistical and geostatistical techniques, in Lagacherie, P., and McBratney, A.B., eds., Digital soil mapping; an introductory perspective: Amsterdam, Elsevier, p. 437-453.

O'Farrell, M.J., Miller, B.W., and Gannon, W.L., 1999, Qualitative identification of free-flying bats using the Anabat Detector: Journal of Mammalogy, v. 80, no. 1, p. 11-23.

Organ Pipe Cactus National Monument, 2006, Ecological Monitoring Program Report 19972005. Organ Pipe Cactus National Monument, Arizona, 25 p.

Pate, A., 2006, Bats, chap. 9 of Organ Pipe Cactus National Monument. Ecological Monitoring Program Report 1997- 2005: Organ Pipe Cactus National Monument, Arizona, p. 1-26 (Available online from http://www.nps.gov/orpi/naturescience/orpi-ecological-monitoringreport.htm).

Petryszyn, Y., and Russ, S., 1996, Nocturnal rodent population densities and distribution at Organ Pipe Cactus National Monument, Arizona: Tucson, University of Arizona, Cooperative National Park Resources Studies Unit, Technical Report No. 52, 52 p.

Pimentel, D., Lach, L., Zuniga, R., and Morrison, D., 1999, Environmental and economic costs of non-indigenous species in the United States: BioScience, v. 50, p. 53-65.

Powell, B.F., Flesch, A.D., Angell, D., Beaupre, K., and Halvorson, W.L., 2007, Landbird monitoring protocol for the Sonoran Desert Network, Version 1.02: Fort Collins, Colo., National Park Service, Natural Resource Report NPS/SODN/NRTR-2007/00X, http://science.nature.nps.gov/im/monitor/protocols/SODN_Landbird.pdf

Prose, D.V., and Wilshire, H.G., 2000, The lasting effects of tank maneuvers on desert soils and intershrub flora: U.S. Geological Survey Open File Report 00-512, 26 p.

Rejman, J., and Brodowski, R., 2005, Rill characteristics and sediment transport as a function of slope length during a storm event on loess soil: Earth Surface Processes and Landforms, v. 30, p. 231-239.

Renard, K., Foster, G., Weesies, G., McCool, D., and Yoder, D., 1997, Predicting soil erosion by water; a guide to conservation planning with the Revised Universal Soil Loss Equation (RUSLE): U.S. Department of Agriculture, Agricultural Handbook No. 703, 23 p. (Available online at http://www.techtransfer.osmre.gov/nttmainsite/Library/hbmanual/rusle/ah703toc.pdf).

Ritter, D.F., Kochel, R.C., and Miller, J.R., 2002, Process geomorphology (4th ed.): New York, McGraw-Hill, $652 \mathrm{p}$.

Robichaud, P.R., and Brown, R.E., 2003, Quick response small catchment monitoring techniques for comparing post-fire rehabilitation treatment effectiveness, in Proceedings of the First Interagency Conference on Research in the Watersheds, 27-30 October 2003, Benson, Ariz.: Tucson, USDA Agricultural Research Service, p. 663-667.

Robichaud, P.R., Wagenbrenner, J.W., Brown, R.E., Wohlgemuth, P.M., and Beyers, J.L., 2008, Evaluating the effectiveness of contour-felled log erosion barriers as a post-fire runoff and erosion mitigation treatment in the western United States: International Journal of Wildland Fire, v. 17, p. 255-273.

Rosenstock, S.S., O'Brien, C.S., Waddell, R.B., and Rabe, M.J., 2004, Studies of wildlife-water developments in southwestern Arizona; wildlife use, water quality, wildlife diseases, wildlife 
mortalities, and influences on native pollinators: Arizona Game and Fish Department Technical Guidance Bulletin 8, 17 p. (Available online fat http://www.azgfd.gov/pdfs/w_c/research/Res_Branch\%20Tech\%20Bulletin\%20No8.pdf).

Rutman, S., and Dickson, L., 2002, Management of buffelgrass on Organ Pipe Cactus National Monument, Arizona, in Tellman, B., ed., Invasive exotic species in the Sonoran Region: Tucson, The University of Arizona Press and the Arizona-Sonora Desert Museum, p. 311-318. Schmidt, C.A., Powell, B.F., Swann, D.E., and Halvorson, W.L., eds., 2006, Vascular plant and vertebrate inventory of Organ Pipe Cactus National Monument: U.S. Geological Survey OpenFile Report 2006-1076. (http://pubs.usgs.gov/of/2006/1076/).

Schoeneberger, P.J., Wysocki, D.A., Benham, E.C., and Broderson, W.D., eds. 2002, Field book for describing and sampling soils, Version 2.0: Natural Resources Conservation Service, National Soil Survey Center, Lincoln, Nebr.

Schreuder, H.T., Ernst, R., and Ramirez-Maldonado, H., 2004, Statistical techniques for sampling and monitoring natural resources: Fort Collins, Colo., U.S. Department of Agriculture, Forest Service, Rocky Mountain Research Station, General Technical Report RMRS-GTR-126, $111 \mathrm{p}$.

Scull, P., Franklin, J., Chadwick, O.A., and McArthur, D., 2003, Predictive soil mapping; a review: Progress in Physical Geography, v. 27, no. 2, p. 171-197.

Scull, P., Franklin, J., and Chadwick, O.A., 2005, The application of classification tree analysis to soil type prediction in a desert landscape: Ecological Modeling, v.181, no. 1, p. 1-15.

Seager, R., Ting, M.F., Held, I.M., Kushnir, Y., Lu, J., Vecchi, G., Huang, H.-P., Harnik, N., Leetmaa, A., Lau, N.-C., Li, C., Velez, J., and Naik, N., 2007, Model projections of an imminent transition to a more arid climate in southwestern North America: Science, v. 316. no. 5828 , p. $1,181-1,184$.

Shinneman, D.J., and Baker, W.L., 2009, Environmental and climatic variables as potential drivers of post-fire cover of cheatgrass (Bromus tectorum) in seeded and unseeded semi-arid ecosystems: International Journal of Wildland Fire, v. 18, p. 191-202.

Sogge, M.K., van Riper, C., III, and Drost, C., 1989, Design considerations for monitoring land birds in Channel Islands National Park: Transactions of the Western Section of the Wildlife Society, v. 25, p. 65-71.

Sprouse, T.W., Emanuel, R.M., and Strorrer, S.A., 2005, Water quality monitoring for highpriority water bodies in the Sonoran Desert network, in Gottfried, G.J., Gebow, B.S., Eskew, L.G., Edminster, and C.B., compilers, Connecting mountain islands and desert seas; biodiversity and management of the Madrean Archipelago II: Fort Collins, Colo., U.S. Department of Agriculture, Forest Service, Rocky Mountain Research Station, Proceedings RMRS-P-36, p. 219-222.

Stevens, D.L., and Olsen, A.R., 2004, Spatially balanced sampling of natural resources: Journal of the American Statistical Association, v. 99, p. 262-278.

Strahler, A.N., 1952, Hypsometric (area-altitude) analysis of erosional topology: Geological Society of America Bulletin v. 63, no. 11, p. 1,117-1,142.

Strahler, A.N., 1957, Quantitative analysis of watershed geomorphology: Transactions of the American Geophysical Union, v. 8, no. 6, p. 913-920.

Tarboton, D., 1997, A new method for the determination of flow directions and upslope areas in grid digital elevation models: Water Resources Research. v. 33, no. 2, p. 309-319. 
Tellman, B., ed., 2002, Invasive exotic species in the Sonoran Region: Tucson, University of Arizona Press and the Arizona-Sonora Desert Museum, $423 \mathrm{p}$.

Thomas, L., Laake, J. L., Strindberg, S., Marques, F. F. C., Buckland, S. T.. Borchers, D. L., Anderson, D. R., Burnham, K. P., Pollard S. L., Hedley, J. H., Bishop, J. R. B., and Marques, T.A., 2005, Distance 5.0. Release Beta 5. Research Unit for Wildlife Population Assessment, University of St. Andrews, Scotland. http://www.ruwpa.st-and.ac.uk/distance/.

Turner, D.S., Schwalbe, C.R., and Warren, P.L., 1997, Reptile and plant inventory of the Mohawk Dunes; inventory and monitoring of unique sand dune ecosystems, Barry M. Goldwater Air Force Range, Arizona: Legacy Resource Management Program, School of Renewable Natural Resources, University of Arizona and The Nature Conservancy, Arizona Chapter, Project \#95-1009, 46 p.

Turner, D.S., Felger, R.S., Mauz, K., Funicelli, C., Van Devender, T., and Malusa, J., 2000, Biological resources of the proposed Sonoran Desert National Monument, Arizona: Tucson, Drylands Institute, for the Sonoran Desert National Park Project, $87 \mathrm{p}$.

U.S. Department of Agriculture, Natural Resources Conservation Service, 2002. Wind erosion: National Agronomy Handbook Part 502, 3rd Edition, p. 23-125.

U.S. Department of Agriculture, Natural Resources Conservation Service, 2004, Soil survey laboratory methods manual: Soil Survey Investigations Report No. 42, Version 4.0, Rebecca Burt, ed., 735 p. (Available online at ftp://ftp-fc.sc.egov.usda.gov/NSSC/Lab_Methods_Manual/SSIR42_2004_view.pdf.).

U.S. Fish and Wildlife Service, 1990, Endangered and threatened wildlife and plants; determination of threatened status for the Mojave population of the desert tortoise: 55 Federal Register 12178, April 2, 1990.

U.S. Fish and Wildlife Service, 1994, Sonoran Pronghorn revised recovery plan: Albuquerque, New Mexico, U.S. Fish \& Wildlife Service, 40 p.

U.S. Geological Survey, 1998, Ditigal orthophoto quadrangles: U.S. Geological Survey Fact Sheet FS-129-95, 2 p.

U.S. Geological Survey, 2009 (variously dated, recent version 2009), National field manual for the collection of water-quality data: U.S. Geological Survey Techniques of Water-Resources Investigations, book 9, chaps. A1-A9, available online at http://pubs.water.usgs.gov/twri9A. van Riper, C., III, 1982, Censuses and breeding observations of the birds on Kohala Mountain, Hawaii: Wilson Bulletin, v. 94, no. 4, p. 463-476.

van Riper, C., III, Sogge, M.K., and Drost, C., 1988, Land bird monitoring handbook; Channel Islands National Park, California: National Park Service, U.S. Department of the Interior, 23 p., Append., 5 p.

Vos, P., Meelis, E., and Ter Keurs, W.J., 2000, A framework for the design of ecological monitoring programs as a tool for environmental and nature management: Environmental Monitoring and Assessment, v. 61, p. 317-344.

Wake, D.B., and Vredenburg, V.T., 2008, Are we in midst of the sixth mass extinction? A view from the world of amphibians: Proceedings of the National Academy of Sciences, v. 105, p. $11,466-11,473$.

Warburton, M., Kuperman, B., Matey, V., and Fisher, R.N., 2002, Parasite analysis of native and non-native fish in the Angeles National Forest, 2001 final report: Prepared for the U.S. Forest Service, Angeles National Forest, 14 p. 
Warren, P.L., Mortenson, B.K., Treadwell, B.D., Bowers, J.E., and Reichhardt, K.L., 1981, Vegetation of Organ Pipe Cactus National Monument: Tucson, University of Arizona, Cooperative National Park Resources Studies Unit, Technical Report No. 8, 80 p. (Available online from http://sdrsnet.srnr.arizona.edu/data/techreports/TECHRPT08.pdf.)

Warren, P.L., and Laurenzi, A.W., 1987, Rare Plant Survey of the Yuma District. Unpublished report prepared for U.S. Bureau of Land Management, Yuma, Arizona by The Nature Conservancy of Arizona, Tucson, $61 \mathrm{p}$.

Webb, N.P., and McGowan, H.A., 2009, Approaches to modeling land erodibility by wind: Progress in Physical Geography, v. 33, p. 587-613.

Webb, R.H., 2002, Recovery of severely compacted soils in the Mojave Desert, California, USA: Arid Land Research and Management, v.16, no. 3, p. 291-305.

Webb, R.H., Belnap, J., and Thomas, K.A., 2009, Natural recovery from severe disturbance in the Mojave Desert, in Webb, R.H., Fenstermaker, L.F., Heaton, J.S., Hughson, D.L., McDonald, E.V., and Miller, D.M., eds., The Mojave Desert; ecosystem processes and sustainability: Reno, University of Nevada Press, p. 343-377.

Wells, W.G., and Wohlgemuth, P.M., 1987, Sediment traps for measuring onslope surface sediment movement: Berkeley, Calif., U.S. Department of Agriculture, Forest Service, Pacific Southwest Forest and Range Experiment Station, Research Note PSW-393, 6 p.

Wiberg, P.L., and Smith, J.D., 1989, Model for calculating bedload transport of sediment: Journal of Hydraulic Engineering, v. 115, no. 1, p. 101-123.

Williams, B. K., Nichols, J. D., and Conroy, M.J., 2002, Analysis and management of animal populations: San Diego, CA, Academic Press.

Williams, B. K., Szaro, R. C., and Shapiro, C.D., 2009, Adaptive Management: The U.S. Department of the Interior Technical Guide. Adaptive Management Working Group, U.S. Department of the Interior, Washington, DC, $86 \mathrm{p}$.

Wilson, D.E., Cole, F.R., Nichols, J.D., Rudran, R., and Foster, M.S., 1996, Measuring and monitoring biological diversity; standard methods for mammals: Washington, D.C. and London, Smithsonian Institution Press, 406 p.

World Meteorological Organization, 1983, Guide to Meteorological Instruments and Methods of Observation: No. 8, 5th edition, Geneva Switzerland.

Yuma Proving Ground, Environmental Sciences Division, 2010, Environmental assessment impact areas expansion. http://www.yuma.army.mil/docs/IAExpansion_EA_Draft_FONSI_25Mar10.pdf.

Zobeck, T.M., Parker, N. C., Haskell, S., and Guoding, K., 2000 , Scaling up from field to region for wind erosion prediction using a field-scale wind erosion model and GIS: Agriculture, Ecosystems \& Environment, v. 82, p. 247-259 


\section{Appendix A. Vegetation Inventory and Mapping Protocol}

Vegetation field sampling and mapping follow the protocols established for the CPNWR and the BMGR-East. The CPNWR protocol is described in a report titled "Vegetation of the Cabeza Prieta National Wildlife Refuge, Arizona" (Malusa, 2003), and the BMGR-East protocol is described in a report titled "Vegetation of the North and South Tactical Ranges, Luke Air Force Base, Barry M. Goldwater Range, Arizona" (University of Arizona Office of Arid Lands, 2006). The following is a summary of the two protocols.

Each vegetation sampling site is designated by the first letters of the 7.5-minute quad sheet name and numbered sequentially (for example, the first sample from the Raven Butte quad would be RB-1). For each sample, record the (a) GPS location (Universal Transverse Mercator, WGS 1984), (b) environment description, and (c) vegetation description of perennial species. The vegetation description includes the mean height $(\mathrm{n}=10)$ of common species estimated to the nearest $10 \mathrm{~cm}$ and tree heights estimated to the nearest $0.5 \mathrm{~m}$. Classification of percent plant covers is summarized in table A.1. In addition, the perennial species with more than 1-percent cover are estimated using the "diameter" method (Malusa, 2003), similar to "nearest neighbor" estimates.

Table A.1. Percent cover system for vegetation mapping.

\begin{tabular}{ll}
\hline \multicolumn{1}{c}{ Class } & \multicolumn{1}{c}{ Percent cover } \\
\hline 0 & unknown \\
1 & $<1 \%$ \\
2 & $1-4 \%$ \\
3 & $5-9 \%$ \\
4 & $10-14 \%$ \\
5 & $15-25 \%$ \\
6 & $26-40 \%$ \\
7 & $41-60 \%$ \\
8 & $61-80 \%$ \\
9 & $81-100 \%$ \\
\hline
\end{tabular}

All data are entered into the database initiated by Malusa (2003) and currently (2011) available at http://sdrsnet.srnr.arizona.edu/index.php?page $=$ datamenu $\&$ lib $=2 \&$ sublib $=16$.

Representative photographs of perennial vegetation are taken at each sampling site, along with the GPS coordinates and photograph azimuth (compass heading). The photographs are stored with file names indexed to the sample site.

Vegetation types are classified to the association level where stand delineation is based on floristic, physiognomic, and habitat homogeneity. The classification includes a hierarchical delineation of vegetative physiognomic classes within the attributes of each feature class polygon. The project uses a standard 1:24,000-scale USGS topographic quadrangle with a minimum mapping unit of 1.0 hectare. Each stand is designated as a polygon feature in a GIS 
feature class. Stands less than 1.0 hectare are mapped as point or linear features when deemed biologically significant.

The boundaries between vegetation stands are identified using a combination of photointerpretation and field observations. GPS routes traveled during the study are recorded as a separate layer in the GIS database. The field crew also maps the locations of invasive plant species when possible. 


\section{Appendix B. Invasive Species Monitoring Protocol}

\section{Invasive Plant Mapping and Monitoring}

Comprehensive census-style surveys are not practical on the BMGR-West because it is so large. Instead, the I\&M plan targets areas considered to be common pathways for the spread of invasive plant species. Limiting the search to road, trail, and wash corridors allows managers to cover a considerably larger portion of the range and design a survey that can be reasonably and efficiently repeated over time. In addition to these usually linear pathways, disturbed areasfor example, sites of military operations, fire, undocumented alien (UDA) routes), or areas of high management value (for example, xeroriparian, dune habitat, and pronghorn habitat) - may also be considered for monitoring. The extent to which these can be included depends on available resources, access issues, and BMGR-West management priorities. However, it is suggested that monitoring of heavily impacted, newly disturbed areas be considered if only for an initial survey and one followup survey.

Surveys along roads can be conducted by vehicle, provided the surveyor has sufficient knowledge and experience to recognize target species from a short distance away. Depending on the type and size of trail corridors, trails could be surveyed by foot, on horseback, or with any motorized vehicle able to navigate the terrain. Washes may prove to be such extensive (long) pathways with access difficulties that it is not feasible to cover them in their entirety. Instead, it is suggested that surveys be conducted for a specified distance at locations where the wash crosses a road or trail, thus providing access to the area. The distance surveyed at each wash/road intersection can be determined by time and personnel constraints, but a minimum of $20 \mathrm{~m}$ in either direction is suggested.

Mapping can occur opportunistically, or a more rigorous sampling scheme can be implemented. The exact length of "transects" in opportunistic maps would vary from time to time, as would the distance of the survey extent from the pathway edge. The intended monitoring area in precise mapping can be subdivided into equal-length blocks with a predetermined width and assigned a unique identifier. Each block is then assessed for invasive species, and those found are described as they occur within each block. While this method requires more field effort and spatial data management, recording presence/absence by block allows reporting of infestations as a percent cover or frequency by species across all blocks sampled. If the proposed area to be monitored is too large to complete in a season, the area can be divided in a manner so that each area identified can be surveyed within the time allotted (season, year, or other). This allows managers to evaluate the data with statistical methods.

\section{Field Methods}

It is suggested that the data collected at least satisfy the minimum requirements proposed by the North American Weed Management Association (2002). Essential fields include:

- species name (scientific name is preferred)

- location in UTM coordinates or latitude and longitude

- extent, mapped polygon

- density (within polygon), using Daubenmire cover classes (Daubenmire, 1959):

- $<1 \%, 2-5 \%, 6-25 \%, 26-50 \%, 51-75 \%, 76-95 \%$, and $96-100 \%$.

- observation date and observer name. 
Additional metadata do not take much extra effort to collect and provide useful ancillary information. These may include aspect, topographic position, soil type, and distance to roads/trails. An example of a field data sheet is given at the end of this appendix. If used, electronic data-collection devices can be loaded with predefined templates to ensure that proper data standards are met.

Before the field season:

- Ensure that all observers are properly trained in identifying all target species in each of their different life stages. Note: Eradication treatment of species before the setting of seeds is preferable. Thus, including life stage as a data field may help prioritize management actions. We suggest using SODN's "Field Identification cards for invasive non-native species known to threaten AZ wildlands," as a field resource (http://www.southwestlearning.org/sites/default/files/products/ID_Cards_Glossary_Info.pdf).

- Purchase GPS or hand-held mapping devices equipped with mapping software.

- Develop appropriate data sheets or electronic data entry forms.

- Identify areas to be surveyed; prepare maps and schedules.

- Write detailed standard operating procedures for how to collect data and rules for contingency sampling.

Surveys:

- Record the survey start date and the total area surveyed for invasive plants. Include a notation if the surveyor was unable to complete the survey to the standard requirements. This allows managers to schedule followup efforts.

- Along each pathway (or pathway unit) identified, collect point or polygon data on each target species encountered. Points are collected when the infestation is a single plant or a patch of plants less than $5 \mathrm{~m}$ across $-5 \mathrm{~m}$ is currently (2011) the average accuracy of hand-held GPS devices. Points are recorded at the midpoint of the patch. Use notes or cover class fields to describe the patch density or number of plants.

- Polygons are used to describe patches greater than $5 \mathrm{~m}$ across. The observer walks around the outer limits of the patch with a GPS. Polygon data fields are identical to point features. It is possible to record multiple species per polygon and later split these polygons by species. The template includes repeat fields for species name and cover class.

- Multiple species are only recorded within the same polygon if the distribution of those species is a close match. This is often the case with delineated areas (for example, roadsides, old fields, or disturbed areas).

- Single plants seen within a patch of another exotic species (mapped as a polygon) are recorded as separate points.

- Assign only one species per point even if different species are present. This simplifies later data management.

- Use common sense to determine whether exact locations (points) are used (for example, a species that is highly invasive and requires management) or whether a rough polygon is sufficient to describe the total area affected (which may lower the estimated cover class). Specific management objectives are considered, as well as efficiencies of time and available funding. 


\section{Data Management}

It is suggested that each dataset be identified by the date of observation and the species observed and that the names of polygon files reflect attributes collected, either as one file that contains many species (for example, BMGR-W_20100422_exotics) or as multiple files that represent individual species locations (for example, BMGR-W_20100422_SIIR, BMGRW_2010_BRTO). Regardless of the method used, it is suggested that standards for file naming and data management be established and organized so that the observation date and species name are foremost in the data-management structure.

If management actions are implemented to treat invasive species, it is suggested that the geodatabase or attribute table of each species recorded be modified to reflect the treatment type and date of treatment. For ongoing and multiple treatment efforts, a geodatabase structure is ideal. This would facilitate ongoing updates and evaluation of treatment effects.

If photos have been included in data collection, it is suggested these be named to reflect the species identified, the date of observation, and the area in which the species was seen (for example, BMGR-W_PECI_20100103_Zone1a.jpeg). Naming conventions are flexible, but it is suggested that they be standardized and contain all relevant information for identification. 


\section{Invasive Species Monitoring}

Field Data Sheet:

Protocol version : 1.00

Datasheet Version: 1.00

Proofread by:

Copied by:

Entered by:

Verified by:

Transect Area/Number Code:

Example: Barry M. Goldwater Range West-Tinajas Altas-Site \#3 (BMGRW-TA-03)

Recorder(s):

Date:

Species:

Point ID $\quad$ and UTM: $\quad, \quad$ E, $\quad, \quad, \quad$ N (UTM, NAD 83, Zone 11 N)

Polygon ID $\quad$ and UTM: $\quad, \quad$ E, , , N

Estimated Polygon Extent: $\quad$ GIS Verified Polygon Extent (computed in lab):

Cover Class within Polygon: $\quad(<1 \%, 2-5 \%, 6-25 \%, 26-50 \%, 50-75 \%, 76-95 \%$ and $96-100 \%$. $)$

Photograph File Name(s)

Additional Information

\begin{tabular}{|l|l|l|l|}
\hline $\begin{array}{l}\text { Human } \\
\text { disturbance: } \mathrm{Y} / \mathrm{N}\end{array}$ & Roads: Y/N & Trails: Y/N & Natural Vegetation Type \\
\hline & & & \\
& & & \\
\hline
\end{tabular}

Notes and Sketches (continue on back): 


\section{Appendix C. Soil Inventory and Erosion Monitoring Protocol}

\section{Soil Map}

Because BMGR-West is a large, remote area with access constraints, conventional fieldbased soil survey methods would be difficult to implement. However, there are a large number of new methods that utilize digital mapping technologies and computer modeling algorithms to optimize the limited field data that could be realistically collected in the BMGR-West. These technologies use remotely sensed spectral data (for example, satellite imagery) and digital elevation models (DEM) as well as other spatial data available in geographic information systems (GIS) format to interpolate soil type across large areas from limited field observations through specialized sampling schemes (Lagacherie and McBratney, 2007; McBratney and others, 2006; McBratney and others, 2003; Odeh and others, 2007; Scull and others, 2005; Scull and others, 2003).

In 2009, Nauman Geospatial used a digital mapping approach to develop a predictive soil map of the entire BMGR using data from adjacent soil maps and GIS datasets to create a predictive extrapolation of soil types into the range (fig. 3.2). Datasets and the predictive map from that project could be utilized for BMGR-West mapping. The predictive map would enable creation of an optimized statistical sampling design to check the Nauman Geospatial pre-map classification accuracy or, if necessary, a new model could be created using the GIS dataset (satellite imagery and DEM). With validation and some correction, the original predictive map might serve as a suitable final soil survey. Nauman Geospatial has also been in contact with Phil Camp, Arizona State Soil Scientist with the Natural Resources Conservation Service (NRCS), and has oral agreement that any final soil map project can be reviewed by the NRCS for inclusion into the national Soil Service Geographic (SSURGO) database.

(http://soils.usda.gov/survey/geography/ssurgo/) dataset. The final products from these survey efforts would be 30-m-pixel raster soil class and property maps, as well as an aggregated 1:24,000 polygon soil class map that would serve as the SSURGO product.

Field work for validation and/or modeling would require at least 30 full soil profile descriptions backed by laboratory data supported by at least another 30 field descriptions. Thirty profile and field samples would ensure at least one soil profile per map unit and provide enough degrees of freedom in model validation statistics. Obtaining full descriptions would involve digging pits or taking auger samples to a depth of about $150 \mathrm{~cm}$ or bedrock, if it is shallower than that depth. Soil horizons can be described by standard methods and sampled for further laboratory work with methods comparable to National Soil Survey standards (U.S. Department of Agriculture, Natural Resources Conservation Service, 2004). It is suggested that handtexturing (David, 1999) and other field soil description methods (Schoeneberger, 2002) be used to describe soils without full laboratory work to help fill in spatial gaps between full description sites without the full cost of laboratory work.

\section{Erosion Potential Maps}

Water Erosion.-Digital erosion-potential modeling techniques can be used in GIS to help elucidate areas where water erosion issues are likely to occur. One of the more flexible erosion potential model approaches, the Unit Stream Power-based Erosion and Deposition, or USPED (Mitasova and Mitas, 1999) method, can be used to create an erosion-yield or erosion- 
potential index using a variety of data sources. Base data needed to do this include a DEM, Normalized Difference Vegetation Index (NDVI) or other vegetation cover parameter source data, and digital soil survey data.

USPED modifies the Revised Universal Soil Loss Equation, or RUSLE (Renard and others, 1997), to include two-dimensional topographical flow patterns. Soil erodibilities can be calculated from SSURGO equivalent or better soil survey data. Slope factors can be calculated according to the USPED model after filling sinks in a DEM and using Tarboton's (1997) "Deterministic Infinity" flow routing routine for flow accumulation to replace the slope-length erosion factor. For vegetation cover, a gridded Cover-Management Factor raster can be calculated from Landsat NDVI following Kouli and others, (2009). The final map from USPED can take several forms, depending on how much of the RUSLE equation is modeled. As outlined, an index is created that indicates where erosion or deposition in a system is likely to occur.

Wind Erosion.-Wind erosion potential can be modeled in GIS similarly to water erosion modeling. The Wind Erosion Equation (WEQ; U.S. Department of Agriculture, Natural Resources Conservation Service, 2002) and Revised Wind Equation (RWEQ; Fryrear and others, 2001) can be used as a framework to create a wind erosion index. Factors in these equations can be represented in a GIS and combined in an empirical form to create a relative prediction of wind erosion susceptibility. Imagery, soil survey data, and topographic data in a GIS will be used to represent the different equation factors required to generate a wind erosion potential map (Zobeck and others, 2000; Leys and others, 2001; Klik, 2000; Guo-ping and others, 2001).

Soil particle size data from the soil inventory, satellite imagery, and digital elevation models would be used in a GIS to create proxy variables for use in a wind erosion equation index. Raster layers representing all these variables would be plugged into either the wind erosion equation or into a process-based model depending on data availability (Leys and others, 2001; Zobeck and others, 2000; Webb and McGowan, 2009). NDVI would be used to represent the vegetation cover factor (Leys and others, 2001; Jabbar and others; 2006), and a topographical wetness index (Moore and others, 1993) would be used to highlight areas that hold soil moisture for greater periods of the year. A neighborhood terrain analysis used to model proximity to sheltered parts of mountains and hills would be created using a DEM to help determine local wind breaks. Imagery would be used to help identify other structures or vegetation that might help slow wind as well. These topographical data along with any barriers delineated from imagery would be used to calculate unsheltered wind distances for use in modeling (Klik, 2000). Climate data would be approximated from local climate stations and interpolated to the best extent possible. Results would yield predicted wind erosion rates that can be used at least as a relative index of wind erosion potential on a pixel-by-pixel basis (most likely 30 -m pixels).

\section{Hillslope Erosion Monitoring at Uplands Soil and Vegetation Plots}

The NPS-based protocol for soil-vegetation plots (Hubbard and others, 2009) proposed for the BMGR-West (Section 3.1.3) offers a unique opportunity to also measure co-located erosion rates. These data would prove valuable in the greater ecological context of vegetation and soil parameters collected at those sites. Since these plots would also have a greater statistical spatial inference, erosion parameters can be applied to that greater inference. Based on resources available, it is suggested that quantitative erosion rate data are collected at all vegetation plots or as large of a subset as possible. If a subset is selected, quantitative methods could be randomly applied to plots to maintain statistical inference with a greater weight placed on plots in areas with higher predicted erosion potential, or with field-observed erosion features. 
The NPS SODN protocol (Hubbard and others, 2009) includes some qualitative field observations to identify the presence of any signs of water erosion (features) at vegetation-soil plots. However, these data are only an estimate of rough percentage classes of commonly found water-erosion-related features (that is, sheeting, rills, gullies, pedestals, burrowing, terracettes, and tunneling). Lacking from the NPS SODN protocol are wind erosion features, including desert lag or pavement, blowout depressions or swales, dune or microdune drifts, or other wind erosion features. However, all these erosion-feature observations that are available to field scientist only offer information on the presence and rough trends of erosion processes and not a quantitative measure of erosion rates.

Of greater value would be more direct measures of actual erosion rates. Base-level pin surveys and sediment traps are the most common methods for erosion-rate monitoring. At the very least, it is suggested that rills, gullies, and obvious areas of sheet erosion be surveyed to estimate soil loss volumes. More effective would be implementation of sediment traps at plots, or at least a subset of plots, to the extent resources permit.

\section{Erosion Feature Survey}

Cross-section profiles along with areal-extent estimates of rills, gullies, and sheet erosion areas would provide a measure of the volume of soil lost in plots. This would involve a focus on measuring dimensions of active erosion features, which can be tedious and destructive to soil resources, if an area is highly eroded and exhibits many features. To keep survey measurements simple, a single measurement of approximate depth and width would be taken at every $2-\mathrm{m}$ length of any of these erosion features. The measurements would be integrated into volume calculations to give an estimate of soil loss (Bewket and Sterk, 2003; Rejman and Brodowski, 2005). Because it would not be known how long the feature has been forming, repeat measurements are needed to yield erosion rates. To begin incorporating more subtle measures of soil loss and wind erosion, it is suggested that wind-erosion features also be surveyed along with some randomly placed rebar or other surface elevation references for repeat base level measurements. All rills and rebar used would be diagrammed by analysts for reference during future measurements. The field crew may decide to not make measurements, if an area is unstable and performing the survey would cause further damage.

\section{Sediment Traps}

To get a more integrated idea of sediment movement in plots, small hillslope sediment traps would be monitored as well at selected sites. Simple field models for water erosion (Wells and Wohlgemuth, 1987) and wind erosion sediment traps (Fryrear, 1986; Leys and others, 2001) would be used in different arrangements. The water-sediment traps to be used are welded sheetmetal boxes with an apron for mounting on the slope surface. Dimensions are 30 by $10 \mathrm{~cm}$ in aperture with a 15-cm depth (Wells and Wohlgemuth, 1987). Design dimensions may be adjusted for field conditions if this proves too big or small for observed sediment collections. The advantage of these traps is the simple design, construction, and installation that allows for flexibility and low costs for the amount of data.

Data collected are recorded in units of mass per slope width. The sampling design allows statistical inference across the slope contour at the bottom of the plot to get an average (with error estimates) soil mass lost per unit slope width. From this, the bulk density of soil samples taken in the plot can be used to convert that measurement to a volumetric soil loss per unit width. Terrain analysis of a local DEM would be used to get an estimate of upslope flow-contributing 
area (Tarboton, 1997) to the plot to get an estimate of the area contributing sediment loss to the slope contour across the bottom of the plot. From this area a volumetric soil loss per area can be calculated. High-accuracy GPS points of the plot corners would be used in a GIS to direct the terrain analysis.

Plots selected for erosion-rate monitoring would be set with at least three water-sediment traps along the downslope boundary, with placement based on random distance selections. Additional traps would be set at any rills or gully outlets at the downhill line of the plot. A 1-m buffer on each side of plot vegetation transects would be excluded from possible water-sediment traps because of monitoring team disturbance at those locations. Larger gullies may require a custom larger trap or another specialized trap design used for small watershed outlets (Robichaud and others, 2008; Robichaud and Brown, 2003).

To measure wind erosion rates, three modern Fryrear field dust-sampler traps would be randomly placed in subplot areas, excluding a 1-m buffer on each side of the vegetation transects. These samplers consist of small triangular prism sheet-metal samplers mounted on a small tower. These traps collect windborne sediments mainly from local saltation and have been used for extensive monitoring over multiple-year time periods (Miles and McTainsh, 1994). After initial plot assessment and a period of monitoring, plots with higher wind erosion may require additional instrumentation to better assess sediment emission. Fryrear traps do not efficiently sample particles smaller than 40 microns, nor can they distinguish between point emission and particles carried by saltation from a distance. If plots are identified for more investigation, high-volume air samplers based on the 10-m tower design of Nickling and Gillies (1993) would be used to fully characterize plot wind-sediment emissions.

\section{Sampling Intervals and Reporting}

For all sediment-trap sampling described above, it is suggested that initial sampling be done at least biannually. Traps collect sediment and thus need to be emptied at each measurement. If the traps completely fill up, sediment will overflow or build up behind traps, introducing error into the measurement. Therefore, it is suggested that initially the sampling interval be relatively short until analysts know how often emptying of the traps is necessary. It is also suggested that local climate stations and storms be monitored because large precipitation events may accelerate trap filling. Climate data are also valuable for analysis of the erosion data, and, to the extent possible, coordination of climate and erosion monitoring sites would be valuable.

The best way to measure sediment caught in traps is to bring a portable battery-powered scale and measure the entire sample mass in the field. Following the field measurement, a subsample can be put into a sealed container to take back and dry in a laboratory, so that the mass can be corrected for soil moisture content. The other option is to remove all trapped sediment from the field for mass measurement in a laboratory. It is suggested that the method for measuring sediment be considered in monitoring plan logistics, as some of these methods would be difficult to implement in poorly accessible areas. Accessibility may need to be considered as part of sample weighing, as was done by Hubbard and others (2009).

It is suggested that erosion-feature surveys be done at the same frequency as vegetation plot evaluations. Plot and sediment-trap data would be integrated for each year, with a focus on trends and identifying areas of extreme erosion or degradation that might require management actions. 
Reporting would be done on an annual basis for all sites with sediment collection traps. Data from each site would be tabulated and summarized, and trends and spatial patterns observed in different areas and watersheds at BMGR-West would be discussed. 
This page intentionally left blank 


\section{Appendix D. Small Mammals and Nocturnal Rodents Monitoring Protocol}

\section{Live Traps and Materials}

We suggest the Sherman long $(7.6 \times 9.5 \times 30.5 \mathrm{~cm}$, model XLK) or extra large $(10.2 \times$ $11.4 \times 38 \mathrm{~cm}$, model XLF15) traps for relatively level conditions and small $(7.6 \times 8.9 \times 22.9 \mathrm{~cm}$, model LFA) traps for rocky areas (http://www.shermantraps.com/). Forty-nine traps are required for a $7 \times 7$ monitoring grid. For additional monitoring equipment see table D.1.

\section{Procedures for Grid and Trap Setup}

Establish a grid of $7 \times 7$ Sherman traps spaced at 15 -m intervals $(90 \times 90$-m total grid area). After identifying and navigating to the locations for live trap grids, place rebar stakes at the grid corners. It is suggested that the grid be laid using a 100-m tape to follow site topography, with transects running upslope and cross transects running along the contours.

Trapping during weather extremes increases metabolic stress on animals, increasing their risk of mortality, and it is suggested that traps always be checked first thing in the morning before temperatures begin to rise to extreme levels. Traps are covered with corrugated plastic shade covers of a light color to regulate temperatures within traps and to reduce maximum temperatures that might harm captured animals. Polyester batting (for example, Dacron ${ }^{\mathrm{TM}}$ ) is placed in traps ( $\sim 2$-in. diameter ball at back of trap) to provide warmth in locations where temperatures are likely to drop near or below freezing.

Sherman traps are baited with a mixture of rolled oats and mixed bird seed containing sunflower seeds and millet. Mix one gallon of rolled oats to one gallon of mixed bird seed. It is important to use consistent types of bait and percentages of each type over time. To properly place bait in a Sherman trap, sprinkle a small handful of oats and seed on the front and inside the back of the trap. It is suggested that traps be baited around dusk.

\section{Data Collection, Handling and Weighing Mammals}

Morning trap checks are completed first thing in the morning before temperatures rise and potentially stress the trapped animal. Each day, record the status of each trap ("OK" or "closed" and "bait missing," "bait OK," or "capture"). Traps are closed after checking them in the morning and reset each evening. This design will result in 98 trap nights ( 2 nights $\times 49$ traps) per grid.

To remove a trapped mammal, place a zip-lock or cloth bag over the opening of the trap and tilt the trap so that the opening is upward until the mammal crawls up and out into the bag. Twist the end of the bag, and using a scale, weigh the bag and the sample. Weigh the bag before inserting anything into the bag. This will ensure a proper weight, in case dirt, excrement, or foreign materials are introduced to the bag. Captured animals are identified to species, sex, age (as juveniles, subadults or adults), examined for breeding status (for example, pregnant, lactating, enlarged testes, or nonbreeding), marked with a black permanent marker on the animal's ventral surface, weighed, and released (no markings are necessary on the second morning). 
Field data sheet:

Trapping Session (1 or 2)

Date

Plot (11, 12, E3, E4, 8, 14)

Trap Station (letter and number)

Time

Species

Weight (in grams)

Sex (determined by size of genitals and their distance from anus, and presence of mammary glands)

Age Class (Based on pelage color; divide into juveniles, sub-adults, and adults)

Reproductive Condition (Females: 0 = non-breeding no swelling, 1 = Genitals slightly swollen, 2 = Pronounced swelling in genitals).

Also record whether female is lactating (mammary glands not swollen $=0$, slightly swollen $=1$, swollen $=2$ ) $($ Males: $0=$ non-

breeding, 1 = testes slightly descended, 2 = testes fully descended).

Capture Code

$$
\begin{array}{ll}
\mathbf{C}= & \text { Trap Closed, nothing in it. } \\
\mathbf{N}= & \begin{array}{l}
\text { New Capture (record this if animal has no mark from previous } \\
\text { trap day) }
\end{array} \\
\mathbf{R}= & \text { Recapture (if animal already has an ear tag) } .
\end{array}
$$

Measurements (Measure body and tail sizes in $\mathbf{m m}$ while the animal is in the bag)

Tail length

Body length

Right Hind Foot

Right Ear

Weather (see bat protocol)

Notes (Anything important not listed above, general observations, and other information)

It is suggested that all traps be cleaned and disinfected after two days of sampling. Empty traps of all bait, organic material, and polyester batting and place the traps into a mild bleach/water (Centers for Disease Control recommends 3 Tablespoons/1 gal) solution or 5percent Lysol solution for approximately 10 minutes. 
Table D.1. Small mammals and nocturnal rodents monitoring equipment list.

\begin{tabular}{lll}
\hline \multicolumn{1}{c}{ Item } & \multicolumn{2}{c}{ Number } \\
\hline Latex or vinyl gloves & 10 & To handle animals \\
Plastic zip lock bags and cloth bags & & Pillow cases will work for bags \\
Pesola Weight scales & 3 & $60 \mathrm{~g}, 100 \mathrm{~g}$, and a 300-g scale \\
Bag of oats and sterile bird seed & 1 & \\
Data sheets and mechanical pencils & Many & \\
Sharpie (for marking captured animals) & 5 & For measuring body length \\
Small and large ruler & 2 & One for each trap \\
Polyester batting & 49 & One for each trap \\
Cut corrugated plastic & 49 & \\
Compass & 1 & \\
100-m tapes & 3 & \\
Soap, water, and hand sanitizer & 1 container of each & \\
\hline
\end{tabular}


This page intentionally left blank 


\section{Appendix E. Bat Guild Monitoring Protocol}

\section{Procedures for Mist Netting}

It is suggested that nets be in place at sunset and that monitoring occur from sunset to 4.5 hours after sunset. To minimize the capture of any birds, keep the nets closed until just before dark. Usually, it is obvious when birds such as doves, thrashers, swallows, and others stop flying for the evening.

Nets are set across the middle of small pools, if at all practical. For larger pools, a net is set up at the lip of one edge of the pool.

It is much easier to set up nets with two people. One person can hold the pole and net, while the other places the panel end-loops over the pole and anchors the pole with cord. The cord may be tied to any nearby object stout enough to hold both the pole and net or tied to stakes driven into the ground for that purpose. See table E.1 for the monitoring equipment list.

When anchoring the poles that hold the net, it is suggested that the top three panel endloops be placed above the anchor cord and the bottom two loops below the anchor cord. Occasionally, the terrain may warrant more net area below the anchor cord (such as across a small ravine, where the poles are on slopes). Under these conditions, three panel end-loops are placed below the anchor cord.

It is suggested that the net be spread taut enough so that a $2.5-\mathrm{cm}$ (1-in.) bag droop occurs in each of the panels. The net itself is stretched tight. As the evening progresses, the rise in humidity will cause the net to droop, so periodic adjustments are made to keep the net taut.

It is suggested that the nets be placed less than $30.5 \mathrm{~m}$ (100 ft) apart. Any greater distance makes it cumbersome to check nets, and time is lost traveling between them.

Nets are checked every 5 min., because bats are capable of swiftly chewing holes in nets. If the nets are left unattended, they may become riddled with holes in a short time.

Nets are maintained until midnight, at which time they are closed. Much of the bat activity at water sources occurs in the first half of the night. Maintaining nets until midnight provides an adequate representation of bat use.

To close a net, push all the panel end-loops together at the anchor cord on the pole. Take a 30.5-cm (12-in.) piece of plastic flagging and tie the end-loops together at each end of the net, using a single knot, but do not include the anchor cord. One end of the net can then be taken off the pole and folded toward the other end. When the net is completely folded, place the tied endloops together and stuff the net into a bag for safe keeping.

For best netting results, it is advisable to consider the following:

1. Sample water sources at different locations; however, whether the water source is small, large, in the open, secluded, or so forth, it is suggested that the same water source be monitored from year to year.

2. Monitor the sites during the latter part of May or in June. This is the driest time of the year with the chance of storms almost nonexistent. In May and June it is warm enough for insects to be active, and therefore bats should be active as well. Also, because the number of available water sources is limited at this time of year, bats are usually more concentrated.

3. Net during moonless nights. Bats possess good eyesight and they are capable of seeing a moonlit net. 


\section{Capturing and Handling Bats}

Capture and handling of bats requires full concentration and attention. Bats can chew holes in the net if left unattended for any length of time, and they can easily become entangled. In the intervals between checking the nets, bat extraction, and data collection, flashlights are off and talking is kept to a minimum. This helps both to maintain concentration and to avoid scaring off the bats.

When a bat is caught in the net, quickly move to extract it before it can escape or become further entangled. Determine from which side of the net the bat entered. Immobilize the bat with a gloved hand (or give the bat a gloved finger to chew on for distraction) and carefully remove the net strands from head, body, and wings. Be especially careful with the fragile wing membrane and bones.

Place the bat in a cloth bag if it cannot be processed right away.

For best sampling results, it is advisable to consider the following: Do not mark the bats. It can safely be assumed that each bat captured in a net during any given night will not be recaptured in that same net during that same night. Past experience with hundreds of marked bats has proven that only a fraction of a percent are ever recaptured the same night. Nonetheless, if there is a desire to mark bats in order to periodically check the probability of recaptures during the same night, a spot of "white-out" applied to the back of the bat's head works well as a temporary mark. The "white-out" is nontoxic and wears off after several days.

\section{Data Collection and Measurements}

All data are entered into the database after completion of monitoring. Therefore, a data sheet must be completed for each trapping event at each location. The sample data sheet may be modified; however, certain information is necessary to ensure that critical data are collected.

Example of field data sheet information:

1. Location. This is the name of the water source or flyway. Include drainage, wash, or canyon name, GPS coordinates, and elevation.

2. Date. Indicate the day, month, and year that netting occurred.

3. Weather conditions:

a. Daily maximum and minimum air temperatures in ${ }^{\circ} \mathrm{C}$, measured $2 \mathrm{~m}$ above ground, is standard

b. Air termperatures in ${ }^{\circ} \mathrm{C}$ at the start of data collection (when nets are opened) and at the end of data collection (when nets are closed)

c. Cloud cover: $0-25 \%, 26-50 \%, 51-75 \%$, or $\geq 76 \%$

d. Precipitation in last 24 hours: Yes or No, with comments.

e. Wind speed and direction: Use anemometers, in Beaufort scale.

f. Relative humidity: Use sling psychrometer or hand-held thermohygrometer (\%).

g. Barometric pressure: Use hand-held or automatic barometer (in HG).

h. Time of sunset: From nearest newspaper, with field check, including time zone.

4. Moon. Indicate the phase of the moon, duration of moon shine while netting, and when moonrise or moonset occurred.

5. Time. Record the capture time for each bat in the net. Occasionally, the capture time may be approximated when several bats are being removed from the net at the same time.

6. Species. Record the species of each bat captured. To speed up the process, a four-letter acronym using the first two letters of the genus and species may be used, for example, PIHE, MYCA, and others (see table E.2 for species codes). 
7. Sex. Use the symbols $\widehat{\sigma}$ for male and $q$ for female

8. Forearm. Record forearm length (right or left, length is undifferentiated). Record the measurement in millimeters; however, do not include a "mm" suffix - this measurement is understood to be in millimeters. Not all bats need to be measured; only those for which this measurement may aid in identification. Those species for which forearm measurement may be helpful in identification are members of the genera Myotis, Eumops, and Nyctinomops.

9. Ear. Record ear length (right or left, length is undifferentiated). Record the measurement in millimeters. However, do not include a "mm" suffix - this measurement is understood to be in millimeters. Not all bats need to be measured; only with some Myotis is ear size helpful in identification.

10. Weight. If possible, it is suggested that each bat be weighed. The bat may be placed in a plastic zip-lock storage bag and weighed on a scale (a Pesola scale suggested). Be certain to deduct the weight of the bag from the total weight when determining the weight of the bat. The use of a $50-\mathrm{g}(1.75-\mathrm{oz})$ capacity scale would be preferred for all species except for members of the genus Eumops, which may require the use of a 100-g (3.5-oz) capacity scale. The brief span of confinement in the storage bag during weighing is not detrimental to the bat.

11. Individual notes. Indicate breeding status (for females: pregnant, lactating, postlactating, nonparous; for males: testes descended [TD]); whether adult or juvenile; presence of ectoparasites; any anatomical damage (for example, hole in wing and so forth) for individual samples.

12. Time net opened/time net closed. Record the time when the net was opened as well as when it was closed.

13. Collective notes. Record comments and other remarks regarding overall observations.

\section{Procedures for Roost Monitoring}

It is important for observers to be thoroughly familiar with the operation of monitoring instruments (binoculars, night vision scopes, video cameras, ultrasonic detectors, and others) and understand their detection limits.

Monitoring Techniques: Nightly emergence counts made as bats depart from day roosts (caves, mines, buildings, tree cavities) are an effective way to estimate the number of bats without disturbing them. Counts are made at predetermined intervals in order to assess intracolony variation in numbers of bats present and/or to determine seasonal variation. In warm weather, it is suggested that roosts be monitored beginning at sunset, until 2.5 hours after sunset. Nightly emergence counts are most effective when departing bats are silhouetted against a clear sky, and there are several observers occupying different vantage points. The following measurements are made at each roost (per data sheet):

1. Site name and coordinates

2. Names of observers

3. Date. Indicate the day, month, and year that roost monitoring occurred.

4. Times of: sunset; beginning and ending times of survey; first bat sighted in area; first bat exiting roost; greatest emergence (usually a range of time)

5. Number of entrances observed; number of entrances suspected.

6. Observation technique: Ambient light; red light; night vision; and others 
7. Bat detector use; Frequency setting; and other information

8. Number of bats: visually counted; passed on detector; estimated from emergence duration; and other information

Table E.1. Bat guild monitoring equipment list.

\begin{tabular}{|c|c|c|c|}
\hline \multicolumn{2}{|c|}{ Technique } & \multirow[b]{2}{*}{ Item } & \multirow[b]{2}{*}{ Comments } \\
\hline Mist net & Roost & & \\
\hline $\mathrm{X}$ & & Mist nets & $18,30,60$ and $120 \mathrm{ft}$ (two $60-\mathrm{ft}$ nets tied together). \\
\hline $\mathrm{X}$ & & Poles & $\begin{array}{l}\text { Two } 5 \text {-ft segments joined by a sleeve are needed at each end of the } \\
\text { net. }\end{array}$ \\
\hline $\mathrm{X}$ & & Anchor cord for poles & \\
\hline $\mathrm{X}$ & & Tent Stakes & \\
\hline $\mathrm{X}$ & & Millimeter ruler & Flexible plastic, $150 \mathrm{~mm}$ (6 in.) is sufficient. \\
\hline $\mathrm{X}$ & & Scales (2) & $100 \mathrm{~g}(3.5 \mathrm{oz})$ (Pesola suggested). \\
\hline $\mathrm{X}$ & & Zip-lock storage bags & $\begin{array}{l}\text { For containing bats while weighing. Quart capacity will suffice for } \\
\text { most bats. }\end{array}$ \\
\hline $\mathrm{X}$ & & Cloth bags & $\begin{array}{l}\text { For holding bats after removing from net. Should have string or } \\
\text { cloth ties. }\end{array}$ \\
\hline $\mathrm{X}$ & $\mathrm{X}$ & Headlamp & Extra batteries and red filters \\
\hline & $\mathrm{X}$ & $\begin{array}{l}\text { Light gathering } \\
\text { binoculars }\end{array}$ & \\
\hline & $\mathrm{X}$ & Night vision goggles & \\
\hline & $\mathrm{X}$ & Bat detector & \\
\hline & $\mathrm{X}$ & White sheet & For backdrop \\
\hline $\mathrm{X}$ & $\mathrm{X}$ & Leather gloves & Lightweight, deerskin preferred \\
\hline $\mathrm{X}$ & $\mathrm{X}$ & Watch & To note the time of capture \\
\hline $\mathrm{X}$ & $\mathrm{X}$ & Clipboard & For holding data forms \\
\hline $\mathrm{X}$ & $\mathrm{X}$ & Data forms & \\
\hline $\mathrm{X}$ & $\mathrm{X}$ & White-out & For marking bats \\
\hline $\mathrm{X}$ & $\mathrm{X}$ & Pencils & \\
\hline $\mathrm{X}$ & $\mathrm{X}$ & Reference Books & Hoffmeister, 1986; Hall, 1981 \\
\hline $\mathrm{X}$ & $\mathrm{X}$ & Digital Camera & Camera with flash \\
\hline $\mathrm{X}$ & $\mathrm{X}$ & Sling psychrometer & \\
\hline $\mathrm{X}$ & $\mathrm{X}$ & Thermometer & \\
\hline $\mathrm{X}$ & $\mathrm{X}$ & Barometer & \\
\hline $\mathrm{X}$ & $\mathrm{X}$ & Anemometer & \\
\hline
\end{tabular}


Table E.2. Bat species codes.

\begin{tabular}{|c|c|c|}
\hline Common name & Scientific name & CODE \\
\hline Allen's Big-eared Bat & Idionycteris phyllotis & IDPH \\
\hline Big Brown Bat & Eptesicus fuscus & EPFU \\
\hline Big Free-tailed Bat & Nyctinomops macrotis & NYMA \\
\hline Brazilian Free-tailed Bat & Tadarida brasiliensis & TABR \\
\hline California Leaf-nosed Bat & Macrotus californicus & MACA \\
\hline California Myotis & Myotis californicus & MYCA \\
\hline Cave Myotis & Myotis velifer & MYVE \\
\hline Fringed Myotis & Myotis thysanodes & MYTH \\
\hline Ghost Faced Bat & Mormoops megalophylla & MOME \\
\hline Hoary Bat & Lasiurus cinereus & LACI \\
\hline Lesser Long-nosed Bat & Leptonycteris curasoae & LECU \\
\hline Little brown Myotis & Myotis occultus & MYOC \\
\hline Long-eared Myotis & Myotis evotis & MYEV \\
\hline Long-legged Myotis & Myotis volans & MYVO \\
\hline Mexican Long-tongued Bat & Choeronycteris Mexicana & CHME \\
\hline Pallid Bat & Antrozous pallidus & ANPA \\
\hline Pocketed Free-tailed Bat & Nyctinomops femorosaccus & NYFE \\
\hline Silver-haired Bat & Lasionycteris noctivagans & LANO \\
\hline Southern Yellow Bat & Lasiurus ega & LAEG \\
\hline Southwestern Myotis & Myotis auriculus & MYAU \\
\hline Spotted Bat & Euderma maculatum & EUMA \\
\hline Townsend's Big-eared Bat & Corynorhinus townsendii & COTO \\
\hline Underwood's Mastiff Bat & Eumops underwoodi & EUUN \\
\hline Western Mastiff Bat & Eumops perotis & EUPE \\
\hline Western Pipistrelle & Pipistrellus Hesperus & PIHE \\
\hline Western Red Bat & Lasiurus blossevillii & LABL \\
\hline
\end{tabular}


This page intentionally left blank 


\section{Bat Guild Monitoring}

Field Data Sheet:

Protocol version : 1.00

Location Name:

Date

Personnel

(Sketch on back?

) Net hours

Netting conditions*

\# of nets

Barometric

Humidity

Proofread by:

Copied by:

Entered by:

Verified by:

\section{Location Coordinates:}

Moon phase

Time net opened

Time net closed

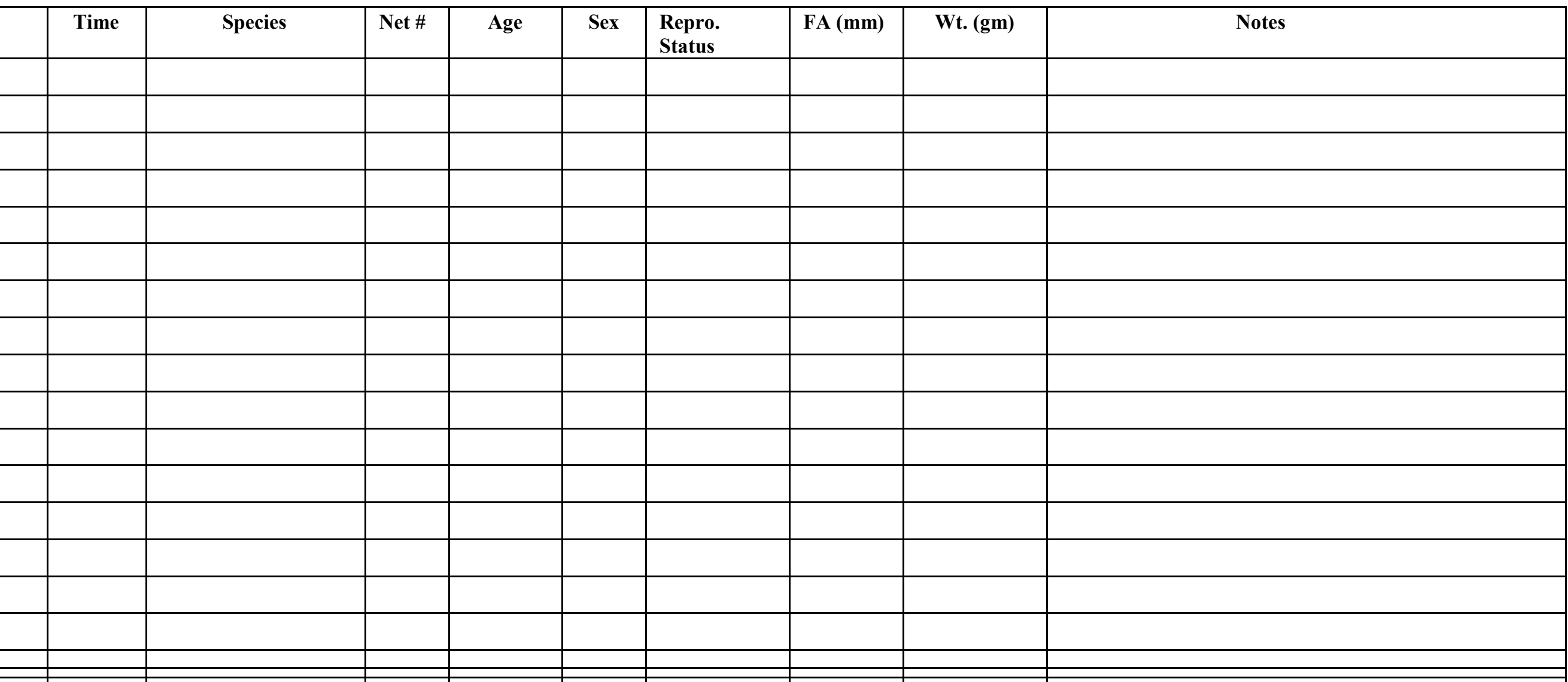

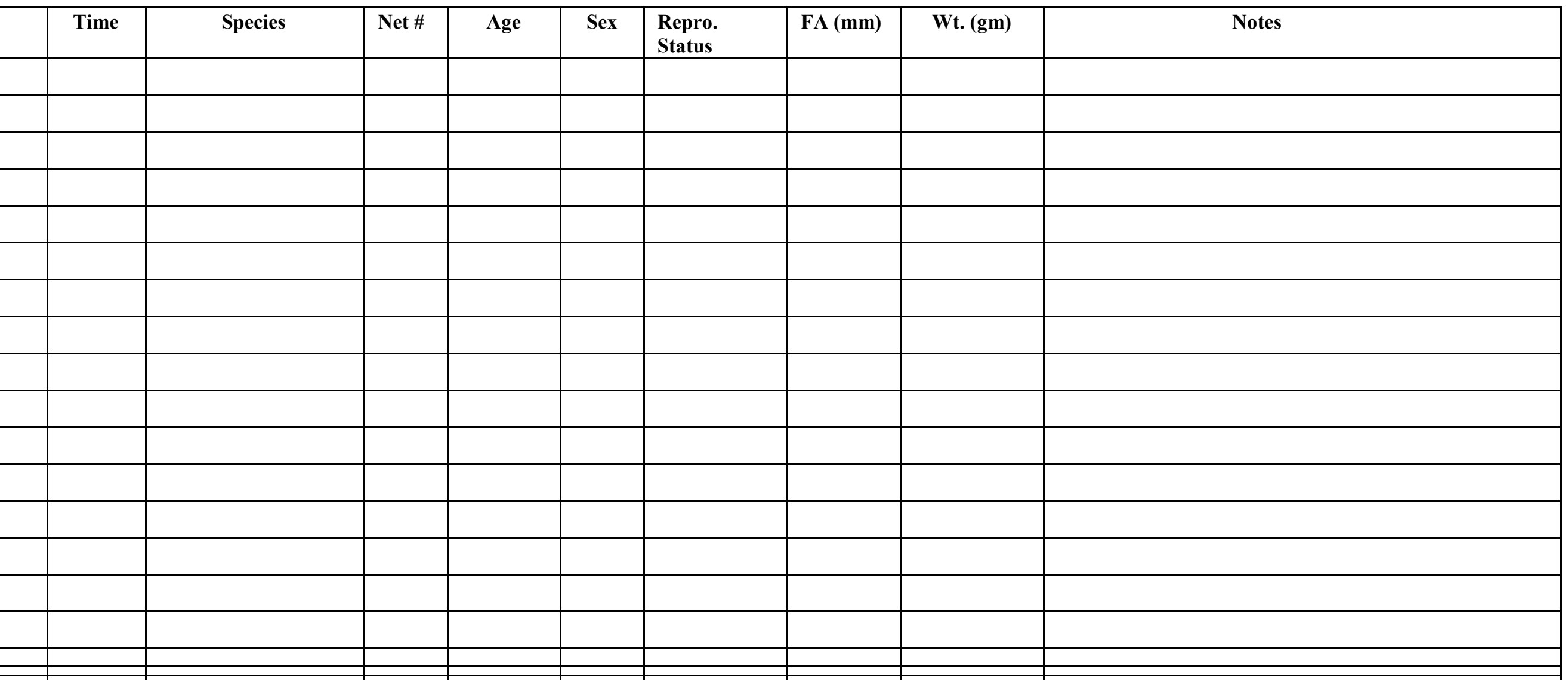

* Excellent $=$ no adverse conditions (wind, rain, moon), Good $=1$ adverse condition for less than $25 \%$ of net time, Fair $=1$ or more adverse conditions less than $50 \%$ of net time, Poor $=1$ or more adverse conditions more than $50 \%$ of net time 
Additional Notes: 


\section{Appendix F. Visitor Use Monitoring Protocol}

\section{Campsite Condition Assessment}

First consider the condition class of the site and record-pertinent data on the Campsite Inventory form. Where there is little perennial vegetation, use the size of the central area that has experienced long-term flattening of the soil surface to differentiate between class 2 and class 3 . In ecosystem types with a poorly developed organic soil horizon, use the level of soil compaction to differentiate between class 3 and class 4 campsites.

- Class 1: The recreation site is barely recognizable. There is only a slight loss of vegetation and minimal disturbance of soil.

- Class 2: Soil surface flattened (for the long term) around fireplace or center of activity.

- Class 3: Soil surface flattened (for the long term) on most of the site, but exposed soil not highly compacted except in a few areas.

- Class 4: Mineral soil exposed and highly compacted (to a cement-like state) over most of the campsite.

- Class 5: Soil erosion is obvious. Plant roots are exposed because of severe erosion of the campsite.

Record any additional information on the data sheet, including the amount of litter (trash), human waste, invasive plants, user-developed trails and user-created structures.

\section{GPS Mapping of Disturbed Areas at Campsites}

It is suggested that the location of the disturbed area of Condition Class 2-5 sites be recorded with a GPS unit and that the extent of the disturbed area be mapped as a polygon. Such mapping may be achieved by using the GPS tracking function or with a handheld GPS/GIS unit (for example, Trimble Recon Handheld (http://www.trimble.com/recon_mgis_handheld.shtml) in conjunction with ESRI ArcPad (http://www.esri.com/software/arcgis/arcpad/index.html)).

Using the GPS in GIS mode, map a polygon of the campsite area and define the extent of the disturbed area by evidence of foot trampling and tire tracks. Signs of disturbed vegetation (damaged woody shrubs and trees used for firewood) are recorded by marking the location of the disturbed specimen with a GPS point. Note the type and amount of damage on the data sheet.

\section{Site Photography}

If possible, campsite photography is conducted near midday, reducing the effects of morning and evening shadows. After photographing a site, check all photographs to make sure they are clearly focused, and

1. Determine the location of the estimated center point of the campsite using a GPS.

2. Standing at the center position, consult a compass and photograph the campsite in both the cardinal and intercardinal directions (N-NE-E-SE-S-SW-W-NW), starting the first photo in the North. For each photograph, focus the center of the camera viewfinder an estimated $20 \mathrm{ft}$ from the site center.

3. Repeat step 2 with another 8 photographs focused at $5 \mathrm{ft}$ from the site center.

Write on the datasheet the campsite ID, UTM coordinates (campsite center) and all image file IDs and photograph directions. 
Campsite Inventory Form

Field Data Sheet:

Protocol version : 1.00

Datasheet Version: 1.00

Proofread by:

Copied by:

Entered by:

Verified by:

Campsite Number:

Example: Barry M. Goldwater Range West-Tinajas Altas-Site \#3

Campsite Number: BMGRW-TA-03

Recorder(s):

Date:

Condition Class Rating (1-5)

Site Center GPS Coordinates: UTM: $\quad, \quad$ E, $\quad, \quad \quad, \quad$ N (UTM, NAD 83, Zone 11 N)

General Site Description:

Photograph File Name(s) 20 m (N-NE-E-SE-S-SW-W-NW)

Photograph File Name(s) 5 m (N-NE-E-SE-S-SW-W-NW)

Additional Information

\begin{tabular}{|l|l|l|l|l|}
\hline $\begin{array}{l}\text { Litter: None, } \\
\text { Some, } \\
\text { Abundant }\end{array}$ & $\begin{array}{l}\text { Human Waste: } \\
\text { None, Some, } \\
\text { Abundant }\end{array}$ & $\begin{array}{l}\text { Invasive } \\
\text { Plants (spp): }\end{array}$ & $\begin{array}{l}\text { User } \\
\text { Developed } \\
\text { Trails: Y/N }\end{array}$ & $\begin{array}{l}\text { User Created Structures } \\
\text { (list type and number) }\end{array}$ \\
\hline & & & & \\
\hline
\end{tabular}

Notes and Sketches (continue on back) 


\section{Appendix G. BMGR-West Workshop Participants, Followup Survey, and Survey Results}

\begin{tabular}{|c|c|c|c|}
\hline $\begin{array}{c}\text { Workshop participant } \\
\text { name }\end{array}$ & Email & Phone & Affiliation \\
\hline John Arnett & John.Arnett@luke.af.mil & $623-856-8491$ & LAFB \\
\hline Scott Blackman & sblackman@AZGFD.gov & $520-742-1911$ & AZGFD \\
\hline Daniel Garcia & Daniel.Garcia@luke.af.mil & $623-856-4265$ & LAFB/BMGR-East \\
\hline Evan Gwilliam & evan_gwilliam@nps.gov & $520-403-3055$ & NPS \\
\hline Edwin Juarez & EJuarez@AZGFD.gov & $602-789-3516$ & AZGFD \\
\hline Jim Malusa & jimmalusa@hotmail.com & $520-621-6424$ & UA \\
\hline Paul Merkley & paul.merkley@dhs.gov & $928-341-6513$ & DHS \\
\hline Valerie Morrill & valerie.morrill@us.army.mil & $928-328-2244$ & unaffiliated \\
\hline Lin Piest & Ipiest@AZGFD.gov & $928-341-4049$ & AZGFD \\
\hline Brian Powell & brian.powell@pima.gov & $520-740-6440$ & Pima County Planning \\
\hline Helen Raichle & hraichle@usgs.gov & $520-626-5529$ & USGS \\
\hline Robert Webb & rhwebb@usgs.gov & $520-670-6671 \times 238$ & USGS \\
\hline Richard Whittle & Richard.Whittle@luke.af.mil & $623-856-9476$ & LAFB \\
\hline Sam Drake & sdrake@nexus.srnr.arizona.edu & $520-621-4501$ & UA/OALS/ARSC \\
\hline Charles Drost & charles_drost@usgs.gov & $928-556-7187$ & USGS \\
\hline Jeff Fehmi & jfehmi@email.arizona.edu & $520-621-7268$ & UA-SNRE \\
\hline Brad Hollingsworth & bhollingsworth@sdnhm.org & $619-255-0277$ & SDNHM \\
\hline Bill Knowles & bknowles@AZGFD.gov & $928-341-4047$ & AZGFD \\
\hline Kim Lovich & KLovich@sandiegozoo.org & $619-685-3209$ & San Diego Zoo \\
\hline Rob Lovich & robert.lovich@navy.mil & $619-889-7587$ & Navy \\
\hline Robert Mesta & robert_mesta@fws.gov & $520-882-0047$ & USFWS \\
\hline Pam Nagler & pnagler@usgs.gov & $520-975-3814$ & USGS \\
\hline Larry Norris & Inorris@ag.arizona.edu & $520-621-7998$ & UA \\
\hline Rob Palmer & robert.I.palmer@navy.mil & $619-532-1817$ & Navy \\
\hline Ron Pearce & ronald.pearce@usmc.mil & $928-269-3404$ & MCAS-Yuma \\
\hline Cecil Schwalbe & cschwalbe@usgs.gov & $520-621-5508$ & USGS \\
\hline Sid Slone & Sid_Slone@fws.gov & $520-387-4993$ & USFWS \\
\hline Charles van Riper & charles_van_riper@usgs.gov & $520-626-7027$ & USGS \\
\hline Miguel Villarreal & miguelluisvillarreal@gmail.com & $520-626-9156$ & USGS \\
\hline Cynthia Wallace & cwallace@usgs.gov & $520-670-5589$ & USGS \\
\hline
\end{tabular}


Summary: The BMGR-West workshop followup survey was hosted online September 21-28, 2009. The survey link was e-mailed to all 26 workshop participants, and 22 completed the survey. Below is a brief summary of responses to each question, followed by the complete survey results and related statistics:

1. Please rank the following specific VEGETATION resources in order of priority $(1=$ HIGHEST, 4 = LOWEST)

Invasive species were ranked highest priority (average rating $=1.76)$ followed by vegetation communities (2.19). Rare plants and dune endemic plants were both considered low priority.

2. Please rank the following specific CLIMATE resources in order of priority $(1=$ HIGHEST, $3=$ LOWEST)

Precipitation was ranked highest (1.40) followed by temperature (2.21) and air quality/dust (2.33). One respondent noted that they were all high priority and could be bundled together for monitoring.

3. Please rank the following specific BIRD resources in order of priority $(1=$ HIGHEST, $7=$ LOWEST)

General bird surveys stood out as the highest priority (1.70), Le Conte's thrasher second (3.33), followed by overwintering birds (3.40). Raptors, Pygmy owl, excavators, and European starling were generally all low priority.

4. Please rank the following specific MAMMAL/WILDLIFE resources in order of priority $(1=$ HIGHEST, 6 = LOWEST)

Sonoran pronghorn were ranked highest priority (1.52), followed by bat guild and Bighorn sheep (2.81 and 2.86, respectively). Kit fox, coyote, and invasive animals were all lower priority.

5. Please rank the following specific AMPHIBIAN resources in order of priority $(1=$ HIGHEST, 4 = LOWEST) 
Sonoran Desert toad and Couch's Spadefoot were highest priority (1.78 and 1.94, respectively). Three respondents suggested that all amphibian species monitoring could be bundled together, so ranking individual species was not critical. One respondent indicated "would not do any."

6. Please rank the following specific REPTILE resources in order of priority $(1=$ HIGHEST, $3=$ LOWEST)

Flat-tailed horned lizard was ranked highest (1.37), followed by desert tortoise (2.15) and fringe-toed lizard (2.30).

7. Please rank the following specific ANTHROPOGENIC IMPACTS in order of priority $(1=$ HIGHEST, 6 = LOWEST)

Transportation corridors (roads and trails) were ranked highest priority (1.29), and visitor use (2.67) and military use (2.90) moderate priority.

8. Please rank the following specific SOIL resources in order of priority $(1=$ HIGHEST, $3=$ LOWEST)

Soil erosion (1.48) and channel change/washes (1.71) were highest priority.

9. Please rank the following specific WATER resources in order of priority $(1=$ HIGHEST, $3=$

\section{LOWEST)}

Seeps, springs, and tinajas were overwhelmingly ranked highest priority (1.15).

\section{In your opinion, how important is it to monitor each of the following 11 broad resource} categories on the BMGR-West ? Please assign a priority level to the each of the following: High priority resource categories (in order of importance) included (1) anthropogenic impacts, (2) vegetation, (3) water resources, and (4) climate. Medium priority resources were amphibians, birds and reptiles (tie), soils, and mammal/wildlife. Low priority resources were invertebrates and natural disturbances (tie). 


\section{SURVEY RESULTS}

Note: Grey boxes highlight the majority column value (priority rank) for each row (resource) based on number of responses. Respondent comments are included at the bottom where applicable.

1. Please rank the following specific VEGETATION resources in order of priority $(1=$ HIGHEST, $4=$ LOWEST $)$

\begin{tabular}{|l||c||c||c||c||c||c|}
\hline & $\mathbf{1}$ & $\mathbf{2}$ & $\mathbf{3}$ & $\mathbf{4}$ & $\begin{array}{c}\text { Rating } \\
\text { Average }\end{array}$ & $\begin{array}{c}\text { Response } \\
\text { Count }\end{array}$ \\
\hline Invasive species & $47.6 \%(10)$ & $33.3 \%(7)$ & $14.3 \%(3)$ & $4.8 \%(1)$ & 1.76 & 21 \\
\hline $\begin{array}{l}\text { Vegetation } \\
\text { communities }\end{array}$ & $38.1 \%(8)$ & $28.6 \%(6)$ & $9.5 \%(2)$ & $23.8 \%(5)$ & 2.19 & 21 \\
\hline Rare plants & $5.0 \%(1)$ & $10.0 \%(2)$ & $65.0 \%(13)$ & $20.0 \%(4)$ & 3.00 & 20 \\
\hline Dune endemic plants & $4.8 \%(1)$ & $28.6 \%(6)$ & $14.3 \%(3)$ & $52.4 \%(11)$ & 3.14 & 21 \\
\hline
\end{tabular}

1. Sahara mustard.

2. Especially DOD Species at risk.

3. Not clear on the concept: does this mean additional monitoring of veg communities? If so, I don't give veg communities a high priority, because they are currently being mapped. Naturally, I think the map should be completed, and, once completed, the effort would turn to invasives and dune endemics

4. Desert wash plant associations

2. Please rank the following specific CLIMATE resources in order of priority $(1=$ HIGHEST, $3=$ LOWEST $)$

\begin{tabular}{|l|c||c||c||c||c|}
\hline \hline & $\mathbf{1}$ & $\mathbf{2}$ & $\mathbf{3}$ & $\begin{array}{c}\text { Rating } \\
\text { Average }\end{array}$ & $\begin{array}{c}\text { Response } \\
\text { Count }\end{array}$ \\
\hline \hline Temperature & $10.5 \%(2)$ & $57.9 \%(11)$ & $31.6 \%(6)$ & 2.21 & 19 \\
\hline Precipitation & $75.0 \%(15)$ & $10.0 \%(2)$ & $15.0 \%(3)$ & 1.40 & 20 \\
\hline Air Quality/Dust & $19.0 \%(4)$ & $28.6 \%(6)$ & $52.4 \%(11)$ & 2.33 & 21 \\
\hline \hline
\end{tabular}

1.These could all be bundled, as all are really a \#1 priority

3. Please rank the following specific BIRD resources in order of priority $(1=$ HIGHEST, $7=$ LOWEST $)$

\begin{tabular}{|l||c||c||c||c||c||c||c||c||c|}
\hline & $\mathbf{1}$ & $\mathbf{2}$ & $\mathbf{3}$ & $\mathbf{4}$ & $\mathbf{5}$ & $\mathbf{6}$ & $\mathbf{7}$ & $\begin{array}{c}\text { Rating } \\
\text { Average }\end{array}$ & $\begin{array}{c}\text { Response } \\
\text { Count }\end{array}$ \\
\hline \hline $\begin{array}{l}\text { General Bird } \\
\text { surveys }\end{array}$ & $\begin{array}{c}70.0 \% \\
(14)\end{array}$ & $\begin{array}{c}10.0 \% \\
(2)\end{array}$ & $\begin{array}{c}10.0 \% \\
(2)\end{array}$ & $5.0 \%(1)$ & $0.0 \%(0)$ & $5.0 \%(1)$ & $0.0 \%(0)$ & 1.70 & 20 \\
\hline $\begin{array}{l}\text { Overwintering } \\
\text { birds }\end{array}$ & \begin{tabular}{c|c}
$0.0 \%(0)$ \\
\hline Le Conte's
\end{tabular} & $\begin{array}{c}40.0 \% \\
(8)\end{array}$ & $\begin{array}{c}25.0 \% \\
(5)\end{array}$ & $\begin{array}{c}10.0 \% \\
(2)\end{array}$ & $\begin{array}{c}10.0 \% \\
(2)\end{array}$ & $\begin{array}{c}10.0 \% \\
(2)\end{array}$ & $5.0 \%(1)$ & 3.40 & 20 \\
\hline \hline
\end{tabular}


3. Please rank the following specific BIRD resources in order of priority $(1=$ HIGHEST, $7=$ LOWEST $)$

\begin{tabular}{|c|c|c|c|c|c|c|c|c|c|}
\hline thrasher & (4) & (6) & & (2) & (2) & (3) & & & \\
\hline Raptors & $0.0 \%(0)$ & $0.0 \%(0)$ & $\begin{array}{c}17.6 \% \\
(3)\end{array}$ & $\begin{array}{c}35.3 \% \\
(6)\end{array}$ & $\begin{array}{c}41.2 \% \\
(7)\end{array}$ & $0.0 \%(0)$ & $|5.9 \%(1)|$ & 4.41 & 17 \\
\hline $\begin{array}{l}\text { Cactus } \\
\text { ferruginous } \\
\text { pygmy-owl }\end{array}$ & $\begin{array}{c}10.5 \% \\
(2)\end{array}$ & $\begin{array}{c}10.5 \% \\
(2)\end{array}$ & $\begin{array}{c}10.5 \% \\
(2)\end{array}$ & $0.0 \%(0)$ & $\begin{array}{c}26.3 \% \\
(5)\end{array}$ & $\begin{array}{c}26.3 \% \\
(5)\end{array}$ & $\begin{array}{c}15.8 \% \\
(3)\end{array}$ & 4.63 & 19 \\
\hline \begin{tabular}{|l|} 
Primary \\
Excavator \\
(Cavity) Guild \\
\end{tabular} & $0.0 \%(0)$ & $5.3 \%(1)$ & $\begin{array}{c}26.3 \% \\
(5)\end{array}$ & $\begin{array}{l}21.1 \% \\
(4)\end{array}$ & \begin{tabular}{|c|}
$10.5 \%$ \\
$(2)$
\end{tabular} & $\begin{array}{c}21.1 \% \\
(4)\end{array}$ & $\begin{array}{c}15.8 \% \\
(3)\end{array}$ & 4.63 & 19 \\
\hline $\begin{array}{l}\text { European } \\
\text { starling }\end{array}$ & $0.0 \%(0)$ & $5.3 \%(1)$ & $5.3 \%(1)$ & \begin{tabular}{c||}
$15.8 \%$ \\
$(3)$
\end{tabular} & $0.0 \%(0)$ & $\begin{array}{c}21.1 \% \\
(4)\end{array}$ & $\begin{array}{c}52.6 \% \\
(10) \\
\end{array}$ & 5.84 & 19 \\
\hline \multicolumn{9}{|c|}{$\begin{array}{l}\text { 1.Golden Eagle Surveys } \\
\text { 2.Most are low priority } \\
\text { 3.gray vireo (utilizes elephant tree fruits) }\end{array}$} & 3 \\
\hline
\end{tabular}

\section{Please rank the following specific MAMMAL/WILDLIFE resources in order of priority $(1=$ HIGHEST, $6=$ LOWEST)}

\begin{tabular}{|c|c|c|c|c|c|c|c|c|}
\hline & 1 & 2 & 3 & 4 & 5 & 6 & $\begin{array}{c}\text { Rating } \\
\text { Average } \\
\end{array}$ & $\begin{array}{c}\text { Response } \\
\text { Count } \\
\end{array}$ \\
\hline Pronghorn & $81.0 \%(17)$ & $4.8 \%(1)$ & $4.8 \%(1)$ & $0.0 \%(0)$ & $9.5 \%(2)$ & $0.0 \%(0)$ & 1.52 & 21 \\
\hline Bat Guild & $9.5 \%(2)$ & $38.1 \%(8)$ & $23.8 \%(5)$ & $23.8 \%(5)$ & $0.0 \%(0)$ & $4.8 \%(1)$ & 2.81 & 21 \\
\hline Kit Fox & $0.0 \%(0)$ & $15.0 \%(3)$ & $10.0 \%(2)$ & $30.0 \%(6)$ & $35.0 \%(7)$ & $10.0 \%(2)$ & 4.15 & 20 \\
\hline Coyote & $0.0 \%(0)$ & $13.6 \%(3)$ & $13.6 \%(3)$ & $4.5 \%(1)$ & $31.8 \%(7)$ & $36.4 \%(8)$ & 4.64 & 22 \\
\hline Invasive animals & $4.8 \%(1)$ & $0.0 \%(0)$ & $19.0 \%(4)$ & $23.8 \%(5)$ & $14.3 \%(3)$ & $38.1 \%(8)$ & 4.57 & 21 \\
\hline Bighorn Sheep & $9.5 \%(2)$ & $33.3 \%(7)$ & $33.3 \%(7)$ & $14.3 \%(3)$ & $4.8 \%(1)$ & $4.8 \%(1)$ & 2.86 & 21 \\
\hline \multicolumn{8}{|c|}{ 1. nocturnal rodents } & $\overline{11}$ \\
\hline
\end{tabular}

5. Please rank the following specific AMPHIBIAN resources in order of priority $(1=$ HIGHEST, $4=$ LOWEST $)$

\begin{tabular}{|l||c||c||c||c||c||c|}
\hline & $\mathbf{1}$ & $\mathbf{2}$ & $\mathbf{3}$ & $\mathbf{4}$ & $\begin{array}{c}\text { Rating } \\
\text { Average }\end{array}$ & $\begin{array}{c}\text { Response } \\
\text { Count }\end{array}$ \\
\hline $\begin{array}{l}\text { Sonoran Desert } \\
\text { toad }\end{array}$ & $44.4 \%(8)$ & $33.3 \%(6)$ & $22.2 \%(4)$ & $0.0 \%(0)$ & 1.78 & 18 \\
\hline red-spotted toad & $11.8 \%(2)$ & $35.3 \%(6)$ & $29.4 \%(5)$ & $23.5 \%(4)$ & 2.65 & 17 \\
\hline Couch's spadefoot & $43.8 \%(7)$ & $18.8 \%(3)$ & $37.5 \%(6)$ & $0.0 \%(0)$ & 1.94 & 16 \\
\hline Great Plains toad & $5.6 \%(1)$ & $11.1 \%(2)$ & $11.1 \%(2)$ & $72.2 \%(13)$ & 3.50 & 18 \\
\hline \hline
\end{tabular}

1.These too, could be bundled, and all would receive similar priority 2.They all comprise the same guild of desert anurans, therefore the breeding habitat (for example, ephemeral pools) needs monitoring

3.auditory surveys for all species - general

4.would not do any

5.not qualified to respond 
6. Please rank the following specific REPTILE resources in order of priority $(1=$ HIGHEST, $3=$ LOWEST $)$

\begin{tabular}{|c|c|c|c|c|c|}
\hline & 1 & 2 & 3 & \begin{tabular}{|l||} 
Rating \\
Average
\end{tabular} & $\begin{array}{c}\text { Response } \\
\text { Count } \\
\end{array}$ \\
\hline Desert tortoise & $30.0 \%(6)$ & $25.0 \%(5)$ & $45.0 \%(9)$ & 2.15 & 20 \\
\hline Fringe-toed lizard & $5.0 \%(1)$ & $60.0 \%(12)$ & $35.0 \%(7)$ & 2.30 & 20 \\
\hline $\begin{array}{l}\text { Flat-tailed horned } \\
\text { lizard }\end{array}$ & $73.7 \%(14)$ & $15.8 \%(3)$ & $10.5 \%(2)$ & 1.37 & 19 \\
\hline
\end{tabular}

1.Is the desert tortoise even found on BMGR westwest

2.not qualified to respond

3.Diurnal lizards, Nocturnal snakes (method-specific)

7. Please rank the following specific ANTHROPOGENIC IMPACTS in order of priority $(1=$ HIGHEST, $6=$ LOWEST)

\begin{tabular}{|c|c|c|c|c|c|c|c|c|}
\hline & 1 & 2 & 3 & 4 & 5 & 6 & \begin{tabular}{|c||} 
Rating \\
Average
\end{tabular} & $\begin{array}{c}\text { Response } \\
\text { Count } \\
\end{array}$ \\
\hline $\begin{array}{l}\text { Transportation Corridors } \\
\text { (Roads and Trails) }\end{array}$ & $76.2 \%(16)$ & $19.0 \%(4)$ & $4.8 \%(1)$ & $0.0 \%(0)$ & $0.0 \%(0)$ & $0.0 \%(0)$ & 1.29 & 21 \\
\hline Visitor use & $9.5 \%(2)$ & $42.9 \%(9)$ & $23.8 \%(5)$ & $19.0 \%(4)$ & $4.8 \%(1)$ & $0.0 \%(0)$ & 2.67 & 21 \\
\hline $\begin{array}{l}\text { Neighboring Land Use/Land } \\
\text { Cover }\end{array}$ & $0.0 \%(0)$ & $0.0 \%(0)$ & $20.0 \%(4)$ & $35.0 \%(7)$ & $40.0 \%(8)$ & $5.0 \%(1)$ & 4.30 & 20 \\
\hline Military & $20.0 \%(4)$ & $30.0 \%(6)$ & $20.0 \%(4)$ & $10.0 \%(2)$ & $10.0 \%(2)$ & $10.0 \%(2)$ & 2.90 & 20 \\
\hline Firewood depletion & $0.0 \%(0)$ & $9.5 \%(2)$ & $23.8 \%(5)$ & $19.0 \%(4)$ & $42.9 \%(9)$ & $4.8 \%(1)$ & 4.10 & 21 \\
\hline Rockhounding & $0.0 \%(0)$ & $0.0 \%(0)$ & $9.5 \%(2)$ & $14.3 \%(3)$ & $0.0 \%(0)$ & $76.2 \%(16)$ & 5.43 & 21 \\
\hline \multicolumn{8}{|l|}{ 1.Border fence } & 1 \\
\hline
\end{tabular}

8. Please rank the following specific SOIL resources in order of priority $(1=$ HIGHEST, $3=$ LOWEST $)$

\begin{tabular}{|c|c|c|c|c|c|}
\hline & 1 & 2 & 3 & \begin{tabular}{|c|} 
Rating \\
Average \\
\end{tabular} & $\begin{array}{c}\text { Response } \\
\text { Count }\end{array}$ \\
\hline Channel change/Washes & $42.9 \%(9)$ & $42.9 \%(9)$ & $14.3 \%(3)$ & 1.71 & 21 \\
\hline Soil erosion & (52.4\%(11) & $47.6 \%(10)$ & $\begin{array}{l}0.0 \%(0) \\
\end{array}$ & 1.48 & 21 \\
\hline Aeolian saltation of soils & $9.5 \%(2)$ & $9.5 \%(2)$ & $81.0 \%(17)$ & 2.71 & 21 \\
\hline \multicolumn{5}{|l|}{ 1. Dune sands } & 1 \\
\hline
\end{tabular}


9. Please rank the following specific WATER resources in order of priority $(1=$ HIGHEST, $3=$ LOWEST $)$

\begin{tabular}{|l|c||c||c||c||c|}
\hline & $\mathbf{1}$ & $\mathbf{2}$ & $\mathbf{3}$ & $\begin{array}{c}\text { Rating } \\
\text { Average }\end{array}$ & $\begin{array}{c}\text { Response } \\
\text { Count }\end{array}$ \\
\hline $\begin{array}{l}\text { Seeps, springs and } \\
\text { tinajas }\end{array}$ & $90.0 \%(18)$ & $5.0 \%(1)$ & $5.0 \%(1)$ & 1.15 & 20 \\
\hline Ground water & $10.5 \%(2)$ & $57.9 \%(11)$ & $31.6 \%(6)$ & 2.21 & 19 \\
\hline Water quality & $5.0 \%(1)$ & $35.0 \%(7)$ & $60.0 \%(12)$ & 2.55 & 20 \\
\hline
\end{tabular}

10. In your opinion, how important is it to monitor each of the following 11 broad resource categories on the Barry M. Goldwater Range West? Please assign a priority level to the each of the following:

\begin{tabular}{|l||c||c||c||c||c|}
\hline & Low & Medium & High & $\begin{array}{c}\text { Rating } \\
\text { Average }\end{array}$ & $\begin{array}{c}\text { Response } \\
\text { Count }\end{array}$ \\
\hline \hline Vegetation & $0.0 \%(0)$ & $27.3 \%(6)$ & $72.7 \%(16)$ & 2.73 & 22 \\
\hline \hline Climate & $22.7 \%(5)$ & $22.7 \%(5)$ & $54.5 \%(12)$ & 2.32 & 22 \\
\hline Birds & $4.8 \%(1)$ & $57.1 \%(12)$ & $38.1 \%(8)$ & 2.33 & 21 \\
\hline Mammal/Wildlife & $14.3 \%(3)$ & $47.6 \%(10)$ & $38.1 \%(8)$ & 2.24 & 21 \\
\hline \hline Amphibians & $23.8 \%(5)$ & $66.7 \%(14)$ & $9.5 \%(2)$ & 1.86 & 21 \\
\hline Reptiles & $9.5 \%(2)$ & $57.1 \%(12)$ & $33.3 \%(7)$ & 2.24 & 21 \\
\hline \hline Anthropogenic impacts & $9.1 \%(2)$ & $9.1 \%(2)$ & $81.8 \%(18)$ & 2.73 & 22 \\
\hline Invertebrates & $52.4 \%(11)$ & $33.3 \%(7)$ & $14.3 \%(3)$ & 1.62 & 21 \\
\hline Natural disturbances & $52.4 \%(11)$ & $19.0 \%(4)$ & $28.6 \%(6)$ & 1.76 & 21 \\
\hline Soil & $33.3 \%(7)$ & $52.4 \%(11)$ & $14.3 \%(3)$ & 1.81 & 21 \\
\hline Water resources & $14.3 \%(3)$ & $28.6 \%(6)$ & $57.1 \%(12)$ & 2.43 & 21 \\
\hline
\end{tabular}

